\title{
Optimal Promotions of Competing Firms in a Frictional Labour Market with Organizational Hierarchies
}
H. Dawid
M. Mitkova
A. Zaharieva 


\title{
Optimal Promotions of Competing Firms in a Frictional Labour Market with Organizational Hierarchies*
}

\author{
Herbert Dawid $\dagger^{\dagger}$ Mariya Mitkova ${ }^{\ddagger}$ Anna Zaharieva ${ }^{\dagger}$
}

April 1, 2019

\begin{abstract}
We study optimal promotion decisions of hierarchical firms, with one junior and one senior managerial position, which interact in a search and matching labor market. Workers acquire experience over time while being employed in a junior position and the firm has to determine the experience level at which the worker receives a promotion which allows her to fill a senior position. Promoted workers move to the senior position in their current firm, if it is vacant, otherwise they search for senior positions on the market. The promotion cutoffs of the competing firms exhibit strategic complementarity, but we show that generically a unique stable symmetric general equilibrium exists. If workers have homogeneous skills, then an increase in the skill level induces faster promotion. In the presence of two skill levels in the work force an increase of the fraction of high skilled leads to slower promotion of both types of workers, where the promotion threshold for high skilled workers is substantially below that for low skilled workers. This implies earlier promotions of high skill workers compared to the low skilled consistent with available empirical evidence. Finally, we show that inserting pyramidal firms, which have twice as many junior than senior positions, into the market induces all firms to promote later. Pyramidal firms in equilibrium promote substantially later than vertical firms which is supported by the existing empirical findings. The paper also makes a methodological contribution by combining search and matching theory with simulations in order to characterize the general equilibrium promotion cut-offs in a market setting with heterogeneous hierarchical firms.
\end{abstract}

Keywords: promotions, theory of the firm, search and matching labour market, organizational hierarchies, job-to-job mobility, simulation

JEL Classification: C63, D21, J63, J64

\footnotetext{
${ }^{*}$ Financial support from the German Science Foundation (DFG) under grant DA $763 / 5$ is gratefully acknowledged.

${ }^{\dagger}$ Department of Business Administration and Economics and Center for Mathematical Economics, Bielefeld University. hdawid@wiwi.uni-bielefeld.de, azaharieva@wiwi.uni-bielefeld.de

${ }^{\ddagger}$ Department of Business Administration and Economics, Bielefeld University. mariya.mitkova@uni-bielefeld.de
} 


\section{Introduction}

Empirical evidence suggests that workers progress in their careers by means of internal promotions within firms, job-to-job transitions between firms and experience accumulation ${ }^{1}$. However, existing research analyzes promotions and job-to-job mobility within different strands of literatures. Whereas search and matching studies developed strong techniques for the analytical treatment of on-the-job search and between-firm mobility of workers, research on internal promotions within firms is conducted in the literature on internal labour markets and principle agent models ${ }^{2}$. In this study we develop a unified search and matching framework with hierarchical firms, experience accumulation, job-to-job mobility and internal promotions. A combination of these areas leads to new insights on how the composition of the applicant pool, competition between (heterogeneous) firms and search frictions influence the optimal timing of promotions. Our model is compatible with the empirical evidence that high skill workers are promoted faster than low skill workers and are overrepresented in higher hierarchical levels of firms. Moreover, in a setting with pyramidal firms we show that stronger competition for workers on lower hierarchical levels forces firms to require more experience which delays internal promotions.

In particular, we develop a search and matching model with three hierarchical levels in the career ladder. The first level consists of non-managerial jobs available to all workers without frictions. In addition, there are firms in the market consisting of two professional positions: one junior position and one senior position. This structure implies that there are three hierarchical job levels and two submarkets in our model: the primary market for young inexperienced individuals applying for their first junior manager position and a secondary market for experienced workers applying for senior manager positions. Firms with open positions post vacancies in each of the two submarkets respectively. As in Gibbons and Waldman (1999) the productivity of junior managers is growing over time due to experience accumulation and there is complementarity between experience and the hierarchical layer the worker is assigned to.

The main choice variable of the firm is the promotion time. Specifically, firms choose the minimum experience cut-off which is necessary for the junior worker to be internally promoted to the senior level. This experience cut-off is announced by the firm in the beginning of the employment relationship. Note that the actual promotion can only take place if the junior worker accumulated the minimum experience level set by the firm and there is an open senior position in this firm. This is different from the model of Gibbons and Waldman (1999), where every worker can always be promoted in every firm and promotions do not depend on the availability of open positions at higher hierarchical levels. The tradeoff for firms can be characterized in the following way: if the inexperienced worker is promoted too early in his/her career, this worker will have a relatively low productivity after the promotion because this worker's experience is too low for the senior level. In this situation it is a better strategy for the firm to wait and search for a more experienced worker in the secondary submarket for senior managers. This submarket exists because some workers have already reached sufficient experience to be promoted, but there are no open positions in their firms. Thus these workers start searching for senior managerial jobs with alternative employers (on-the-job search). This is different from the model of Burdett and Mortensen (1998), where all employees are always searching for better paid jobs, and shows

\footnotetext{
${ }^{1}$ Baker et al. (1994), Lluis (2005), Bidwell and Mollick (2015), Cassidy et al. (2016)

${ }^{2}$ Excellent surveys on both research directions are Rogerson et al. (2005) and Waldman (2009) respectively
} 
that promotions and on-the-job search are closely linked to each other, moreover, this link is missing in the previous studies.

Based on this model we find that the optimal promotion time of a given firm is increasing in the average promotion time of the market, so there is strategic complementarity between the promotion times of the different firms. This is because the optimal individual promotion time of the firm depends on the distribution of experience of managerial applicants in the secondary submarket, which again is determined by the promotion decisions of the other firms in the market. We account for this competition effect by characterizing Nash equilibrium assuming steady states of the labor flows. We find that there are two symmetric Nash equilibria but only one of them is stable. In addition, we analyze the steady state adjustment of worker stocks and transition probabilities in response to the optimal promotion time set by the firms. We find that this general equilibrium effect is mitigating the individual intentions of firms. In particular, if one firm has incentives to delay promotions of its' junior workers and hire more senior managers in the market it will choose a higher experience requirement. Positive optimal response implies that other firms also delay promotions of their junior workers and require higher experience. Because of this workers stay longer in junior positions and there are fewer applicants in the senior submarket, so job-to-job transitions between firms are substantially reduced and internal promotions become a more important source of upward mobility for workers. This shows how the general equilibrium effect counteracts the initial decision of firms.

We consider three extensions of our benchmark model. First, we assume that additional output is generated if two workers (junior and senior) are working together as a team. We find that such team synergy is associated with earlier promotions. The reason is that search frictions in the senior submarket are more severe, so hiring junior workers is easier for firms in our model than hiring experienced managers. So, in order to fill both positions, firms promote their own junior employees earlier compared to the benchmark case and try to hire another junior worker afterwards. This strategy leads to the highest gain from the team synergy for firms.

In the second extension we consider skill heterogeneity of workers, assuming that high skill workers are more productive than low skill workers only in senior managerial jobs. This model extension can explain the empirical evidence that high skill workers are promoted earlier than low skill workers (Baker et al. (1994), McCue (1996) and Lluis (2005)). In addition, there is substitution between the two skill groups. If there are exogenous reasons forcing firms to promote one skill group earlier, they will delay promotions of the other skill group and let them accumulate more experience. We show that increasing the fraction of high skill workers in the population induces slower promotions of all workers, whereas in a setting with homogeneous workers an increase of the skill level leads to faster promotions. The key difference between these scenarios is that under worker heterogeneity an increase of the fraction of high skill workers increases the expected skill of a worker hired from the market relative to the skill of the junior worker under consideration for internal promotion, regardless of the actual type of the junior worker. This induces a delay in internal promotions. With homogeneous workers by definition the skill of an outside hire is always identical to that of an internally promoted worker.

In the third extension a fraction of professional firms has a pyramidal structure with one senior position and two junior positions. Here we follow the empirical evidence, e.g. Caliendo et al. (2015) who reports that a vast majority of firms in their sample have a hierarchical 
pyramidal structure with several layers, such that workers situated at higher layers earn higher wages. We find that in the presence of pyramidal firms promotions occur later than if only vertical firms are in the market. The reason is that a larger number of junior positions in the market leads to the oversupply of experienced workers, thus hiring experienced managers becomes easier for firms. At the same time there is stronger competition between firms for inexperienced workers starting their career since there is a larger number of vacancies in this submarket. Thus a longer experience requirement allows firms to keep their junior workers longer in the firm and reduces the cost of labour turnover. Pyramidal firms promote later than their vertical competitors because the fraction of time in which they have vacant senior positions is smaller which makes it more attractive to keep junior workers longer in their current position. One empirical implication of this finding is that workers in large pyramidal firms have more experience and earn higher wages compared to the small vertical firms, which is supported by the existing empirical research (Lallemand et al., 2007; Oi and Idson, 1999). Moreover, we find that the firm size wage premium is increasing with the hierarchical level of the position, which is inline with a recent empirical finding in Fox (2009).

Apart from these new economic insights about optimal promotion strategies of firms this paper also makes a methodological contribution to the literature by combining an analytical approach with a simulation analysis in order to characterize general equilibrium behavior of firms also in the extensions of the model with heterogeneous firms and workers in which a full analytical treatment is no longer feasible. For the benchmark model with homogeneous firms and workers we are able to provide a full analytical characterization of the firms' best response functions and also of the labor flows under the stationary distribution. Based on this we can numerically determine the general equilibrium of the model under different parameter settings.

For the extension with heterogeneous workers we are still able to provide an analytical characterization of firms' best response, but we can no longer determine in closed form the transition rates resulting from a given set of promotion cut-offs followed by all firms on the market. Hence, we use an agent-based simulation framework to determine the long-run transition rates. Finally, for the extension with heterogeneous firms also the characterization of the firms' best responses by analytical means is no longer feasible. Hence, in this case we also employ a simulation approach to numerically determine the best response functions of the firms of different type and use this to determine the general equilibrium of the model. In order to validate the simulation approach we first implement it for the benchmark case for which analytical results are available and show that the simulation approach replicates the analytical results with a high degree of precision and reliability. Our methodological approach allows to analyze models, which otherwise would be intractable, in a rigorous way based on standard equilibrium concepts. The validation of our simulation approach using theoretical findings for the benchmark serves as disciplining device for the setup and implementation of the simulation study. We believe that this combination of methodologies can be fruitfully applied for many issues in labor market research and beyond.

Our study is closely related to the literature on organizational hierarchies and internal labour markets. Organizational hierarchies are intensively studied since the seminal contribution by Garicano (2000). This paper considers an endogenous formation of firm hierarchies based on the time constraint for acquiring knowledge by workers. Some (ex-ante homogeneous) agents 
acquire special knowledge and are specializing in problem-solving; these agents are the managers and are situated on the top level of the firm hierarchy, while other agents are specialized on the actual production. Thus the equilibrium organization structure is pyramidal, with each layer of a smaller size than the previous one. This benchmark model is extended in different directions by Garicano and Rossi-Hansberg (2015). The literature on knowledge-based hierarchies is successful in explaining empirical facts and it is an appealing feature of this theory that hierarchies arise endogenously when matching problems to those who know how to solve them. On the other hand, this research direction is lacking dynamics in individual careers, as workers assigned to different levels are never promoted within or across firms, thus there is no link between organizational hierarchies and career paths of individuals.

The second research stream is dealing with internal labour markets, so the main focus here is on individual career paths and promotions but the firm hierarchy is taken exogenously and fixed in this literature. One large research direction here includes tournament models in the spirit of Lazear and Rosen (1981). In their setting promotion decisions are modeled as a tournament in which workers exert costly effort to perform better than their coworkers and to be considered for promotion. Later tournament models include the fact that promotions can be used as a signal of higher ability, see for example, Zabojnik and Bernhardt (2001). Recent studies, such as DeVaro (2006) confirm empirically that firms are choosing wage spreads strategically to elicite more effort from their employees. In addition, DeVaro and Waldman (2012) find that promotions are sometimes used as a signal of worker's ability. While the role of competition in providing working incentives to employees must be acknowledged, we focus on human capital accumulation as a reason for promotion and analyse between-firm competition for experienced employees.

The literature on human capital accumulation and job assignments is more closely related to our research. The seminal contribution here is by Gibbons and Waldman (1999). In their study worker's productivity depends on the individual's skill level, accumulated experience and the hierarchical layer the worker is assigned to. As workers accumulate experience and knowledge they are optimally promoted by firms to higher positions due to the assumed complementarity between workers productivity (skills and accumulated experience) and hierarchical layers within the firm. We use the same setup as a starting point in our model. Overall, the literature on career paths and promotions is successful in explaining wage dynamics of individuals within firms, whether due to experience accumulation or exerted effort. However, most of this literature is based on the principal agent modeling approach in isolation from the labour market and doesn't allow for the study of interaction between organizational structures and the economy. Most of these studies make restrictive assumptions on the model structure ensuring that there are no job changes between firms in the equilibrium.

Next our study is conducted in the search and matching framework (Diamond (1982), Mortensen (1982), and Pissarides (1985)). We model job-to-job transitions following the approach of Burdett and Mortensen (1998). To the best of our knowledge the first study analyzing tenure in a search and matching framework with job-to-job transitions is Pissarides (1994). There are good and bad jobs in his setting, thus unemployed workers accept bad jobs but continue searching for good jobs. An important feature of the model is that workers accumulate job-specific experience and their wage grows over time. In the equilibrium very experienced workers with high wages stop searching at all since the gain from moving to a good job becomes 
smaller than the cost of searching. The main difference of this study from current work is that we treat experience as transferable across firms while it is completely lost upon the quit in Pissarides (1994). Recent work in this field includes prominent extensions by Burdett and Coles (2003), Burdett et al. (2011) and Bagger et al. (2014). These studies analyse tenure accumulation with on-the-job search, but they do not consider internal promotions. From the perspective of matching we use an urn-ball matching mechanism. Pissarides and Petrongolo (2001) and Albrecht et al. (2003) show that this matching function is increasing in both unemployment and vacancies and has constant returns to scale for large values of both arguments. The reason for using the urn-ball matching mechanism rather than a more traditional Cobb-Douglas approach, is that the urn-ball matching function is micro-founded and can be directly implemented in the simulation whereas the Cobb-Douglas approach is a "black box" from the perspective of practial implementation. Thus using the urn-ball matching technology allows us to closely replicate the analytical model in the simulation setting and avoid discrepancies in the approximation of the matching technology.

Finally, our study is related to work in the area of agent-based simulations of the labour market. The usefulness of this approach for the analysis of dynamic labour market issues has been clearly demonstrated in the literature, which is reviewed for example in Neugart and Richiardi (2018). Moreover, it has also been shown that agent-based models are very successful in reproducing large sets of empirical stylized facts on different levels of aggregation in several economic areas, including labour markets (see e.g. Axtell (2018), Dawid and Delli Gatti (2018), Dawid et al. (2018), Dosi et al. (2017)). The high potential of agent-based approaches for the analysis of labour market issues, in particular such that consider effects of institutional differences, has been stressed among others by Richard Freeman in Freeman (1998, 2007).

The rest of the paper is structured as follows. In section 2 we introduce the economic framework and analyse the dynamics of workers and firms across states. Section 3 presents the value functions of firms and their choice of the optimal promotion time as well as the emerging partial and general equilibrium in the benchmark setting. In section 4 we extend the model to two skill groups. Section 5 considers the extension of the benchmark model with pyramidal firms and section 6 shows the robustness of our findings with respect to changes in the firms' production function. Section 7 concludes the paper. The Appendices contain additional details of our analysis, including an extensive description and validation of the simulation approach used in parts of our study.

\section{The Model}

\subsection{The economic framework}

Time is continuous with an infinite horizon. There is a continuum of both firms and workers with a total measure of workers normalised to 1 . The inflow of new workers into the labour market is denoted by $d$. In the benchmark model all entering workers are homogeneous with identical skills, however, in the extension we also analyze consequences of skill heterogeneity. Job ladders have three hierarchical levels. All young workers entering the market immediately take simple jobs on the low level. These are subsistence jobs that don't yield any professional experience. All entering firms are identical and every firm is a dyad consisting of two positions: 
one junior position and one senior (managerial) position. The inflow of new firms is denoted by $n$. Both positions are empty when the firm enters the market and can be posted simultaneously. Posting an open position (junior or senior) is associated with a flow cost $s$ for the firm. For the purpose of tractability we assume that there are no dismissals, thus the pool of applicants for junior positions consists of young workers employed in low level jobs. Only workers with substantial professional experience are eligible to apply for senior positions. Let $u$ denote the stock of workers in low level jobs, $e_{1}$ - are workers employed in junior positions and $e_{2}$ denotes managers in senior positions, so that $u+e_{1}+e_{2}=1$ due to the normalisation.

Once accepted in the junior position young workers start accumulating professional experience $x \geq 0$ with $\dot{x}=1$. This experience is observable by the current employer but not by other firms in the market. It is general human capital and can be fully transferred to other firms. In the beginning of the employment relationship with some inexperienced worker every firm $i$ chooses an experience cut-off $\bar{x}_{i}$, which makes the worker eligible for promotion to the senior position in this firm. Even though $\bar{x}_{i}$ is an endogenous choice variable of the firm, we assume that it is written down in the labour contract and verifiable by court. Once the worker reached experience $\bar{x}_{i}$, the firm is obliged to provide an experience evaluation to the worker and promote this worker to the senior position if this position is free. In the opposite case when the senior position is filled, the worker starts applying to senior positions in other firms. This is the process of on-the-job search. The documented experience evaluation is a sufficient proof of experience for other employers. We assume that experience accumulation is costly to workers, thus workers stop learning upon receiving an experience evaluation and start searching on-thejob. Intuitively, we model situations when firms encourage junior workers to attend training courses taking a part of the working time up to the level of human capital $\bar{x}_{i}$ (e.g. language and computer courses, MBA or CFA, dual studies). Beyond this level of human capital workers are expected to focus on their job tasks and firms do not permit any training activities at work.

This model structure leads to the existence of two separate submarkets, one where firms are posting junior positions and anticipate a worker with $x=0$ and another one where firms are posting their senior positions and anticipate workers searching on-the-job and possessing a proof of sufficient experience. Workers employed in junior positions produce output $d_{1}+c_{1} e^{\gamma x}$, whereas workers employed in senior positions (managers) produce output $d_{2}+c_{2} e^{\gamma x}$, where $d_{1}>d_{2}$ and $c_{1}<c_{2}$ as in Gibbons and Waldman (1999). Intuitively, this means that the fixed component of output $d_{j}, j=1,2$ is falling with a higher hierarchical level, while experience becomes more important, that is $c_{j}, j=1,2$ is increasing with $j$. In a symmetric equilibrium all firms choose an identical promotion cut-off $\bar{x}$, thus firms correctly anticipate that applicants to senior positions achieved an experience level $\bar{x}$ and their output in senior positions is $d_{2}+c_{2} e^{\gamma \bar{x}}$. There is no experience accumulation in senior positions and output is constant. This is a proxy for decreasing returns to experience accumulation. Workers employed in senior managerial positions retire at an exogenous rate $\rho$. If the manager retires and the junior position is not filled, the firm is empty and exits the labour market. In our analysis we only consider the steady state, moreover the entry and exit parameters $d$ and $\rho$ are chosen to keep the population size constant.

Since the focus of the paper is on the optimal promotion decisions of firms and feedback effects of these decisions on the resulting structure of the labour market, we assume that workers don't act strategically in the model and take their behavior as given. Specifically, young workers 
without experience are always searching for their first job, accumulate experience till the level specified in their labour contract and start applying to managerial jobs if there is no open position in their firm. It is a simplifying assumption of the model that there is no labour market exit among searching workers and those employed in junior positions.

Let $1-\beta$ denote the fraction of output accruing to firms, thus the flow profit is equal to $(1-\beta)\left(d_{j}+c_{j} e^{\gamma x}\right)$ depending on the hierarchical level of the position $j=1,2$ and worker's experience $x$. Workers receive a wage $w_{j}(x)=\beta c_{j} e^{\gamma x}$, thus $\ln w_{j}(x)=\ln \beta+\ln c_{j}+\gamma x$. This means that $\gamma$ can be interpreted as a return to tenure in the model. Output $\beta d_{j}$ is paid out by firms as a cost of capital. This shows that wages in our model can grow due to the accumulation of tenure, internal promotions and between firm transitions. Further, we assume that there is a profit synergy $\Delta$ if the firm is employing both workers simultaneously, that is, one junior worker accumulating experience and one senior manager. So the total profit of this firm is given by $(1-\beta)\left(d_{1}+c_{1} e^{\gamma x}+d_{2}+c_{2} e^{\gamma \bar{x}}\right)+\Delta$. Intuitively, this is a synergy from team work because younger inexperienced workers gain from the advice of senior managers, whereas senior managers may gain from the innovative new ideas of younger workers.

Variable $d_{00}$ denotes the stock of empty new firms in the market, whereas $d_{01}$ is the stock of firms with a senior manager but no junior worker. Since all these firms have an open junior position the total stock of open junior positions available for matching is equal to $d_{00}+d_{01}$. These positions are randomly matched with $z u$ searching inexperienced workers, where $z$ denotes the search effort of workers. More precisely, $z$ is the fraction of searching workers who prepare and send an application at every instant of time. To determine the number of matches in the submarket for junior positions we use an urn-ball matching mechanism. Suppose some worker sends an application to one randomly chosen firm, then the probability that a given firm doesn't receive this application is $1-\frac{1}{d_{00}+d_{01}}$. Since workers send their applications independently without coordination, the probability that this firm doesn't get any of the $z u$ applications is given by $\left(1-\frac{1}{d_{00}+d_{01}}\right)^{z u}$. Let $q_{1}$ be the job-filling rate resulting from this application process and $\lambda_{1}$ be the job-finding rate for inexperienced workers. They are given by:

$$
q_{1}=1-\left(1-\frac{1}{d_{00}+d_{01}}\right)^{z u} \quad \lambda_{1}=z \frac{q_{1}\left(d_{00}+d_{01}\right)}{z u}=q_{1} \frac{\left(d_{00}+d_{01}\right)}{u}
$$

The term $q_{1}\left(d_{00}+d_{01}\right)$ is a total number of matches in the junior market, thus $\frac{q_{1}\left(d_{00}+d_{01}\right)}{z u}$ is a probability of matching for workers conditional on sending an application in a given matching round. Multiplying this conditional matching probability with $z$ we obtain the job-finding rate for junior workers. Further, let $d_{10}$ denote firms with a junior worker but no senior manager. This means that the total number of open managerial positions is given by $d_{00}+d_{10}$. Finally, let $d_{11}^{N}$ denote the stock of full firms with both employees, where the worker in the junior position is not yet eligible for promotion $(x<\bar{x})$. In a similar way, $d_{11}^{S}-$ is the stock of full firms, where the junior worker is already eligible for senior positions and searching on-the-job. This means that the stock of applicants in the managerial market is given by $z d_{11}^{S}$. So the job-filling rate in the managerial market $q_{2}$ and the workers' job-finding rate in this market $\lambda_{2}$ are given by:

$$
q_{2}=1-\left(1-\frac{1}{d_{00}+d_{10}}\right)^{z d_{11}^{S}} \quad \lambda_{2}=z \frac{q_{2}\left(d_{00}+d_{10}\right)}{z d_{11}^{S}}=q_{2} \frac{\left(d_{00}+d_{10}\right)}{d_{11}^{S}}
$$


Note that we assume the same search intensity parameter $z$ in both markets. This setting can be generalized to different search intensities for experienced and inexperienced workers, however, it is not important for our main results. So we keep the model simple and consider only one search intensity parameter $z$.

The total number of firms in the market is given by $d_{00}+d_{01}+d_{10}+d_{11}^{N}+d_{11}^{S}$. This notation also allows us to calculate the number of workers, so normalising the population size to 1 yields:

$$
u+d_{10}+d_{01}+2 d_{11}^{N}+2 d_{11}^{S}=1
$$

Here $e_{1}=d_{10}+d_{11}^{N}+d_{11}^{S}$ is the total number of employees in junior positions, and $e_{2}=$ $d_{01}+d_{11}^{N}+d_{11}^{S}$ is the total number of employees in senior positions.

\subsection{Firm Dynamics}

Transitions of firms are illustrated in figure 1. Consider changes in the stock of new empty firms $d_{00}$. The inflow of new firms into the market is given by $n$. Since every new firm posts both the junior and the senior position in the respective submarkets it exits the state $d_{00}$ whenever it finds the first employee. So the outflow of firms from $d_{00}$ takes place at rate $q_{1}+q_{2}$. In this paper we restrict our analysis to the steady states and consider a stationary distribution of workers and firms across states. This means that $\dot{d}_{00}=0$ in the steady state:

$$
0=\dot{d}_{00}=n-\left(q_{1}+q_{2}\right) d_{00} \quad \Rightarrow \quad d_{00}=\frac{n}{q_{1}+q_{2}}
$$

The entry of firms into the market is given by $n$, whereas the exit is $\rho d_{01}$. These are the firms that lose their only employee due to retirement, which happens at rate $\rho$. Thus we get $d_{01}=n / \rho$ to guarantee a constant number of firms in the market. This is equivalent to the standard assumption of a constant population of workers.

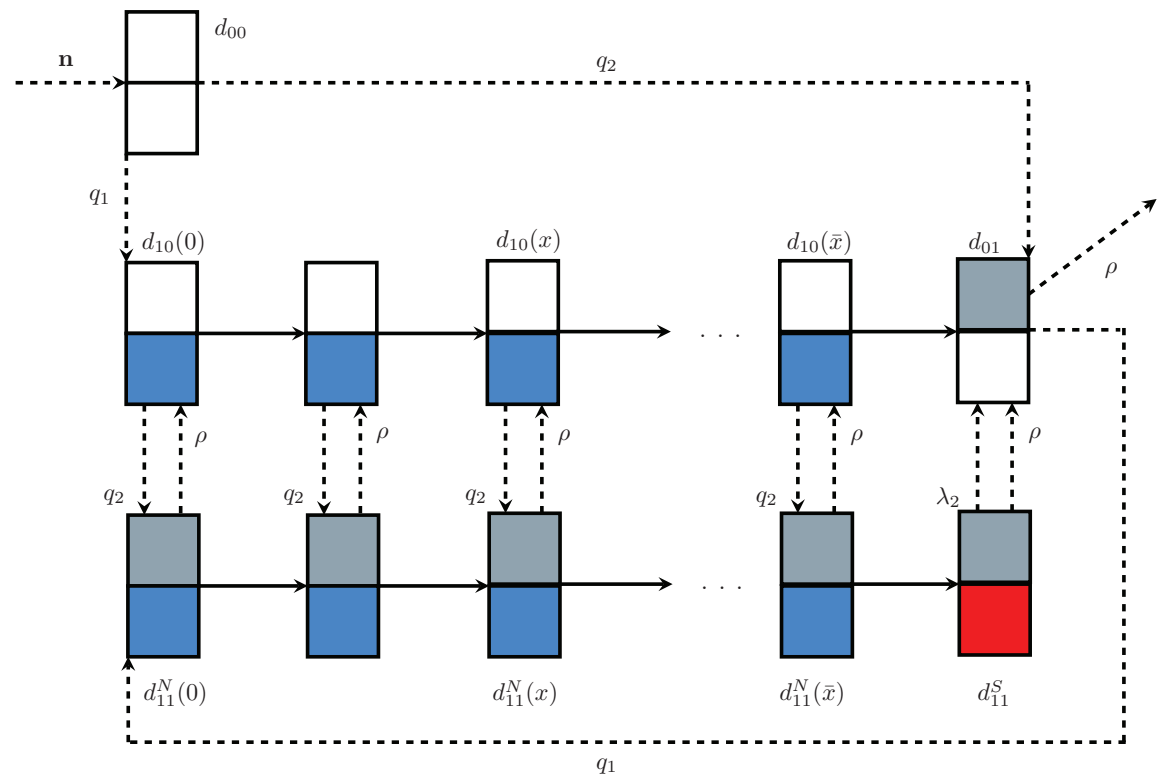

Figure 1: Types of firms and their transitions 
Further, consider changes in the stocks of firms $d_{10}(x)$ and $d_{11}^{N}(x)$. Note that workers with experience $0 \leq x \leq \bar{x}$ are not yet searching on-the-job since their experience is not sufficient for managerial positions and there are no gains from changing to another junior job. Variable $\bar{x}$ here denotes the equilibrium promotion cut-off and will be determined in section 3 . This means that the inflow of firms into state $d_{10}(x)$ is equal to $\rho d_{11}^{N}(x)$. These are the firms where the manager retires at rate $\rho$ and they are left with only one junior worker. At the same time $\rho d_{11}^{N}(x)$ is the outflow of firms from the state $d_{11}^{N}(x)$. If the manager retires firms post the open position in the second submarket for experienced workers and find a manager at rate $q_{2}$. This means that the outflow of workers from the state $d_{10}(x)$ is equal to $q_{2} d_{10}(x)$. This is also the inflow of firms into the state $d_{11}^{N}(x)$. So we get the following system of two first order linear differential equations ${ }^{3}$ :

$$
\left\{\begin{array}{l}
\partial d_{10}(x) / \partial x=-q_{2} d_{10}(x)+\rho d_{11}^{N}(x) \\
\partial d_{11}^{N}(x) / \partial x=q_{2} d_{10}(x)-\rho d_{11}^{N}(x)
\end{array}\right.
$$

The coefficient matrix of this homogeneous system has eigenvalues 0 and $-\left(\rho+q_{2}\right)$, so the general solution is given by:

$$
\left\{\begin{array}{l}
d_{10}(x)=k_{1} \rho+k_{2} e^{-\left(\rho+q_{2}\right) x} \\
d_{11}^{N}(x)=k_{1} q_{2}-k_{2} e^{-\left(\rho+q_{2}\right) x}
\end{array}\right.
$$

In order to find the constant terms $k_{1}$ and $k_{2}$ we use the following initial conditions: $q_{1} d_{00}=$ $d_{10}(0)$ and $q_{1} d_{01}=d_{11}^{N}(0)$. The first condition implies that the stock of firms $d_{10}(0)$ always consists of new firms finding their first junior worker $q_{1} d_{00}$. The second condition implies that the stock of firms $d_{11}^{N}(0)$ consists of firms $d_{01}$ who find a junior worker, that is $q_{1} d_{01}$. Using these initial conditions we find that:

$$
k_{1}=\frac{q_{1} n\left(\rho+q_{1}+q_{2}\right)}{\rho\left(\rho+q_{2}\right)\left(q_{1}+q_{2}\right)}>0 \quad k_{2}=-\frac{\left(q_{1}\right)^{2} n}{\left(\rho+q_{2}\right)\left(q_{1}+q_{2}\right)}<0
$$

One can see that $k_{2}<0$, this means that $d_{10}(x)$ is increasing while $d_{11}^{N}(x)$ is decreasing in $x$. Intuitively this means that the flow $\rho d_{11}^{N}(x)$ due to retirement of senior managers always dominates the flow $q_{2} d_{10}(x)$ implying that finding senior managers is a difficult task for firms in the considered setting. Note that the sum of two variables is a constant, that is $d_{10}(x)+d_{11}^{N}(x)=$ $k_{1}\left(\rho+q_{2}\right) \forall x \in[0 . . \bar{x}]$.

By integrating variables $d_{10}(x)$ and $d_{11}^{N}(x)$ over the interval $[0 . . \bar{x}]$ we find the total stocks of firms $d_{10}$ and $d_{11}^{N}$ :

$$
\begin{aligned}
& d_{10}=\int_{0}^{\bar{x}} d_{10}(x) d x=k_{1} \rho \bar{x}+\frac{k_{2}}{\rho+q_{2}}\left(1-e^{-(\rho+q 2) \bar{x}}\right) \\
& d_{11}^{N}=\int_{0}^{\bar{x}} d_{11}^{N}(x) d x=k_{1} q_{2} \bar{x}-\frac{k_{2}}{\rho+q_{2}}\left(1-e^{-(\rho+q 2) \bar{x}}\right)
\end{aligned}
$$

\footnotetext{
${ }^{3}$ In general the stock variable $d_{10}(x, t)$ may depend on time $t$, so the total derivative is given by:

$$
\frac{\partial d_{10}(x, t)}{\partial x} \frac{\partial x}{\partial t}+\frac{\partial d_{10}(x, t)}{\partial t}=-q_{2} d_{10}(x)+\rho d_{11}^{N}(x)
$$

Since the distribution of firms $d_{10}(x, t)$ is stationary in the steady state we set the time derivative $\dot{d}_{10}=\frac{\partial d_{10}(x, t)}{\partial t}$ equal to zero. Moreover, experience $x$ is accumulating one to one with the time because $\dot{x}=\partial x / \partial t=1$ ).
} 
The remaining unknown stock of firms is $d_{11}^{S}$. These are the firms with two employees, where the junior one is already searching for jobs with alternative employers. All firms of type $d_{11}^{N}(\bar{x})$ automatically enter the state $d_{11}^{S}$ since the junior worker starts searching on-the-job upon attaining experience $\bar{x}$. This is the inflow of workers into the state $d_{11}^{S}$. At rate $\rho$ the senior manager retires and the firm promotes the junior worker to the managerial job. In addition, it can also happen that the junior worker finds a new employer at rate $\lambda_{2}$. As one can see from figure 1 , in both cases the firm leaves the state $d_{11}^{S}$ and enters the stock of firms $d_{01}$. Hence we get:

$$
0=\dot{d}_{11}^{S}=d_{11}^{N}(\bar{x})-\left(\rho+\lambda_{2}\right) d_{11}^{S} \quad \Rightarrow \quad d_{11}^{S}=\frac{d_{11}^{N}(\bar{x})}{\rho+\lambda_{2}}=\frac{k_{1} q_{2}-k_{2} e^{-\left(\rho+q_{2}\right) \bar{x}}}{\rho+\lambda_{2}}
$$

Finally, recall that $u$ are the young individuals searching for their first job, so that $\dot{u}=d-\lambda_{1} u$. In the steady state it should be that the inflow into this state $d$ should be equal to the outflow $\lambda_{1} u$, where the outflow are young inexperienced workers finding their first employer. So we get $u=d / \lambda_{1}$. Variable $d$ is the endogenous entry of young individuals, which we can find from normalising the total population of workers to 1 :

$$
\frac{d}{\lambda_{1}}=1-\left(d_{10}+d_{01}+2 d_{11}^{N}+2 d_{11}^{S}\right)
$$

Solving jointly the system of equations (2)-(7), $d_{01}=n / \rho, u=d / \lambda_{1}$ we can find the equilibrium distribution of firms $\left\{d_{00}, d_{10}, d_{11}^{N}, d_{11}^{S}, d_{01}\right\}$, as well as variables $d$ and $u$ and the equilibrium transition rates $\lambda_{j}$, and $q_{j}, j=1,2$. Note that variable $\bar{x}$ (promotion cut-off) is taken as given at this stage and will be endogenously derived in section 3 .

\subsection{Transition rates}

We proceed by illustrating the mechanism of our model with a help of a numerical example which resembles realistic career paths of workers in developed economies. In this section we focus on the transitions of workers and firms for a given promotion cut-off $\bar{x}$. One period of time is set to be one quarter. Consider young workers entering the market at the age of 18 years. Variable $z$ is the search intensity parameter which is the driving force behind the job-finding rate $\lambda_{1}$. We set $z=0.0146$, this corresponds to $\lambda_{1}=0.0145$ and implies that workers stay in level 0 jobs for approximately $1 / \lambda_{1}=69$ quarters or 17.25 years. Intuitively, this means that workers find their first managerial job on level $e_{1}$ at the age of 35.25 years on average. In state $e_{1}$ workers start accumulating professional managerial experience $x$. We assume that $\bar{x}=45$, this means it takes 45 quarters or 11.25 years for workers to be eligible for the position of a senior manager. Thus workers reach the pre-specified necessary level of experience at the age of 46.5 years on average.

Recall that $d_{10}(\bar{x})$ is a stock of workers who are directly promoted to senior positions within their firm at every point in time. At the same time $d_{11}^{N}(\bar{x})$ is a stock of workers eligible for promotions, however, they can not be promoted directly within their firm since the senior position is occupied. These workers start searching on the job and enter the accumulated pool of workers searching and applying to senior positions $d_{11}^{S}$. So the total stock of workers eligible for promotion in a given period of time is $d_{10}(\bar{x})+d_{11}^{N}(\bar{x})+d_{11}^{S}=k_{1}\left(\rho+q_{2}\right)+d_{11}^{S}$. Out of these workers $d_{10}(\bar{x})+\left(\rho+\lambda_{2}\right) d_{11}^{S}$ are actually promoted, where $d_{10}(\bar{x})+\rho d_{11}^{S}$ are promoted directly within their firms and $\lambda_{2} d_{11}^{S}$ make a transition to a senior position in another firm. So 
the average duration of time from the moment of becoming eligible $\bar{x}$ till the actual promotion within or between firms is given by:

$$
\frac{k_{1}\left(\rho+q_{2}\right)+d_{11}^{S}}{k_{1} \rho+k_{2} e^{-\left(\rho+q_{2}\right) \bar{x}}+\left(\rho+q_{2}\right) d_{11}^{S}}
$$

In our model this duration is equal to 14 quarters or 3.5 years, so that workers become senior managers at the age of 50 years on average. This duration is achieved by setting the number of entering firms $n$ equal to 0.0026 . This also implies that the average stock of firms active in the market is equal to 0.6. So there are on average 600 active firms or 1200 positions per 1000 workers. However, not all of these positions are filled due to the search frictions and experience requirements. Further, we set $\rho=0.015$, so the average time workers spend in senior positions till retirement is $1 / \rho=66.6$ quarters or 16.6 years. So workers retire on average at the age of 66.6 years. Finally, the total population is normalized to 1 . Given that the exit rate of workers is $\rho=0.015$, constant size of the population can be achieved by setting $d=0.0052$. This means that 5.2 workers on average enter the market with a population of 1000 workers. Our choice of parameters at this stage is summarized in table 1 . Note that variable $\bar{x}$ is endogenous in the overall model, even though we keep it fixed at the current stage of analysis. Endogenous values of the quarterly transition rates in the steady-state are summarized on the right side of table 1.

\begin{tabular}{c|c|l||c|c|l}
\hline Parameter & Value & Interpretation & Variable & Value & Interpretation \\
\hline$z$ & 0.0146 & Search intensity of workers & $q_{1}$ & 0.0171 & Job-filling rate, level 1 \\
$\rho$ & 0.0150 & Exit/retirement rate & $q_{2}$ & 0.0036 & Job-filling rate, level 2 \\
$n$ & 0.0026 & Entry of empty firms & $\lambda_{1}$ & 0.0145 & Job-finding rate, level 1 \\
$d$ & 0.0052 & Entry of young workers & $\lambda_{2}$ & 0.0146 & Job-finding rate, level 2 \\
\hline
\end{tabular}

Table 1: Values of exogenous parameters and quarterly transition rates

Table 2 shows the distributions of workers and firms in the steady-state. We can see that $35.7 \%$ of all workers remain on average in simple jobs $e_{0}$. Further, $29.7 \%$ are employed in junior positions $e_{1}$, where $6.3 \%$ of workers are searching on-the-job and applying to senior positions $\left(d_{11}^{S}\right) .34 .5 \%$ of workers occupy senior management positions $e_{2}$. These numbers imply that $p_{1}=0.297 /(0.297+0.345)=0.462$, that is $46.2 \%$ of workers in professional jobs are employed in junior positons, with the remaining $53.7 \%$ being employed in senior positions. Considering transitions of workers, we can see that $1.2 \%$ of $e_{1}$ workers reach senior positions by changing employers. Another $5.7 \%$ of junior workers are internally promoted within their firms per year. Even though internal mobility of workers is not intensive, these numbers are close to the empirical findings. For example, Lluis (2005) finds that in Germany the annual probibility of internal promotions is $5.7 \%$ for relatively young workers with less than 10 years of market experience and it falls afterwards with an average for all workers groups equal to $2.7 \%$. The same study reports that internal mobility is more intensive in the US, with $6.7 \%$ for men and $6.2 \%$ for women with less than 10 years of experience and $5.0 \%$ on average for all men ( $4.6 \%$ for all women). A more recent study by Cassidy et al. (2016) reports an average probability of internal promotions equal to $4.6 \%$ in Finland.

The left panel of figure 2 shows the stocks of firms $d_{10}(x)$ and $d_{11}^{N}(x)$ for different experience 


\begin{tabular}{c|c||l|l|c}
\hline Variable & Value & Variable & Equation & Value \\
\hline$d_{00}$ & 0.1273 & Workers in simple jobs $e_{0}$ & $=1-e_{1}-e_{2}$ & 0.3577 \\
$d_{01}$ & 0.1760 & Workers in junior jobs $e_{1}$ & $=d_{10}+d_{11}^{N}+d_{11}^{S}$ & 0.2966 \\
$d_{10}$ & 0.1270 & Workers in managerial jobs $e_{2}$ & $=d_{01}+d_{11}^{S}+d_{11}^{N}$ & 0.3456 \\
$d_{11}^{S}$ & 0.0633 & Internally promoted (per year) & $=\left(d_{10}(\bar{x})+\rho d_{11}^{S}\right) / e_{1}$ & 0.0576 \\
$d_{11}^{N}$ & 0.1063 & Job-to-job movers (per year) & $=\lambda_{2} d_{11}^{S} / e_{1}$ & 0.0124 \\
\hline
\end{tabular}

Table 2: Stationary distributions of workers and firms for parameters from Table 1 and $\bar{x}=45$

levels $x$ of the junior worker. As expected $d_{10}(x)$ is increasing, while $d_{11}^{N}(x)$ is decreasing with $x$. Note that the starting ratio of these two stocks is $d_{10}(0) / d_{11}^{N}(0)=\rho /\left(q_{1}+q_{2}\right)$ but the long-run ratio for larger values of $x$ is: $\lim _{x \rightarrow \infty} d_{10}(x) / \lim _{x \rightarrow \infty} d_{11}^{N}(x)=\rho / q_{2}$. So the ratio is clearly increasing with higher experience levels. At the same time we know that the sum of these two stocks is fixed and equal to $k_{1}\left(\rho+q_{2}\right)$ and each of them is a monotonous function of $x$. This confirms again that $d_{10}(x)$ should be increasing. So as workers accumulate more and more experience they are more likely to find themselves in a situation with an open senior position. The reason is that senior managers retire over time, but the probability of substituting them with an external candidate is relatively low.
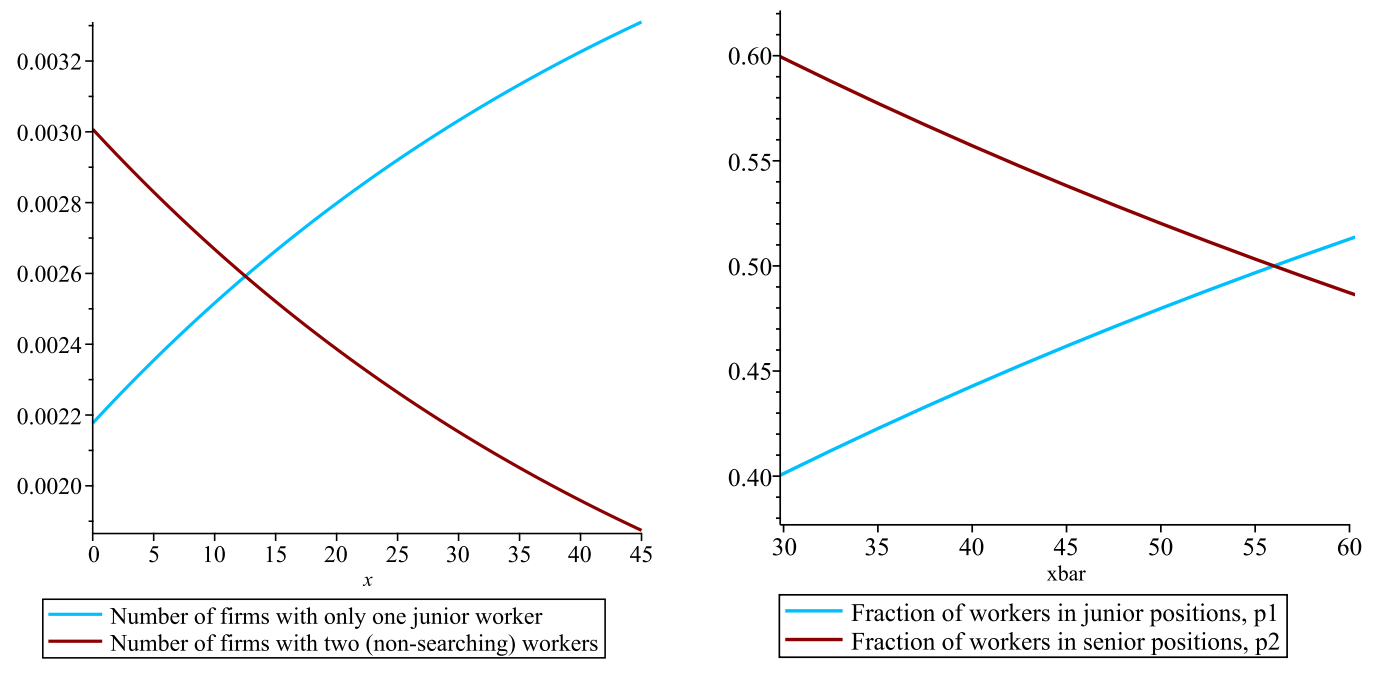

Figure 2: Left panel: Numbers of firms with only one worker in the junior position $d_{10}(x)$ and with two (non-searching) workers $d_{11}^{N}(x)$ as a function of worker's experience $x(\bar{x}=45)$. Right panel: Fractions of workers employed in the junior level $p_{1}=e_{1} /\left(e_{1}+e_{2}\right)$ and in the senior level $p_{2}=1-p_{1}$ depending on the promotion cut-off $\bar{x}$

The right panel of figure 2 shows comparative statics results with respect to the promotion cut-off $\bar{x}$. We vary this variable in the range [30..60] quarters or [7.5..15] years, with the benchmark value $\bar{x}=45$, that is 11.25 years. We can see that earlier promotions reduce the fraction of workers in junior positions $p_{1}$ and increase the fraction of workers in senior positions $p_{2}=1-p_{1}$. If we consider the implications of earlier promotions for the pool of applicants to senior positions then there are two counteracting effect. If there are many open senior vacancies in the economy then a smaller $\bar{x}$ will lead to many internal promotions, so the pool of external applicants to senior positions will diminish. But on the other hand, if the number of senior positions is limited and internal promotions are rare, a smaller $\bar{x}$ will increase the pool of external applicants to 
senior positions. We find that the second effect is dominating in our setting. This is a general equilibrium effect, which is not anticipated by individual firms when they choose their optimal promotion cut-off.

The left panel of figure 3 shows changes in the mobility of workers between levels 1 and 2 with respect to the promotion cut-off $\bar{x}$. Later promotions reduce the intensity of transitions from junior to senior positions. Both internal promotions and job-to-job transitions are less frequent with a higher promotion cut-off. This is because workers have to wait for the experience evaluation by firms certifying their skills to other employers. The same figure (right axis) also illustrates the relative fraction of internally promoted workers, we obtain it by dividing the number of promoted workers $d_{10}(\bar{x})+\rho d_{11}^{S}$ with a total number of workers making it to the senior position $\lambda_{2} d_{11}^{S}+d_{10}(\bar{x})+\rho d_{11}^{S}$. We can see that this relative fraction is increasing from $77 \%$ when $\bar{x}=25$ to $86 \%$ when $\bar{x}=65$. This reveals an unusual general equilibrium effect in our model. If some firm $i$ decides to delay internal promotions and wants to hire more senior managers on the external market it sets a higher cut-off value $\bar{x}_{i}$. However, if all firms follow the same strategy and set a higher cut-off $\bar{x}$ then the relative fraction of senior managers reaching senior positions via internal promotions is increasing. Thus internal promotions become a more important source of upward mobility for workers even though the individual intention of every firm is different ${ }^{4}$. The reason is that with a higher experience requirement $\bar{x}$, there are less applicants in the external market, so the job-to-job mobility rate declines stronger then the internal promotion rate.
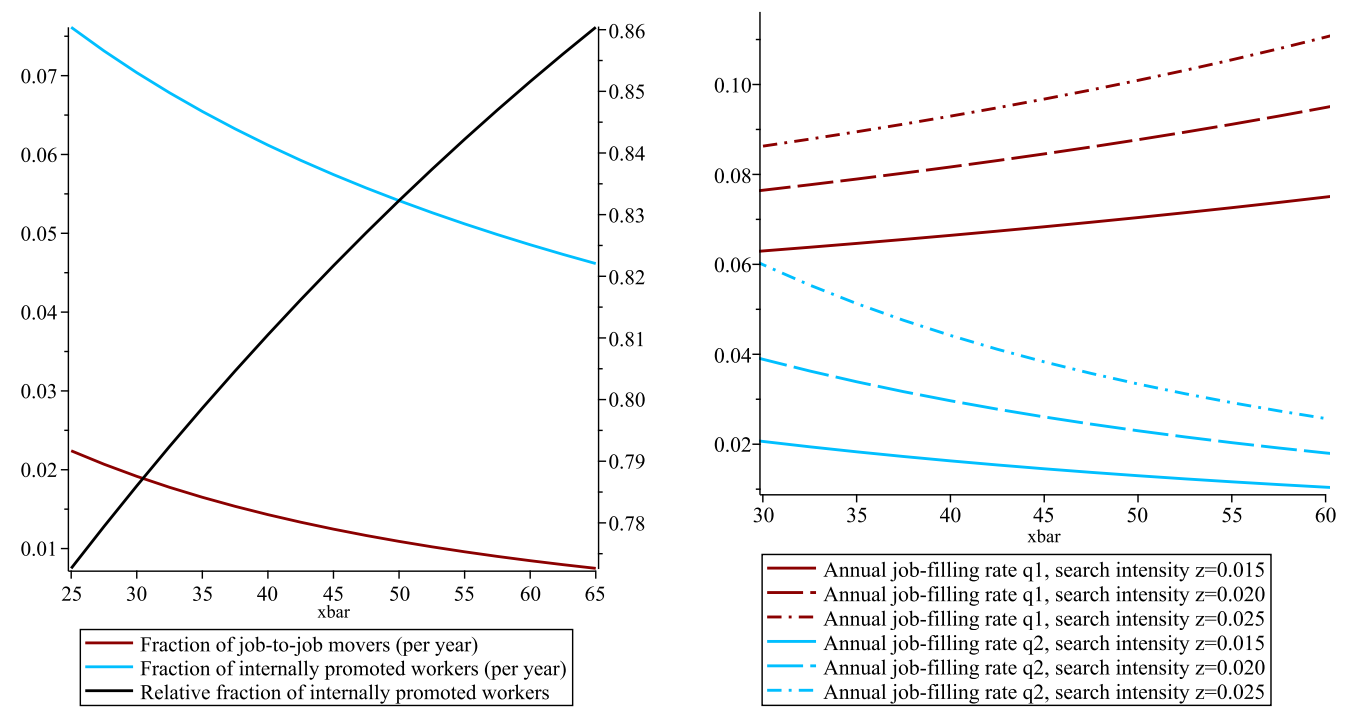

Figure 3: Selected variables for different values of the promotion cut-off $\bar{x}$ and search intensity $z$. Left panel: Fractions of internally promoted workers $\left(d_{10}(\bar{x})+\rho d_{11}^{S}\right) / e_{1}$ and job-to-job movers $\lambda_{2} d_{11}^{S} / e_{1}$ per year. Right panel: Annual job-filling rates $q_{1}$ and $q_{2}$.

The right panel of figure 3 shows changes in the job-filling rates $q_{1}$ and $q_{2}$. More intensive job search by workers makes it easier for firms to fill their open positions, so $q_{1}$ and $q_{2}$ are both increasing in $z$. But there are adverse effects of the promotion cut-off $\bar{x}$. Later promotions reduce

\footnotetext{
${ }^{4}$ This is illustrated in figure 15 in Appendix B. We simulate the relative fraction of internally promoted workers of a single firm $i$ for varying $\bar{x}_{i}$ while keeping the promotion cut-off of all other firms constant. By delaying internal promotions firm $i$ is able to hire more senior workers from the market if other firms don't change their strategy.
} 
the pool of competing vacancies on level 1. Reduced competition of firms in this submarket improves their hiring chances, so the job-filling rate $q_{1}$ is increasing with $\bar{x}$. There is an opposite effect in the second submarket for experienced workers. Delayed promotions reduce the pool of applicants for senior positions which leads to the lower job-filling rate $q_{2}$.

\section{Optimal promotion by firms}

\subsection{Firm's best response}

This section is dedicated to the analysis of the optimal promotion time chosen by an individual firm. Denoting by $J_{00}\left(\bar{x}_{i}, \bar{x}\right)$ the present value of a firm starting to search for a worker, i.e. a firm with neither a junior nor a senior level worker, which uses a promotion threshold $\bar{x}_{i}$, whereas all other firms on the market promote at $\bar{x}$. When a new firm opens it has to choose its promotion strategy and the optimal choice is given by

$$
\bar{x}_{i}^{*}(\bar{x})=\arg \max _{\bar{x}_{i} \geq 0} J_{00}\left(\bar{x}_{i}, \bar{x}\right) .
$$

In order to analyze this optimization problem the value function $J_{00}$ has to be determined. When entering the market the firm has two open positions - one junior and one senior - so the firm is searching for workers in both markets simultaneously and has a double cost $2 s$. Therefore,

$$
r J_{00}\left(\bar{x}_{i}, \bar{x}\right)=-2 s+q_{1}\left(J_{10}\left(0 \mid \bar{x}_{i}, \bar{x}\right)-J_{00}\right)+q_{2}\left(J_{01}\left(\bar{x} \mid \bar{x}_{i}, \bar{x}\right)-J_{00}\right),
$$

where $J_{10}\left(x \mid \bar{x}_{i}, \bar{x}\right)$ is the present value for a firm with only one junior worker, whose experience is $x$, and no senior level worker and $J_{01}\left(y \mid \bar{x}_{i}, \bar{x}\right)$ is the present value for a firm with only one senior level worker, whose experience is $y$, and no junior worker. If the firm first finds an inexperienced worker, which happens at rate $q_{1}$ it moves to the state $J_{10}(0)$, since we know that $x=0$. In contrast, if the firm first finds a senior manager which happens at rate $q_{2}$ it moves to the state $J_{01}(\bar{x})$ since we know that all managers in the senior market have experience $\bar{x}$.

To determine $J_{10}\left(x \mid \bar{x}_{i}, \bar{x}\right)$ let $J_{11}^{N}\left(x, y \mid \bar{x}_{i}, \bar{x}\right)$ be the present value of profits for a firm with a worker, whose experience is $x$, and a manager with experience $y$. Note that both value functions indirectly depend on the promotion cut-off $\bar{x}_{i}$ chosen by firm $i$ and on the market experience level $\bar{x}$ chosen by competing firms. Let $\pi_{1}(x)=\left(d_{1}+c_{1} e^{\gamma x}\right)(1-\beta)$ and $\pi_{2}(y)=\left(d_{2}+c_{2} e^{\gamma y}\right)(1-\beta)$ denote the flow profits obtained by the firm from a filled junior and senior position respectively. The present value $J_{10}\left(x \mid \bar{x}_{i}, \bar{x}\right)$ is given by the following equation:

$$
r J_{10}\left(x \mid \bar{x}_{i}, \bar{x}\right)=\pi_{1}(x)-s+q_{2}\left(J_{11}^{N}\left(x, \bar{x} \mid \bar{x}_{i}, \bar{x}\right)-J_{10}\left(x \mid \bar{x}_{i}, \bar{x}\right)\right)+\frac{\partial J_{10}\left(x \mid \bar{x}_{i}, \bar{x}\right)}{\partial x}
$$

The firm receives a flow profit $\pi_{1}(x)$ by employing its worker in the junior position and the worker is accumulating experience $x$. In addition, the firm pays a flow cost $s$ for posting a vacancy in the market for experienced workers. At rate $q_{2}$ the firm is successful in this market and moves to the state $J_{11}^{N}\left(x, \bar{x} \mid \bar{x}_{i}, \bar{x}\right)$, where $\bar{x}$ is the market level of experience set by other firms and guaranteeing workers' eligibility for senior positions. For the ease of exposition in the following we use $J_{10}(x)$ for $J_{10}\left(x \mid \bar{x}_{i}, \bar{x}\right)$ and $J_{11}^{N}(x, y)$ for $J_{11}^{N}\left(x, y \mid \bar{x}_{i}, \bar{x}\right)$ and omit the indirect 
dependence on $\left\{\bar{x}_{i}, \bar{x}\right\}$ in other value functions. We come back to the explicit notation when we determine the optimal promotion time $\bar{x}_{i}^{*}$ of firm $i$ and the equilibrium value of $\bar{x}$ in the end of this section.

Next consider the present value $J_{11}^{N}(x, y)$, where $x$ is the current experience of the worker in the junior position and $y$ is the constant experience level of the manager. Note that $y=\bar{x}$ if the manager was hired in the market but it can be different from $\bar{x}$ if the manager was promoted within the firm:

$$
r J_{11}^{N}(x, y)=\pi_{1}(x)+\Delta+\pi_{2}(y)-\rho\left(J_{11}^{N}(x, y)-J_{10}(x)\right)+\frac{\partial J_{11}^{N}(x, y)}{\partial x}
$$

Here the firm receives additional profit $\Delta$ from teamwork, but may lose the manager due to retirement which happens at rate $\rho$. Let $\Delta J(x, \bar{x})=J_{11}^{N}(x, \bar{x})-J_{10}(x)$ be the capital gain of the firm from filling a senior position in the market which guarantees experience $y=\bar{x}$, so that

$$
\left(r+\rho+q_{2}\right) \Delta J(x, \bar{x})=\pi_{2}(\bar{x})+\Delta+s+\frac{\partial \Delta J(x, \bar{x})}{\partial x}
$$

The general solution of this first order linear differential equation is given by:

$$
\Delta J(x, \bar{x})=\frac{\pi_{2}(\bar{x})+\Delta+s}{r+\rho+q_{2}}+K e^{\left(r+\rho+q_{2}\right) x}
$$

where $K$ is the integration constant. This equation shows that the capital gain from hiring a manager in the market has three componets: (1) the firm receives the flow profit $\pi_{2}(\bar{x})$ and $(2)$ the additional profit $\Delta$ from team work and (3) the firm saves the cost of posting a vacancy $s$. Next insert $\Delta J(x, \bar{x})$ into equation (9), this yields:

$$
r J_{10}(x)=\pi_{1}(x)-s+q_{2} \frac{\left(\pi_{2}(\bar{x})+\Delta+s\right)}{r+\rho+q_{2}}+q_{2} K e^{\left(r+\rho+q_{2}\right) x}+\frac{\partial J_{10}(x)}{\partial x}
$$

This allows us to find the general solution for the present value of profits $J_{10}(x)$ (with $A$ denoting the integration constant, see Appendix A for the derivation) and $J_{11}^{N}(x, \bar{x})$. Recall that $J_{11}^{N}(x, \bar{x})=\Delta J(x, \bar{x})+J_{10}(x)$, so we get:

$$
\begin{aligned}
J_{10}(x) & =\frac{d_{1}(1-\beta)-s}{r}+q_{2} \frac{\left(\pi_{2}(\bar{x})+\Delta+s\right)}{r\left(r+\rho+q_{2}\right)}+A e^{r x}+\frac{c_{1}(1-\beta) e^{\gamma x}}{r-\gamma}-\frac{q_{2} K e^{\left(r+\rho+q_{2}\right) x}}{\rho+q_{2}} \\
J_{11}^{N}(x, \bar{x}) & =\frac{\left(\pi_{2}(\bar{x})+\Delta+s\right)\left(r+q_{2}\right)}{r\left(r+\rho+q_{2}\right)}+\frac{\rho K e^{\left(r+\rho+q_{2}\right) x}}{\rho+q_{2}}+\frac{d_{1}(1-\beta)-s}{r}+A e^{r x}+\frac{c_{1}(1-\beta) e^{\gamma x}}{r-\gamma}
\end{aligned}
$$

Next consider $J_{01}(y)$, which is the present value of profits for a firm with only one manager, whose experience level is $y$ :

$$
r J_{01}(y)=\pi_{2}(y)-\rho J_{01}(y)-s+q_{1}\left(J_{11}^{N}(0, y)-J_{01}(y)\right)
$$

The firm receives the flow profit $\pi_{2}(y)=\left(d_{2}+c_{2} e^{\gamma y}\right)(1-\beta)$ generated by the manager and is continuously posting a vacancy in the market for junior workers, which is associated with a flow cost $s$. At rate $q_{1}$ the firm is successful in this market and moves to the state $J_{11}^{N}(0, y)$. This is because applicants to junior positions are young and inexperienced with $x=0$. Finally, at rate 
$\rho$ the firm may lose the senior manager and remains empty. All empty firms exit the market. Rewrite $J_{01}(y)$ in the following way:

$$
J_{01}(y)=\frac{\pi_{2}(y)-s+q_{1} J_{11}^{N}(0, y)}{r+\rho+q_{1}}
$$

The last state for the firm is when the junior worker has already accumulated experience necessary for promotion. Recall that $\bar{x}_{i}$ denotes promotion cut-off of some arbitrary firm $i$. This means that the junior worker obtains experience evaluation and becomes eligible for senior positions having accumulated experience $\bar{x}_{i}$. This promotion cut-off is chosen by the firm upon signing the employment contract. If the senior position is open in firm $i$, the worker with $x=\bar{x}_{i}$ is promoted immediately. However, it is also possible that the senior position is occupied, so the worker starts searching for alternative employment. Let $J_{11}^{s}\left(\bar{x}_{i}, y\right)$ be the present value of profits for a firm with a searching worker whose experience is $\left(\bar{x}_{i}\right)$ and a manager $(y)$ :

$$
r J_{11}^{s}\left(\bar{x}_{i}, y\right)=\pi_{1}\left(\bar{x}_{i}\right)+\Delta+\pi_{2}(y)-\rho\left(J_{11}^{s}\left(\bar{x}_{i}, y\right)-J_{01}\left(\bar{x}_{i}\right)\right)-\lambda_{2}\left(J_{11}^{s}\left(\bar{x}_{i}, y\right)-J_{01}(y)\right)
$$

This equation shows the following. The firm obtains the flow profit generated by both workers $\pi_{1}\left(\bar{x}_{i}\right)+\pi_{2}(y)$ and additional profit $\Delta$ from teamwork. At rate $\rho$ the manager may retire, so the searching worker is promoted to the senior position and the firm moves to the state $J_{01}\left(\bar{x}_{i}\right)$. Alternatively, it may happen that the worker finds alternative employment and quits at rate $\lambda_{2}$. In this case the firm is left with only one manager and the present value of profits is $J_{01}(y)$. Next we know that other firms promote their workers at $\bar{x}$, so all managers hired in the market have experience $y=\bar{x}$. Then $J_{11}^{S}\left(\bar{x}_{i}, \bar{x}\right)$ is given by:

$$
J_{11}^{S}\left(\bar{x}_{i}, \bar{x}\right)=\frac{\pi_{1}\left(\bar{x}_{i}\right)+\Delta+\pi_{2}(\bar{x})+\rho J_{01}\left(\bar{x}_{i}\right)+\lambda_{2} J_{01}(\bar{x})}{r+\rho+\lambda_{2}}
$$

In order to find the two integration constants $A$ and $K$ we use the following two boundary conditions: $J_{10}\left(\bar{x}_{i}\right)=J_{01}\left(\bar{x}_{i}\right)$ and $J_{11}^{N}\left(\bar{x}_{i}, \bar{x}\right)=J_{11}^{S}\left(\bar{x}_{i}, \bar{x}\right)$. The first condition says that firms are committed to promote the worker upon experience $\bar{x}_{i}$ if the senior position is open, so the present value of the firm changes from $J_{10}\left(\bar{x}_{i}\right)$ to $J_{01}\left(\bar{x}_{i}\right)$. The second condition says that workers with experience $\bar{x}_{i}$ stop accumulating experience and start searching for alternative jobs at $\bar{x}_{i}$ if the senior position is filled, so the present value of the firm is changing from $J_{11}^{N}\left(\bar{x}_{i}, \bar{x}\right)$ to $J_{11}^{S}\left(\bar{x}_{i}, \bar{x}\right)$.

The first boundary condition $J_{10}\left(\bar{x}_{i}\right)=J_{01}\left(\bar{x}_{i}\right)$ can be written as:

$$
\begin{aligned}
J_{10}\left(\bar{x}_{i}\right) & =\frac{d_{1}(1-\beta)-s}{r}+q_{2} \frac{\pi_{2}(\bar{x})+\Delta+s}{r\left(r+\rho+q_{2}\right)}+A e^{r \bar{x}_{i}}+\frac{c_{1}(1-\beta) e^{\gamma \bar{x}_{i}}}{r-\gamma}-\frac{q_{2} K e^{\left(r+\rho+q_{2}\right) \bar{x}_{i}}}{\rho+q_{2}} \\
& =\frac{\pi_{2}\left(\bar{x}_{i}\right)-s+q_{1} J_{11}^{N}\left(0, \bar{x}_{i}\right)}{r+\rho+q_{1}}=J_{01}\left(\bar{x}_{i}\right)
\end{aligned}
$$

The second boundary condition $J_{11}^{N}\left(\bar{x}_{i}, \bar{x}\right)=J_{11}^{S}\left(\bar{x}_{i}, \bar{x}\right)$ becomes:

$$
\begin{aligned}
& J_{11}^{N}\left(\bar{x}_{i}, \bar{x}\right)=\frac{\left(\pi_{2}(\bar{x})+\Delta+s\right)\left(r+q_{2}\right)}{r\left(r+\rho+q_{2}\right)}+\frac{\rho K e^{\left(r+\rho+q_{2}\right) \bar{x}_{i}}}{\rho+q_{2}}+\frac{d_{1}(1-\beta)-s}{r}+A e^{r \bar{x}_{i}}+\frac{c_{1}(1-\beta) e^{\gamma \bar{x}_{i}}}{r-\gamma} \\
= & \frac{\pi_{1}\left(\bar{x}_{i}\right)+\Delta+\pi_{2}(\bar{x})}{r+\rho+\lambda_{2}}+\frac{\rho\left(\pi_{2}\left(\bar{x}_{i}\right)-s+q_{1} J_{11}^{N}\left(0, \bar{x}_{i}\right)\right)}{\left(r+\rho+\lambda_{2}\right)\left(r+\rho+q_{1}\right)}+\frac{\lambda_{2}\left(\pi_{2}(\bar{x})-s+q_{1} J_{11}^{N}(0, \bar{x})\right)}{\left(r+\rho+\lambda_{2}\right)\left(r+\rho+q_{1}\right)}=J_{11}^{S}\left(\bar{x}_{i}, \bar{x}\right)
\end{aligned}
$$


Note that one term which is still unknown in both boundary conditions is $J_{11}^{N}\left(0, \bar{x}_{i}\right)$. We derive this term in Appendix A. Solving these two boundary conditions for $A$ and $K$ we can see that both variables depend on the individual decision of firm $i$ and on the behavior of other firms $\bar{x}$, that is $A\left(\bar{x}_{i}, \bar{x}\right)$ and $K\left(\bar{x}_{i}, \bar{x}\right)$.

Based on this analysis we can now write the firm's optimization problem (8) as

$$
\bar{x}_{i}^{*}(\bar{x})=\arg \max _{\bar{x}_{i} \geq 0}\left[q_{1} J_{10}\left(0 \mid\left\{\bar{x}, A\left(\bar{x}_{i}, \bar{x}\right), K\left(\bar{x}_{i}, \bar{x}\right)\right\}\right)+q_{2} J_{01}\left(\bar{x} \mid\left\{\bar{x}, A\left(\bar{x}_{i}, \bar{x}\right), K\left(\bar{x}_{i}, \bar{x}\right)\right\}\right)\right],
$$

where we show explicitly the arguments of functions $J_{10}(0)$ and $J_{01}(\bar{x})$. The solution of this maximization problem gives the optimal response function $\bar{x}_{i}(\bar{x})$ of firm $i$. Since firms are homogeneous with respect to their profit functions, they all have identical optimal response functions. In light of this in what follows we restrict our attention to symmetric Nash equilibria and impose the equilibrium condition $\bar{x}_{i}^{*}(\bar{x})=\bar{x}$ to find the equilibrium promotion time $\bar{x}$.

\subsection{Partial and general equilibrium}

The complexity of the expressions derived for $J_{10}$ and $J_{01}$ makes an analytical characterization of the best response function and the resulting equilibrium infeasible, even if we consider a partial equilibrium with fixed transition rates. Therefore, we illustrate the main properties of the best response function and the equilibrium by extending the calibration of our model developed in Section 2.3 (Table 1) and carrying out a numerical analysis. First, we consider a partial equilibrium framework with fixed transition rates $\left\{q_{1}, q_{2}, \lambda_{1}, \lambda_{2}\right\}$, with the corresponding values from table 1 . We choose the annual discount rate equal to $4 \%$, so that $r=0.01$. We also take a standard value of the bargaining power $\beta=0.5$ following Pissarides and Petrongolo (2001) and Pissarides (2009). The flow cost of an open vacancy is set low $(s=0.1)$, as it is not in the focus of our analysis. Further, parameters $d_{2}<d_{1}$ and $c_{2}>c_{1}$ are calibrated so that $\bar{x}=45$, corresponding to a promotion time of 11.25 years, is an equilibrium outcome of the overall model. Even though it is an endogenous variable in the complete model, we keep it fixed in this section and analyse the optimal response of a single firm $i$. We start with a benchmark value $\Delta=0$ and postpone the analysis of production complementarities to the next section.

We set the rate of return to tenure at $1.2 \%$ per year, which yields $\gamma=0.003$ on the quarterly basis. According to Farber (1999) the usual OLS estimate of the return to tenure in the United States is $2 \%$ per year with the same employer. Empirical methods generally separate this number into two parts: 1 . human capital accumulation within the firm and 2. selection component due to the fact that high ability workers stay longer in their jobs and earn more. Farber (1999) finds that $1.5 \%$ of the return to tenure is due to the accumulation of human capital and only $0.5 \%$ due to selection. In a more recent study Bingley and Westergaard-Nielsen (2003) report the same $2 \%$ return to tenure in Denmark, but the human capital component is estimated only at $0.5 \%$ per year. These numbers reveal that our parameter choice $-1.2 \%$ per year due to human capital accumulation within the firm - is in the middle range of the existing empirical estimates. Moreover, it coincides with the return to tenure estimated by Iftikhar and Zaharieva (2018) for Germany. The second set of parameters is summarized in table 3 below:

Figure 4 shows the objective function of firm $i-J_{00}\left(\bar{x}_{i}\right)$ - for a fixed market promotion time $\bar{x}=45$ and for fixed transition rates $\left\{q_{1}, q_{2}, \lambda_{1}, \lambda_{2}\right\}$ (left panel). We can see that promoting junior 


\begin{tabular}{c|c|l||c|c|l}
\hline & Value & Interpretation & & Value & Interpretation \\
\hline$r$ & 0.010 & Quarterly discount rate & $\gamma$ & 0.003 & Quarterly return to tenure \\
$\beta$ & 0.500 & Bargaining power & $s$ & 0.100 & Flow cost of an open vacancy \\
$c_{1}$ & 0.500 & Slope parameter, level 1 & $c_{2}$ & 2.000 & Slope parameter, level 2 \\
$d_{1}$ & 0.200 & Intercept parameter, level 1 & $d_{2}$ & 0.100 & Intercept parameter, level 2 \\
\hline
\end{tabular}

Table 3: Values of exogenous parameters

workers too early is not optimal for the firm. This is despite the fact that $d_{1}+c_{1}<d_{2}+c_{2}$, which means that the flow profit of the firm is higher in the senior position even if the worker doesn't possess any managerial experience and $x=0$. The reason is that firms are forward-looking and anticipate a larger gain from promotion once the worker accumulated some managerial experience. At the same time waiting too long is also suboptimal for the firm because the foregone profit is increasing. This is the indirect cost of delayed promotions. In addition, there is the direct flow cost of an open vacancy in the senior position $s$. As can be clearly seen for our considered parameter values the optimal promotion time is $\bar{x}_{i}^{*}(45)=45$.
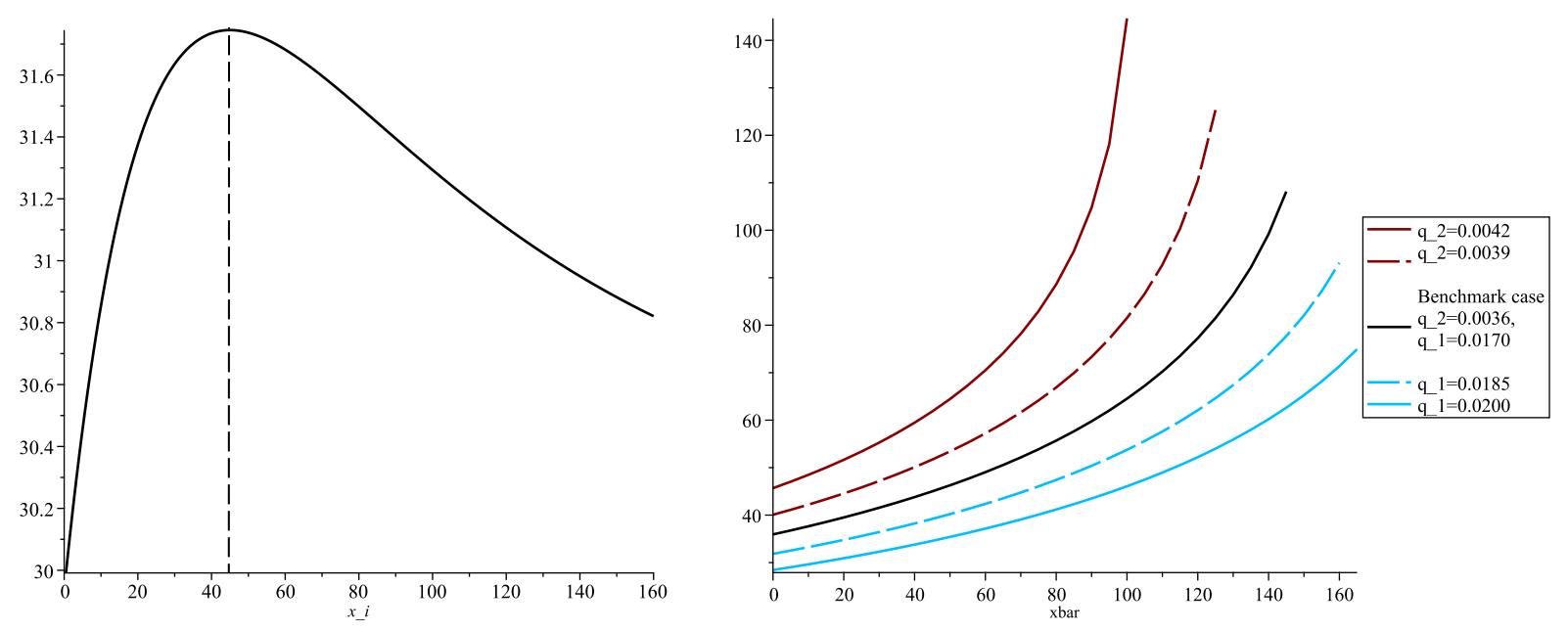

Figure 4: Left panel: Objective function of firm $i$ and the optimal choice $\bar{x}_{i}^{*}(\bar{x})$ for a fixed market promotion cut-off $\bar{x}=45$ and fixed transition rates. Right panel: Optimal response function $\bar{x}_{i}^{*}(\bar{x})$ for different values of $\bar{x}$, comparative statics with respect to the job-filling rates $q_{1}$ and $q_{2}$

The right panel of figure 4 shows the optimal response function $\bar{x}_{i}^{*}(\bar{x})$ for different values of the market promotion time $\bar{x}$ and fixed transition rates (black solid curve). We can see that firm $i$ has strong incentives to delay promotions if other firms in the market promote their junior workers later. Higher $\bar{x}$ implies that managers applying externally are more experienced, so the quality of the candidate pool in the managerial market is better. In this situation it is optimal for firm $i$ to wait longer because the marginal gain from waiting is increasing with $\bar{x}$ due to the better quality of external candidates. Hence, we obtain that there is strategic complementarity between the promotion times of the different firms in the market.

Further, we consider the effect of increasing the job-filling rate $q_{1}$ keeping fixed all other transition rates. So it becomes easier for firms to fill their junior positions. The right panel of figure 4 shows that the optimal response curve $\bar{x}_{i}^{*}(\bar{x})$ is shifting downwards for all $\bar{x}$. Note that $s / q_{1}$ is the average cost of an open junior position because $s$ is the cost per unit time and $1 / q_{1}$ 
is the average duration of the vacancy. Higher $q_{1}$ lowers the cost of open junior positions, so it is optimal for the firm to promote its junior worker earlier. The opposite is true when we increase $q_{2}$, so the optimal response curve $\bar{x}_{i}^{*}(\bar{x})$ is shifting upwards for all $\bar{x}$. In this case open senior positions become cheaper because $s / q_{2}$ is decreasing, so firm $i$ finds it optimal to delay promotions. This shows that the two positions are substitutes from the perspective of the firm.

We already know that $\bar{x}_{i}^{*}=\bar{x}^{p e}=45$ for all firms $i$ is a symmetric partial equilibrium of the model for the given transition rates (values from table 1). But is it a unique partial equilibrium? Figure 5 shows that in addition to the low equilibrium $\bar{x}_{l}^{p e}=45$ there also exists a second partial equilibrium with $\bar{x}_{h}^{p e}=157.6$ for these transition rates. Both equilibria are illustrated on the right panel of figure 5 . In light of the strategic complementarity between the optimal promotion times of the firms it is not surprising that multiple equilibria exist in our model. However, as can be clearly seen in right panel of figure 5 only the low equilibrium is strategically stable. Any best response dynamics initialized with a market promotion level $\bar{x} \in\left[0, \bar{x}_{h}^{p e}\right]$ converges to the lower equilibrium $\bar{x}_{l}^{p e}=45$.
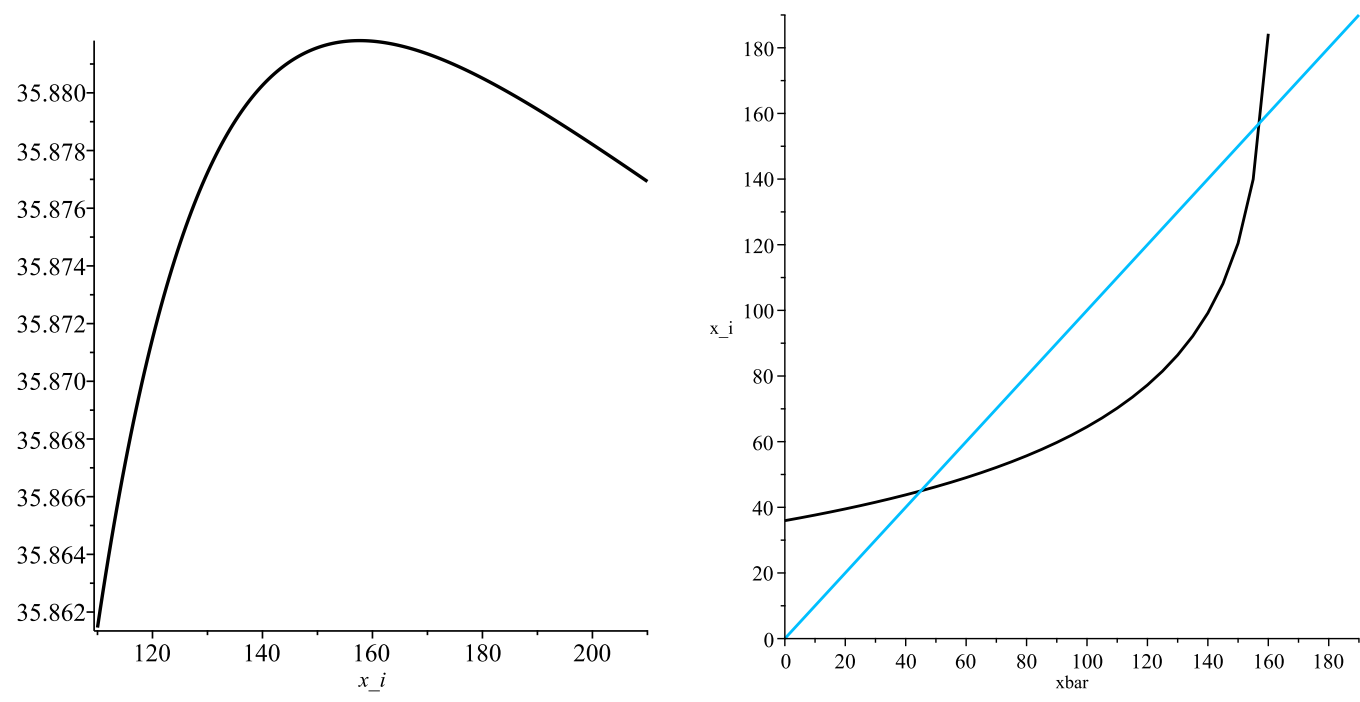

Figure 5: Left panel: Objective function of firm $i$ for $\bar{x}=157.6$. Right panel: Optimal response curve $\bar{x}_{i}^{*}(\bar{x})$ exhibiting the two partial equilibria $\bar{x}_{l}^{p e}=45$ and $\bar{x}_{h}^{p e}=157.6$ for fixed transition rates from table 1

In Section 2.3 we have shown that if all firms use a promotion threshold of $\bar{x}=45$, then the transition rates under the stationary distribution are given by $\left\{q_{1}=0.0171, q_{2}=0.0036, \lambda_{1}=\right.$ $\left.0.0145, \lambda_{2}=0.0146\right\}$ (see Table 1). Since these are exactly the transition rates under which we have carried out the partial equilibrium analysis above, it follows directly that $\bar{x}_{i}^{*}=\bar{x}_{l}^{p e}=45, i \in$ $[0,1]$ is also a general equilibrium of the model. Similarly to the partial equilibrium setting, also with endogenous transition rates a second equilibrium with a very high promotion threshold exists, which however is unstable. Hence in what follows we focus on the lower equilibrium and in the following section examine how the equilibrium promotion threshold changes in response to a variation of key parameters in the model. 


\subsection{Comparative statics: partial and general equilibrium effects}

Based on the benchmark numerical example developed in the previous section we now address two key questions of our study: (1) how promotion chances of junior workers are affected if there exist production complementarities and synergies from the team work and (2) what is the link between the optimal promotion time and the skill level of the worker?

In order to address the first question we gradually increase the synergy parameter $\Delta$, which was fixed at 0 in the benchmark case. This is illustrated on the left panel of figure 6 . If the synergy parameter is increasing from 0 to 0.6 the promotion cut-off $\bar{x}^{g e}$ in the general equilibrium is decreasing from 45 down to 43.7. Stronger complementarities in the production process create stronger incentives for firms to employ a full team of two employees rather than having open vacancies. In our setting the job-filling rate in the junior market $q_{1}=0.0171$ is substantially higher than the job-filling rate in the senior market $q_{2}=0.0036$ which means that hiring junior workers is easier than senior managers. In this situation firms prefer earlier promotions of junior employees in the hope that the junior position will be filled faster than the senior position and the firm can gain additional profits from the team production process. Note that this gain comes at the expense of accepting less experienced senior managers.
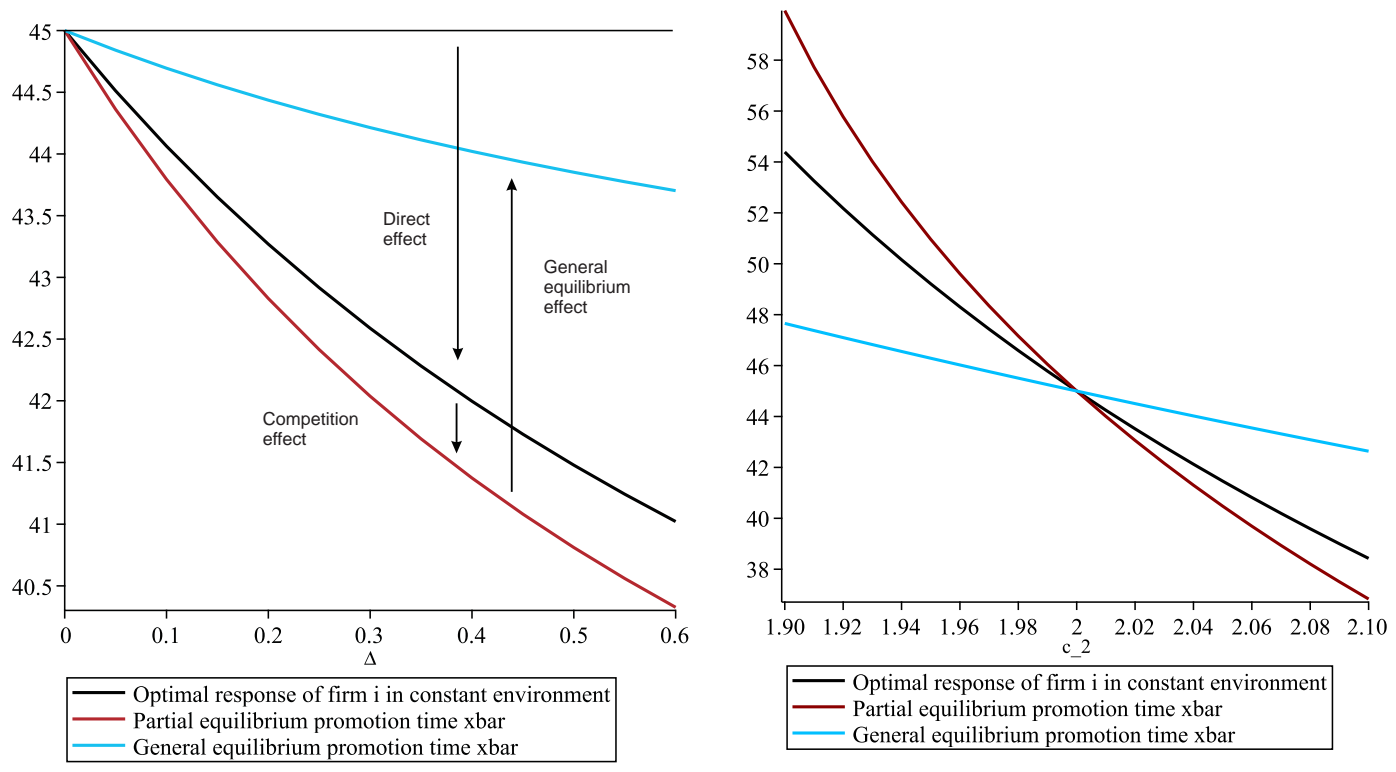

Figure 6: Left panel: Equilibrium promotion time $\bar{x}_{i}($.$) as a function of the synergy parameter$ $\Delta$. Right panel: Equilibrium promotion time $\bar{x}_{i}($.$) as a function of the skill parameter c_{2}$

Further, we decompose this effect into three parts. We write the individually optimal promotion threshold $\bar{x}_{i}^{*}(\bar{x}, \zeta, \Delta)$ as a function of the market promotion level $\bar{x}$ as well as the vector of transition rates $\zeta$ and the synergy parameter $\Delta$. Furthermore, $\bar{x}^{p e}(\zeta, \Delta)$ denotes the (partial) equilibrium market cutoff under transitions rates $\zeta$ and $\zeta^{\Delta}$ the general equilibrium transition rates for the synergy parameter $\Delta$. The general equilibrium cutoff under synergy $\Delta$ is then denoted as $\bar{x}^{g e}(\Delta):=\bar{x}^{p e}\left(\zeta^{\Delta}, \Delta\right)$. Hence $\bar{x}_{i}^{*}\left(\bar{x}^{p e}\left(\zeta^{0}, 0\right), \zeta^{0}, 0\right)=\bar{x}^{p e}\left(\zeta^{0}, 0\right)=\bar{x}^{g e}(0)=45$. Using 
this notation we obtain the following decomposition of the effect of a change in $\Delta$ :

$$
\begin{aligned}
\bar{x}^{g e}(0)-\bar{x}^{g e}(\Delta) & =\bar{x}^{p e}\left(\zeta^{0}, 0\right)-\bar{x}^{p e}\left(\zeta^{\Delta}, \Delta\right)=\bar{x}_{i}^{*}\left(\bar{x}^{p e}\left(\zeta^{0}, 0\right), \zeta, 0\right)-\bar{x}_{i}^{*}\left(\bar{x}^{p e}\left(\zeta^{\Delta}, \Delta\right), \zeta^{\Delta}, \Delta\right)= \\
& =\underbrace{\left[\bar{x}_{i}^{*}\left(\bar{x}^{p e}\left(\zeta^{0}, 0\right), \zeta^{0}, 0\right)-\bar{x}_{i}^{*}\left(\bar{x}^{p e}\left(\zeta^{0}, 0\right), \zeta^{0}, \Delta\right)\right]}_{\text {Direct effect }} \\
& +\underbrace{\left[\bar{x}_{i}^{*}\left(\bar{x}^{p e}\left(\zeta^{0}, 0\right), \zeta^{0}, \Delta\right)-\bar{x}_{i}^{*}\left(\bar{x}^{p e}\left(\zeta^{0}, \Delta\right), \zeta^{0}, \Delta\right)\right]}_{\text {Competition effect }} \\
& +\underbrace{\left[\bar{x}_{i}^{*}\left(\bar{x}^{p e}\left(\zeta^{0}, \Delta\right), \zeta^{0}, \Delta\right)-\bar{x}_{i}^{*}\left(\bar{x}^{p e}\left(\zeta^{\Delta}, \Delta\right), \zeta^{\Delta}, \Delta\right)\right]}_{\text {General equilibrium effect }}
\end{aligned}
$$

First, figure 6 (left panel) shows the direct effect, this is a change in the optimal promotion time of firm $i$ as a function of $\Delta$ in a setting with constant environment. As we can see from the figure, the firm has very strong incentives to promote earlier. If the synergy parameter is increasing from 0 to 0.6 the optimal promotion cut-off of firm $i$ is decreasing from 45 down to 41 (black curve). So the direct effect for $\Delta=0.6$ is equal to $4=45-41$. Second, we allow for changes in the behavior of competing firms $\bar{x}^{p e}\left(\zeta^{0}, \Delta\right)$ but keep the set of transition rates $\zeta^{0}$ fixed. This is the competition effect. We already know from figure 4 that earlier promotions by the competitors lead to earlier promotions of firm $i$. This is illustrated by the red curve on figure 6. If the synergy parameter is increasing from 0 to 0.6 and the firm takes earlier promotions of competitiors into account the optimal promotion cut-off is decreasing even stronger from 41 down to 40.3 , so the competition effect is equal to $0.7=41-40.3$. It makes promotions more sensitive to the production complementarity $\Delta$. The sum of these two effects would be observed in a partial equilibrium setting, in which the transition rates are kept constant. Third, we analyze the general equilibrium effect and allow for the endogenous changes in the transition rates. From figure 3 we already know that if all firms set earlier promotion times then $q_{1}$ is decreasing and $q_{2}$ is increasing. Intuitively, this means that earlier promotions make it easier for firms to hire senior managers but hiring junior workers becomes more difficult. This general equilibrium effect mitigates the incentives of firm $i$ to promote earlier and makes promotions less sensitive to the production complementarity $\Delta$. The general equilibrium effect is illustrated by the blue curve and is equal to $-3.4=40.3-43.7$. Based on this decomposition we can conclude that the direct effect and the general equilibrium effect are quantitatively larger than the competition effect in our setting.

Next we turn to the effect of education. We proxy this effect by changes in the parameter $c_{2}$. The intuition behind this proxy is that more educated workers with higher skills will be more productive in senior positions than low skill workers even if they have similar practical experience. This is due to the methodological competence, broader knowledge and problemsolving skills associated with higher education. Following this logic we assume that higher $c_{2}$ corresponds to the labour market with more educated workers but there are no productivity differences in junior jobs $\left(c_{1}\right)$. The right panel of figure 6 shows changes in the promotion times where $c_{2}=2$ is the benchmark case in the middle of the figure. We can see that higher education generally leads to earlier promotions. The effects are reversed when the labour force is less qualified: if $c_{2}$ is decreasing from 2 to 1.95, firm $i$ responds by setting the equilibrium promotion time equal to 49.2 in a constant environment. If all competitors follow the same strategy and 
set longer promotion times the partial equilibrium is achieved at $\bar{x}_{i}^{*}\left(\bar{x}^{p e}\right)=\bar{x}^{p e}=51$. The decomposition reveals again that the general equilibrium effect dampens the direct effect of the parameter change on the optimal promotion time and makes it less sensitive to the education parameter. We obtain for $c_{2}=1.95$ a general equilibrium cut-off of $\bar{x}^{g e}=46.3$. Even though this result provides first evidence of the positive link between education and the speed of promotions in our model, it is only a comparative statics result and it is not clear if it will be confirmed in a setting where two skill types are mixed in the same labour market. We continue this analysis in the next section.

\section{Two skill levels}

\subsection{Optimal promotion with two skill levels}

In this section we extend the model to the setting with two skill groups and analyze the spillover effects that the presence of one skill group imposes on the other group. To keep the model tractable we refrain from the synergy effect and set $\Delta=0$ throughout this extension. Let $c_{2}^{L}$ be the education parameter of low skill workers. Once employed in the senior job they generate the flow profit $\pi_{2}^{L}(x)=\left(d_{2}+c_{2}^{L} e^{\gamma x}\right)(1-\beta)$ for the firm. Further, $c_{2}^{H}>c_{2}^{L}$ denotes the education parameter of high skill workers, so they generate the flow profit $\pi_{2}^{H}(x)=\left(d_{2}+c_{2}^{H} e^{\gamma x}\right)(1-\beta)$. We assume that the difference between $c_{2}^{L}$ and $c_{2}^{H}$ is sufficiently small so that firms do not reject low skill applicants. Moreover, $c_{1}$ remains the same for both worker groups indicating that high and low skill workers are equally productive when performing junior level jobs. It is the difference in managerial abilities that we want to capture in this extension. Let $a$ denote the fraction of low skill workers in the population. Variables $\bar{x}_{i}^{L}$ and $\bar{x}_{i}^{H}$ denote the promotion times set by firm $i$ for each skill group respectively. As before this decision is made upon the entry and there is full commitment on the side of the firm.

Further, let $\alpha_{1}$ denote the fraction of low skill applicants in the junior market and $\alpha_{2}$ be the fraction of low skill applicants in the senior market. Consider some firm with an inexperienced worker of skill $j=L, H$ employed in the junior position and an open vacancy on the senior level. The present value of discounted future profits of this firm is denoted by $J_{j 0}$ and given by:

$$
r J_{j 0}(x)=\pi_{1}(x)-s+q_{2}\left[\alpha_{2} J_{j L}^{N}\left(x, \bar{x}_{L}\right)+\left(1-\alpha_{2}\right) J_{j H}^{N}\left(x, \bar{x}_{H}\right)-J_{j 0}(x)\right]+\frac{\partial J_{j 0}(x)}{\partial x}
$$

With probability $\alpha_{2}$ the firm will hire another low skill worker for the senior position, which generates the present value of profits $J_{j L}^{N}\left(x, \bar{x}_{L}\right)$, while with the opposite probability $1-\alpha_{2}$ the firm will hire a high skill worker which generates the present value of profits $J_{j H}^{N}\left(x, \bar{x}_{H}\right)$. Note here that $\bar{x}_{j}$ denotes the market experience level of applicants in the managerial market with a skill level $j=L, H$. Variables $J_{j f}^{N}(x, y), j, f=L, H$ can be found as:

$$
r J_{j f}^{N}(x, y)=\pi_{1}(x)+\pi_{2}^{f}(y)-\rho\left(J_{j f}^{N}(x, y)-J_{j 0}(x)\right)+\frac{\partial J_{j f}^{N}(x, y)}{\partial x}
$$

Here $\pi_{2}^{f}(y)$ is the flow profit generated by the senior manager who may retire and exit the market at rate $\rho$. In this case the firm is left with the inexperienced junior worker and the corresponding present value $J_{j 0}(x)$. Further, we define an auxilliary variable $\bar{J}_{j}(x) \equiv \alpha_{2} J_{j L}^{N}\left(x, \bar{x}_{L}\right)+(1-$ 
$\left.\alpha_{2}\right) J_{j H}^{N}\left(x, \bar{x}_{H}\right)$ which is a weighted average between the two present values and is given by:

$$
r \bar{J}_{j}(x)=\pi_{1}(x)+\alpha_{2} \pi_{2}^{L}\left(\bar{x}_{L}\right)+\left(1-\alpha_{2}\right) \pi_{2}^{H}\left(\bar{x}_{H}\right)-\rho\left(\bar{J}_{j}(x)-J_{j 0}(x)\right)+\frac{\partial \bar{J}_{j}(x)}{\partial x}
$$

Note that formally, $\bar{J}_{j}\left(x, \bar{x}_{L}, \bar{x}_{H}\right)$ depends on $\bar{x}_{L}$ and $\bar{x}_{H}$ but this dependence is suppressed for the ease of exposition. Equation (11) can then be written as:

$$
r J_{j 0}(x)=\pi_{1}(x)-s+q_{2}\left[\bar{J}_{j}(x)-J_{j 0}(x)\right]+\frac{\partial J_{j 0}(x)}{\partial x}
$$

In addition, define another auxilliary variable $\Delta J_{j}(x) \equiv \bar{J}_{j}(x)-J_{j 0}(x)$, this is the average present value gain of finding a manager. Taking difference between equations (13) and (14) it becomes:

$$
\left(r+\rho+q_{2}\right) \Delta J_{j}(x)=\alpha_{2} \pi_{2}^{L}\left(\bar{x}_{L}\right)+\left(1-\alpha_{2}\right) \pi_{2}^{H}\left(\bar{x}_{H}\right)+s+\frac{\partial \Delta J_{j}(x)}{\partial x}
$$

The general solution of this first order linear differential equation is:

$$
\Delta J_{j}(x)=\frac{\alpha_{2} \pi_{2}^{L}\left(\bar{x}_{L}\right)+\left(1-\alpha_{2}\right) \pi_{2}^{H}\left(\bar{x}_{H}\right)+s}{r+\rho+q_{2}}+K_{j} e^{\left(r+\rho+q_{2}\right) x}
$$

where $K_{j}$ is the integration constant. Let $\bar{\pi}_{2}\left(\bar{x}_{L}, \bar{x}_{H}\right)=\alpha_{2} \pi_{2}^{L}\left(\bar{x}_{L}\right)+\left(1-\alpha_{2}\right) \pi_{2}^{H}\left(\bar{x}_{H}\right)$ denote the average flow profit of the firm associated with hiring a manager in the market. With this notation we can rewrite equation (14) for $J_{j 0}(x)$ by inserting $\Delta J_{j}(x)$ in the following way:

$$
r J_{j 0}(x)=\pi_{1}(x)-s+q_{2}\left[\frac{\bar{\pi}_{2}\left(\bar{x}_{L}, \bar{x}_{H}\right)+s}{r+\rho+q_{2}}+K_{j} e^{\left(r+\rho+q_{2}\right) x}\right]+\frac{\partial J_{j 0}(x)}{\partial x}
$$

With $A_{j}$ denoting the integration constant, the general solution of this differential equation can be written as:

$$
J_{j 0}(x)=\frac{d_{1}(1-\beta)-s}{r}+q_{2} \frac{\bar{\pi}_{2}\left(\bar{x}_{L}, \bar{x}_{H}\right)+s}{r\left(r+\rho+q_{2}\right)}+A_{j} e^{r x}+\frac{c_{1}(1-\beta) e^{\gamma x}}{r-\gamma}-\frac{q_{2} K_{j} e^{\left(r+\rho+q_{2}\right) x}}{\rho+q_{2}}
$$

Finally, inserting $J_{j 0}(x)$ into equation (12) we get the last differential equation for $J_{j f}^{N}(x, y)$ which allows us to solve the main part of the model (see Appendix A for the derivation):

$$
\begin{aligned}
J_{j f}^{N}(x, y) & =\frac{d_{1}(1-\beta)-s}{r}+\frac{\pi_{2}^{f}(y)}{r+\rho}+\frac{\rho q_{2} \bar{\pi}_{2}\left(\bar{x}_{L}, \bar{x}_{H}\right)}{r\left(r+\rho+q_{2}\right)(r+\rho)}+\frac{s\left(r+q_{2}\right)}{r\left(r+\rho+q_{2}\right)} \\
& +A_{j} e^{r x}+\frac{c_{1}(1-\beta) e^{\gamma x}}{(r-\gamma)}+\frac{\rho K_{j} e^{\left(r+\rho+q_{2}\right) x}}{\left(\rho+q_{2}\right)}+D_{j f} e^{(r+\rho) x}
\end{aligned}
$$

where $D_{j f}$ is the corresponding integration constant. Evaluating $J_{j L}^{N}(x, y)$ at $y=\bar{x}_{L}$ with the corresponding term $D_{j L}, J_{j H}^{N}(x, y)$ at $y=\bar{x}_{H}$ with the corresponding term $D_{j H}$ and taking a weighted average between the two we get $\alpha_{2} J_{j L}^{N}\left(x, \bar{x}_{L}\right)+\left(1-\alpha_{2}\right) J_{j H}^{N}\left(x, \bar{x}_{H}\right)=\bar{J}_{j}(x)=\Delta J_{j}(x)+$ $J_{j 0}(x)$. In Appendix A we show that this equation implies that $\alpha_{2} D_{j L}+\left(1-\alpha_{2}\right) D_{j H}=0$.

In the next step we consider the last Bellman equations for firms with experienced junior workers and senior managers. Let $J_{0 f}(y)$ denote the present value of future profits for a firm 
with only one senior manager whose experience is $y$ :

$$
r J_{0 f}(y)=\pi_{2}^{f}(y)-s-\rho J_{0 f}(y)+q_{1}\left[\alpha_{1} J_{L f}^{N}(0, y)+\left(1-\alpha_{1}\right) J_{H f}^{N}(0, y)-J_{0 f}(y)\right]
$$

With probability $\alpha_{1}$ the firm fills its junior position with a low skill worker, while with probability $\left(1-\alpha_{1}\right)$ the open position is filled with a high skill worker. The last state that we have to take into account is $J_{j f}^{S}(x, y)$, where the junior worker accumulated sufficient experience and is already searching for senior positions in competing firms. It is given by:

$$
r J_{j f}^{S}(x, y)=\pi_{1}(x)+\pi_{2}^{f}(y)-\rho\left(J_{j f}^{s}(x, y)-J_{0 j}(x)\right)-\lambda_{2}\left(J_{j f}^{s}(x, y)-J_{0 f}(y)\right)
$$

If the senior manager retires, the remaining worker is promoted to the senior position, so the firm ends up with a present value of profits $J_{0 j}(x)$. In contrast, if the junior worker quits the firm ends up with a present value of profits $J_{0 f}(y)$.

As before we impose several boundary conditions:

$$
J_{j 0}\left(\bar{x}_{i}^{j}\right)=J_{0 j}\left(\bar{x}_{i}^{j}\right) \quad J_{j f}^{N}\left(\bar{x}_{i}^{j}, \bar{x}_{f}\right)=J_{j f}^{S}\left(\bar{x}_{i}^{j}, \bar{x}_{f}\right) \quad j, f=L, H
$$

These conditions imply that firms commit to promoting workers whenever they reach a prespecified skill-specific experience level $\bar{x}_{i}^{j}$ depending on their skills $j=L, H$. However, if the senior position is filled the worker starts searching on-the-job. Combining this set of 6 equations with 2 equations $\alpha_{2} D_{j L}+\left(1-\alpha_{2}\right) D_{j H}=0$ we can find a vector of 8 integration constants $\left\{A_{j}, K_{j}, D_{j f}\right\}$ for the optimal skill-specific promotion times $\bar{x}_{i}^{j}$ of firm $i$ and market experience cut-offs $\bar{x}_{j}$.

In the final step we consider the objective function of firm $i$. Given that the firm has to determine its startegy upon the entry, it aims at maximizing the present value of expected future profits $J_{00}$ given by:

$r J_{00}=-2 s+q_{1}\left[\alpha_{1} J_{L 0}(0)+\left(1-\alpha_{1}\right) J_{H 0}(0)-J_{00}\right]+q_{2}\left[\alpha_{2} J_{0 L}\left(\bar{x}_{L}\right)+\left(1-\alpha_{2}\right) J_{0 H}\left(\bar{x}_{H}\right)-J_{00}\right]$

This equation shows that there are four sources of uncertainty for the firm at this stage: which position will be filled first - junior or senior - and which type of worker will be hired - high or low skilled. The choice variables of the firm are $\bar{x}_{i}^{L}$ and $\bar{x}_{i}^{H}$ which are the promotion cut-offs for each of the two skill groups. The firm solves the optimization problem

$$
\begin{aligned}
\left\{\bar{x}_{i}^{L *}, \bar{x}_{i}^{H *}\right\} & =\arg \max _{\bar{x}_{i}^{L}, \bar{x}_{i}^{H}} q_{1}\left[\alpha_{1} J_{L 0}\left(0 \mid\left\{\bar{x}_{i}^{L}, \bar{x}_{i}^{H}, \bar{x}_{L}, \bar{x}_{H}\right\}\right)+\left(1-\alpha_{1}\right) J_{H 0}\left(0 \mid\left\{\bar{x}_{i}^{L}, \bar{x}_{i}^{H}, \bar{x}_{L}, \bar{x}_{H}\right\}\right)\right] \\
& +q_{2}\left[\alpha_{2} J_{0 L}\left(\bar{x}_{L} \mid\left\{\bar{x}_{i}^{L}, \bar{x}_{i}^{H}, \bar{x}_{L}, \bar{x}_{H}\right\}\right)+\left(1-\alpha_{2}\right) J_{0 H}\left(\bar{x}_{H} \mid\left\{\bar{x}_{i}^{L}, \bar{x}_{i}^{H}, \bar{x}_{L}, \bar{x}_{H}\right\}\right)\right]
\end{aligned}
$$

where $\left\{\bar{x}_{i}^{L *}, \bar{x}_{i}^{H *}\right\}$ denote the optimal choices. As before we consider symmetric equilibria, so that $\bar{x}_{i}^{L *}\left(\bar{x}_{L}, \bar{x}_{H}\right)=\bar{x}_{L}$ and $\bar{x}_{i}^{H *}\left(\bar{x}_{L}, \bar{x}_{H}\right)=\bar{x}_{H}$ which guarantee that firms do not have incentives to deviate. 


\subsection{Partial equilibrium}

To illustrate the implications of skill heterogeneity for our results we first consider again a partial equilibrium framework with fixed transition rates from table 1 . We set $c_{2}^{L}=1.95$ and $c_{2}^{H}=2.05$, so that high skill workers are more productive than low skill workers in senior jobs. From our analysis in section 3.3 we know that for these parameters and the transition rates emerging from our default setting (see Table 1), in the absence of high-skill workers (i.e. $\alpha_{1}=\alpha_{2}=1$ ), the partial equilibrium promotion threshold for low skill workers is $\bar{x}_{L}^{p e}=51$. We start with a situation when $\alpha_{1}=\alpha_{2}=0.7$, which implies that $70 \%$ of workers in the market are low skilled. For comparison, Albrecht and Vroman (2002) use a close value of $67 \%$, while in the model by Stupnytska and Zaharieva (2017) the fraction of low skill workers is taken at $60 \%$. The left panel of figure 7 shows the objective function of the firm for the default transition rates. We find that the partial equilibrium is achieved for $\bar{x}_{L}^{p e}=59.7$ and $\bar{x}_{H}^{p e}=28.4$, which implies that high skill workers are promoted much earlier than low skill workers. Intuitively, a firm with a low skill worker in a junior position has a strong incentive to delay the promotion of this worker because this delay increases the chance for the firm to hire a high skill worker from the market for the senior position. Quite on the contrary, if the junior worker has high skills then it is profitable for the firm to exploit these skills in the senior position rather than hiring from the market which comes at the risk of putting a low skill worker into the senior position.
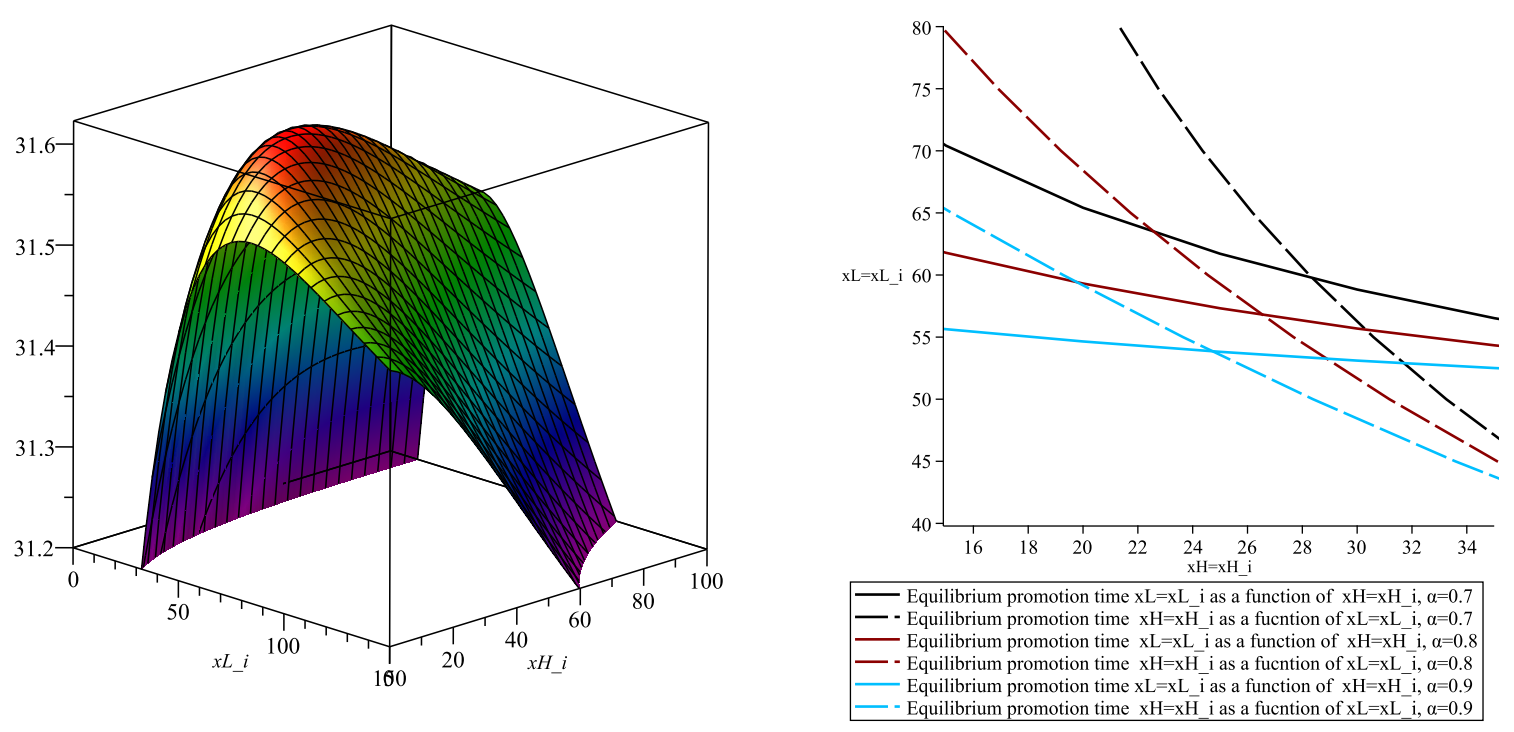

Figure 7: Left panel: Two-dimensional objective function of the firm in the space $\left\{\bar{x}_{i}^{L}, \bar{x}_{i}^{H}\right\}$ for $\alpha_{1}=\alpha_{2}=0.7$ and market promotion cut-offs of $\bar{x}_{L}=59.7, \bar{x}_{H}=28.4$. Right panel: Sequence of partial equilibria for different values of $\alpha=\alpha_{1}=\alpha_{2}$.

In the right panel of figure 7 we illustrate the nature of the partial equilibrium in the model with two worker groups. First, we find the optimal promotion cut-offs for high skill workers $\bar{x}_{i}^{H *}\left(\bar{x}_{H}, \bar{x}_{i}^{L}=\bar{x}_{L}\right)=\bar{x}_{H}$ for any given promotion cut-off of low skill workers $\bar{x}_{i}^{L}=\bar{x}_{L}$. If we exogenously decrease $\bar{x}_{i}^{L}=\bar{x}_{L}$ we can see that firms respond by later promotions of high skill workers (black dashed curve). Considering the left panel of figure 7 we can see that this negative dependence of the optimal threshold for $x_{i}^{L}$ respectively $x_{i}^{H}$ from the value of the other threshold 
also arises if we keep the thresholds of all other firms constant. Intuitively, faster promotion of own low-skill workers makes it more likely that the firm's senior position is filled at any point in time. A firm never wants to provide experience evaluation to high-skill workers and make them eligible for promotion at a point in time when its senior position is filled, due to the higher risk of losing these workers. Hence the increase of the probability of a filled senior position induced by a decrease of $\bar{x}_{L}$ reduces the firm's incentive to set a low promotion cut-off for high-skill workers. Even though there are also other side effects, the numerical evidence shown in figure 7 suggests that the described mechanism dominates giving rise to strategic substitutability between the two promotion thresholds. A substitution effect also applies if we consider the impact of an exogenous decrease of $\bar{x}_{i}^{H}=\bar{x}_{H}$ on the optimal promotion threshold for low skilled, although the effect is much smaller in this case (black solid curve). The partial equilibrium obtains at the intersection of the two curves, since no firm has incentives to deviate.

If we increase $\alpha_{1}=\alpha_{2}$ to 0.8 we find the equilibrium promotion cut-offs $\bar{x}_{L}^{p e}=56.8, \bar{x}_{H}^{p e}=$ 26.5 , thus both types of workers are promoted earlier (red curves). This trend is continued further when we increase $\alpha_{1}=\alpha_{2}$ to 0.9 . Here the equilibrium promotion cut-offs are $\bar{x}_{L}^{p e}=53.9$ and $\bar{x}_{H}^{p e}=24.7$ (blue curves). In the limiting case when $\alpha_{1}=\alpha_{2}=1$ we arrive at the economy with only low skill workers with productivity level $c_{2}^{L}=1.95$ and the corresponding equilibrium threshold is $\bar{x}_{L}^{p e}=51$ (see section 3.3). Hence, we can conclude that a lower average skill level in the labour force (due to the larger share of low skill workers) is associated with earlier promotions. In the next section we check if this result will persist after the general equilibrium adjustment in the transition rates.

\subsection{General equilibrium}

Finding a general equilibrium for the model with heterogeneous skills is substantially more complex compared to the benchmark case with homogeneous workers treated in Section 3.2. First, the number of states in which a single firm can be found is more than doubled in a setting with heterogeneous workers. Combined with the fact that the shares of high and low skill workers in the pool of applicants are endogenous, this would triple the number of steady-state equations describing firms' transitions in a heterogeneous setting. Second, the best response function, for which a fixed-point has to be found is two dimensional. Third, the determination of the best response $\left(\bar{x}_{i}^{L *}, \bar{x}_{i}^{H *}\right)$ to a pair of market promotion values $\left(\bar{x}_{L}, \bar{x}_{H}\right)$ in a general equilibrium setting requires to first calculate the transition rates and the average fraction of each skill group in the pools of applicants $\left(\alpha_{1}\right.$ and $\left.\alpha_{2}\right)$ under the stationary distribution implied by $\left(\bar{x}_{L}, \bar{x}_{H}\right)$ and then to determine the individually optimal promotion threshold based on the analysis presented in Section 4.1. All of these steps are computationally intensive, so due to the high complexity of the model we follow a different path for the analysis of the general equilibrium and rely on a simulation of the model which captures explicitly the (stochastic) transition of each worker between simple jobs, junior and senior positions. Another advantage of this approach is a possibility of performing several extensions, such as a case of pyramidal firms, which is a straightforward extension of the simulation but would require a completely different and hardly tractable analytical model. 

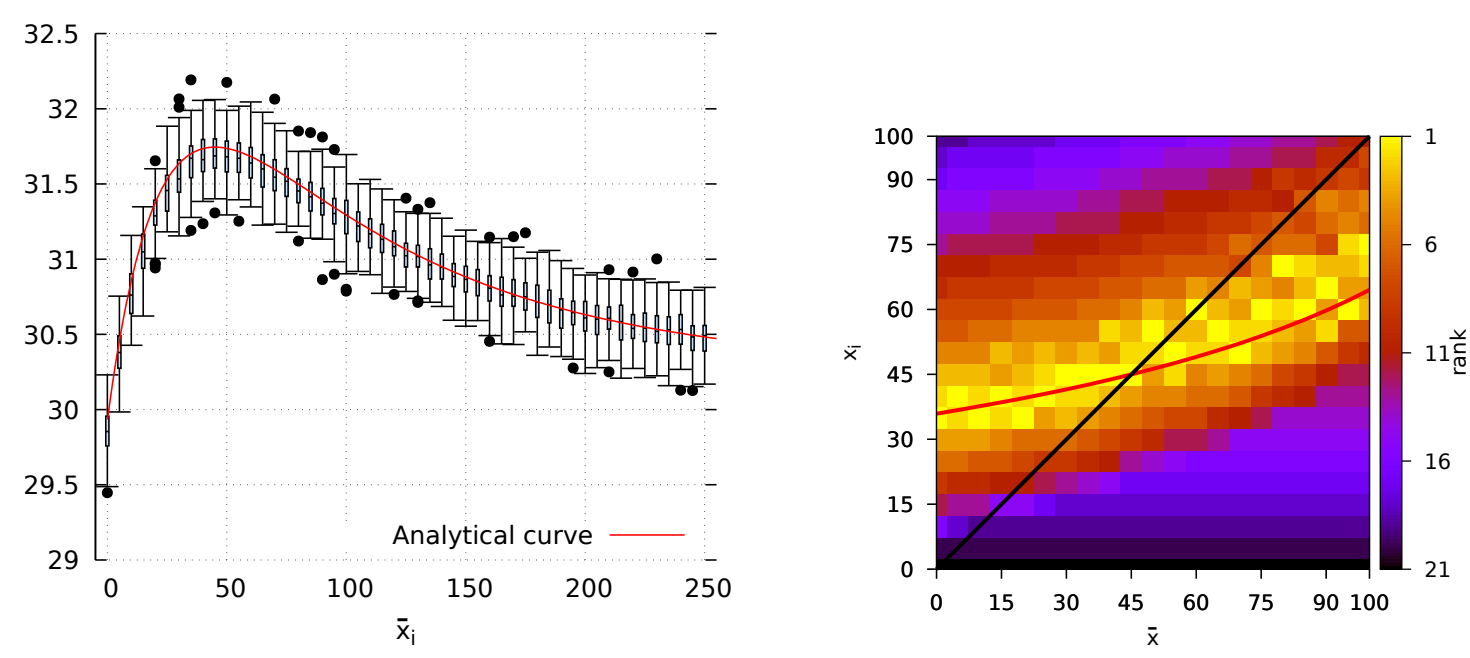

Figure 8: Replication of figure 4. Left panel: Estimated expected firm profits for $\bar{x}=45$. Each box plot summarizes 100 profit estimations obtained by simulation for a given $\bar{x}_{i}$. The red curve is the exact value of the objective function depicted also in figure 4. Right panel: Approximated best response function. For each value of the market promotion cut-off $\bar{x}$ the mean of the estimated expected discounted profits for different values of $\bar{x}_{i}$ are ranked with 1 being the highest.

\subsubsection{Simulation analysis of the model}

We implement a simulation model in which every firm and worker is a separate agent and the stochastic matching between firms and workers as well as the random retirement of workers by firms is explicitly modeled. For every profile of the firms' promotion thresholds the resulting long-run transition rates as well as the discounted expected present values of the different firms upon entering the market are determined based on a sufficiently large ensemble of simulation runs. The details of the simulation are described in Appendix B. ${ }^{5}$ In order to validate this approach and to show that it replicates very well the theoretical results for the cases, in which such findings are available, we first consider our benchmark case discussed in Section 3.2 with fixed promotion time $\bar{x}=45$ and $a=1$, i.e. workers are homogeneous with respect to skills. Table 4 displays the results of the simulation analysis and compares them to the numerical results presented in section 2.3. It can be seen that the results obtained through the simulations closely match the values obtained through the analytical approach. In Appendix B it is also demonstrated that the dependence of the rates $d_{10}(x), d_{11}^{N}(x)$ on the junior worker's experience $x$, as well as the dependence of the different rates on the market threshold $\bar{x}$, as shown in Figures 2 and 3 , are exactly reproduced using the simulation approach. Finally, figure 8 also shows that the best response function $\bar{x}_{i}^{*}(\bar{x})$ can be obtained by comparing the expected values of an entering firm generated through simulations across different values of an individual firm's threshold $\bar{x}_{i}$. The figure compares the simulation results to the analytical ones shown in figure 4 . The heat map in the right panel of figure 8 provides a summary of the simulation results by ranking the means of the simulated discounted sums of profits for each promotion choice of a deviating firm $\bar{x}_{i}$ on the $\mathrm{y}$-axis for a given market promotion $\bar{x}$ on the $\mathrm{x}$-axis. Then, the lighter the color, the higher discounted sum of profits the firm achieves on average by setting the corresponding $\bar{x}_{i}$

\footnotetext{
${ }^{5}$ The simulation is done in RepastJ, a software for agent-based modeling.
} 
$a=1 ; \bar{x}=45$

\begin{tabular}{c|c|c||c||c|c|c|c}
\hline \hline & Simulation & SD & Numerical & & Simulation & SD & Numerical \\
\hline$\lambda_{1}$ & 0.0145 & 0.0002 & 0.0145 & Internally promoted & 0.0575 & 0.0007 & 0.0576 \\
$\lambda_{2}$ & 0.0146 & 0.0006 & 0.0146 & Job-to-job movers & 0.0126 & 0.0004 & 0.0124 \\
$q_{1}$ & 0.0171 & 0.0002 & 0.0171 & $d_{00}$ & 0.1256 & 0.0021 & 0.1273 \\
$q_{2}$ & 0.0036 & 0.0002 & 0.0036 & $d_{01}$ & 0.1772 & 0.0021 & 0.1760 \\
$e_{0}$ & 0.3545 & 0.0041 & 0.3577 & $d_{10}$ & 0.1270 & 0.0021 & 0.1270 \\
$e_{1}$ & 0.2985 & 0.0021 & 0.2966 & $d_{11}^{S}$ & 0.0633 & 0.0018 & 0.0633 \\
$e_{2}$ & 0.3487 & 0.0030 & 0.3456 & $d_{11}^{N}$ & 0.1082 & 0.0014 & 0.1063 \\
\hline
\end{tabular}

Table 4: Comparison between simulation and numerical results, SD: standard deviation. Simulation values are obtained by taking an average over the last 1000 iterations of each run, where one run consists of 1500 iterations. Averages over 100 simulation runs are shown.

for a given $\bar{x}$. These results indicate that the simulation model is not only in a reliable way generating the transition rates emerging under a certain strategy profile of firms, but is also well suited to determine an individual firm's optimal promotion strategy. Our simulation approach can be used also in settings in which an analytical characterization of this best response is not feasible, which will become particularly relevant in several model extensions considered below.

\subsubsection{Equilibrium promotion cut-offs}

For the version of the model with two skill levels the analysis in section 4.1 allows us to (numerically) determine the symmetric partial equilibrium thresholds $\left(\bar{x}_{L}^{p e}(\zeta), \bar{x}_{H}^{p e}(\zeta)\right)$ for a given vector $\zeta$ of transition rates and market thresholds. Therefore, in this section the simulation is used only to determine the long-run transition rates for a given strategy profile. We first set the promotion cut-offs equal to the partial equilibrium values under the given vector of transition rates and fractions of low skill applicants in the two markets, which we denote by $\zeta^{0}$ (see section 4.2). Using the simulation we then determine the actual transition rates and fractions of low skill applicants in the two markets $\zeta^{1}=\left\{\lambda_{1}, \lambda_{2}, q_{1}, q_{2}, \alpha_{1}, \alpha_{2}\right\}$ under these promotion cut-offs. Inserting $\zeta^{1}$ into the firm's decision problem (20) we then calculate the symmetric partial equilibrium profile $\left(\bar{x}_{L}^{p e}\left(\zeta^{1}\right), \bar{x}_{H}^{p e}\left(\zeta^{1}\right)\right)$ under these rates and adjust the conjecture for the values of $\left\{\bar{x}_{L}, \bar{x}_{H}\right\}$ in the direction of these new partial equilibrium values. This procedure is repeated till the partial equilibrium values (rounded to the nearest integer) determined under the adjusted transition rates coincide with the conjectured profile under which the rates have been calculated and therefore a general equilibrium profile $\left(\bar{x}_{L}^{g e}, \bar{x}_{H}^{g e}\right)$ has been found. ${ }^{6}$

In table 5 the general equilibrium thresholds and the corresponding transition rates are displayed for different fractions of low-skill workers in the population. In all scenarios the fraction of low-skill workers among the applicants for junior positions $\left(\alpha_{1}\right)$ are close to their average fraction in the workforce $(a)$, whereas the fraction of low-skilled among the applicants for senior positions $\left(\alpha_{2}\right)$ are significantly smaller: $\left(\alpha_{2}<a\right)$. This effect is due to the slower promotion of low-skill workers compared to their high-skill peers, which makes them underrepresented in the market for senior positions. For instance in the case $a=0.7$, even though

\footnotetext{
${ }^{6}$ In Table 7 in Appendix B we illustrate the algorithm by displaying all steps needed to find the equilibrium values of $\bar{x}_{L}$ and $\bar{x}_{H}$ for $a=0.7$. Although we do not provide a general convergence proof for our algorithm, we were able to find general equilibrium values for all considered scenarios using this approach.
} 


\begin{tabular}{c|c|c|c}
\hline & $a=0.9$ & $a=0.8$ & $a=0.7$ \\
\hline \hline $\begin{array}{c}\text { Equilibrium } \\
\text { Promotion } \\
\text { Cut-Offs }\end{array}$ & $\left\{\bar{x}_{L}^{g e}, \bar{x}_{H}^{g e}\right\}=\{49,25\}$ & $\left\{\bar{x}_{L}^{g e}, \bar{x}_{H}^{g e}\right\}=\{52,27\}$ & $\left\{\bar{x}_{L}^{g e}, \bar{x}_{H}^{g e}\right\}=\{55,28\}$ \\
\hline \hline & $\alpha_{1}=0.8903 ; \alpha_{2}=0.8650$ & $\alpha_{1}=0.7813 ; \alpha_{2}=0.7385$ & $\alpha_{1}=0.6733 ; \alpha_{2}=0.6169$ \\
& $(0.0033) ;(0.0088)$ & $(0.0043) ;(0.0121)$ & $(0.0048) ;(0.0130)$ \\
Transition & $\lambda_{1}=0.0145 ; \lambda_{2}=0.0146$ & $\lambda_{1}=0.0145 ; \lambda_{2}=0.0146$ & $\lambda_{1}=0.0145 ; \lambda_{2}=0.0145$ \\
Rates: $\zeta^{g e}$ & $(0.0002) ;(0.0005)$ & $(0.0002) ;(0.0005)$ & $(0.0002) ;(0.0005)$ \\
& $q_{1}=0.01720 ; q_{2}=0.00355$ & $q_{1}=0.01717 ; q_{2}=0.00355$ & $q_{1}=0.01716 ; q_{2}=0.00357$ \\
& $(0.0002) ;(0.0002)$ & $(0.0002) ;(0.0001)$ & $(0.0002) ;(0.0001)$ \\
\hline \hline & $e_{0}^{L}=0.3485 ; e_{0}^{H}=0.3901$ & $e_{0}^{L}=0.3443 ; e_{0}^{H}=0.3873$ & $e_{0}^{L}=0.3393 ; e_{0}^{H}=0.3852$ \\
& $(0.0045) ;(0.0130)$ & $(0.0042) ;(0.0092)$ & $(0.0048) ;(0.0066)$ \\
& $e_{1}^{L}=0.3110 ; e_{1}^{H}=0.2276$ & $e_{1}^{L}=0.3200 ; e_{1}^{H}=0.2347$ & $e_{1}^{L}=0.3293 ; e_{1}^{H}=0.2392$ \\
& $(0.0025) ;(0.0074)$ & $(0.0024) ;(0.0049)$ & $(0.0027) ;(0.0040)$ \\
& $e_{2}^{L}=0.3415 ; e_{2}^{H}=0.3832$ & $e_{2}^{L}=0.3367 ; e_{2}^{H}=0.3790$ & $e_{2}^{L}=0.3324 ; e_{2}^{H}=0.3766$ \\
& $(0.0034) ;(0.0121)$ & $(0.0032) ;(0.0083)$ & $(0.0040) ;(0.0062)$ \\
\hline \hline
\end{tabular}

Table 5: Equilibrium promotion cut-offs with two skill groups. Transition rates and distribution values for each run are obtained by averaging over the last 1000 iterations, where one run consists of 1500 iterations. The displayed values are averages over 100 simulation runs with standard deviation across runs in parenthesis.

$70 \%$ of the agents are low skill, only $61.7 \%$ or of the applicants to senior positions are also low skill.

Comparing the general equilibrium thresholds with the partial equilibrium values discussed in section 4.2 we observe that the promotion thresholds for high-skill workers are hardly affected by general equilibrium effects, whereas the promotion threshold for low-skill worker are significantly lower in general equilibrium compared to the partial equilibrium. For the case of $a=0.7$ we obtain $\bar{x}_{L}^{g e}\left(\zeta^{g e}\right)=55$ in general equilibrium compared to a threshold of $\bar{x}_{L}^{p e}\left(\zeta^{0}\right)=60$ obtained for the partial equilibrium under the benchmark transition rates and the assumption that both for the junior and the senior positions the fraction of low-skill workers is given by $\alpha_{1}=\alpha_{2}=$ $a=0.7$. Intuitively, the reason for this difference is that under the partial equilibrium values $\left(\bar{x}_{L}^{p e}, \bar{x}_{H}^{p e}\right)=(60 / 28)$ the firm's actual job filling rate for senior positions on the market $q_{2}$ (see Table 7 in Appendix B) is lower and that for junior positions $q_{1}$ is higher compared to the value assumed in the partial equilibrium (see Table 4). As we know from figure 4, this induces the firm to promote earlier, especially the majority group of low-skill workers and as a result $\bar{x}_{L}$ is lower in general equilibrium than under partial equilibrium.

Analyzing the impact of $a$, we can see that qualitatively, the result that higher share of low skill workers is associated with earlier promotions remains unchanged after endogenizing the transition rates. Recall that in section 3.3 we have shown that lower quality of the homogeneous labour force is associated with later promotions. How can these two findings be reconciled? The key difference between these settings is that under worker heterogeneity an increase of the fraction of low skill workers reduces the expected skill of a worker hired from the market relative to the skill of the junior worker under consideration for internal promotion, regardless of the actual type of the junior worker. So the internal candidate becomes better in relative terms compared to the average external candidate. This induces earlier internal promotions. With 
homogeneous workers by definition the skill of an outside hire is always identical to that of an internal candidate. So when the skill level is falling firms want to compensate for the lower qualification of their internal candidates and let them accumulate more experience by delaying internal promotions. Thus changes in the quality of the labour force can have principally different implications for promotions in the two settings with homogeneous and heterogeneous workers. Taking into account that the firm's senior job filling rate decreases with the fraction of low skill workers we observe that the general equilibrium reinforces the partial equilibrium effect and leads to even earlier promotions of low skill workers. Overall, this discussion highlights that explicitly considering potential heterogeneities in the workforce is essential for understanding the relationship between the (average) skill level in the worker population and the firms' optimal promotion thresholds.

Table 5 also displays the distribution of high and low skill workers across hierarchical levels. In equilibrium larger fraction of high skill workers are in managerial positions. For instance, considering the case in which $70 \%$ of the agents are low skill $(a=0.7)$, approximately $61.2 \%$ $\left(=e_{2}^{H} /\left(e_{1}^{H}+e_{2}^{H}\right)\right)$ of high skill workers who are employed in professional jobs are on level $2(61.8 \%$ in the case $a=0.8$ and $62.8 \%$ when $a=0.9$ ). This follows from the earlier promotion time firms set for high skill workers. As the fraction of low skill workers $(a)$ decreases, the equilibrium promotion cut-offs: $\bar{x}^{L}$ and $\bar{x}^{H}$ increase which leads to fewer workers in senior positions $\left(e_{2}^{L}\right.$ and

$e_{2}^{H}$ ) for both skill groups. This result corresponds to the findings from the benchmark model that later promotions increase the fraction of workers employed in junior jobs and decrease the fraction of senior workers.

\section{Pyramidal firm structure}

In this section we make a final extension to the model by introducing pyramidal firms with two junior positions and one senior. Here, we follow the empirical evidence that firms are organized as hierarchical pyramids in which the number of positions on each level decreases the higher the hierarchical level (Caliendo et al., 2015). Moreover, empirical studies find that firms of different sizes vary in many aspects concerning workers' careers. For instance, large firms pay higher wages than small firms (Brown and Medoff, 1989; Fox, 2009; Oi and Idson, 1999), employees in bigger firms tend to be older, have longer tenure and higher human capital (Oi and Idson, 1999). Following the documented size-related differences in firm behavior, we introduce "large" firms into the simulation to explore how the firm size affects promotion timing. More specifically, we consider the case when some of the firms on the market have a pyramidal structure with three positions ("large" firms) while the rest have a vertical hierarchy with two positions ("small" firms) as in the benchmark model. In order to isolate the firm structure effect on optimal promotion, we abstract from the synergy effect and consider the case of homogeneous workers.

We define the additional possible states of pyramidal firms as follows: $d_{20}$ are firms which have two junior workers and no senior worker, $d_{21}^{N N}$ are the firms which have all three positions filled and none of the junior workers is searching for a senior position in another firm. Next, $d_{21}^{N S}$ denotes the pyramidal firms which have two junior workers and one senior worker and one of the junior workers is already searching. And finally, $d_{21}^{S S}$ denotes the firms in which both junior 


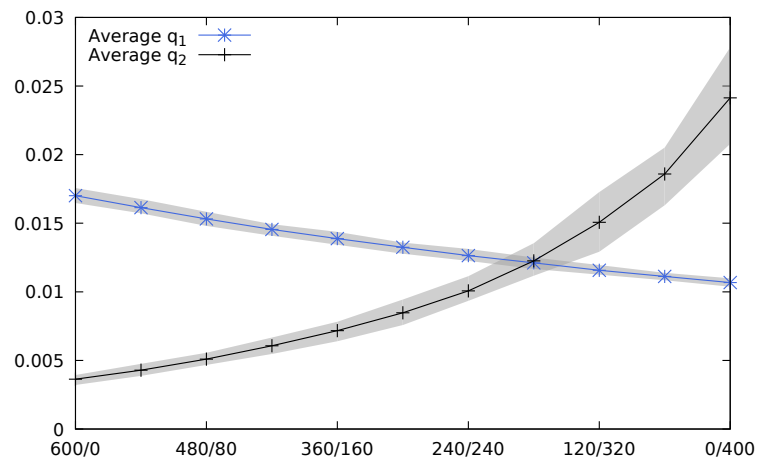

(a) Vacancy-filling rates

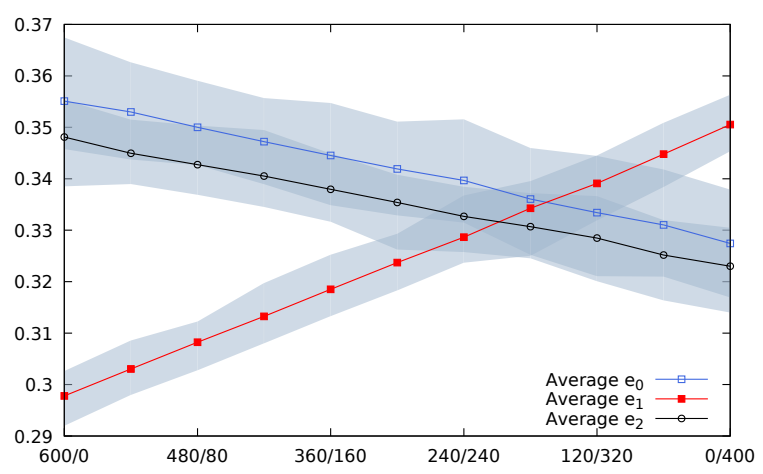

(c) Distribution of workers

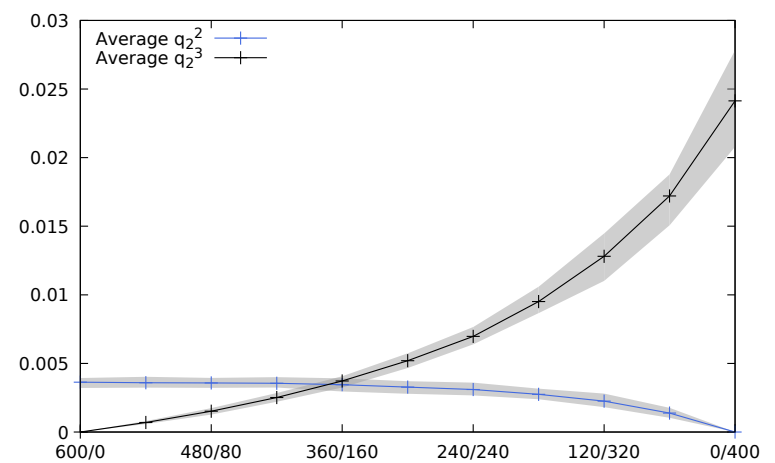

(b) $q_{2}$ decomposition

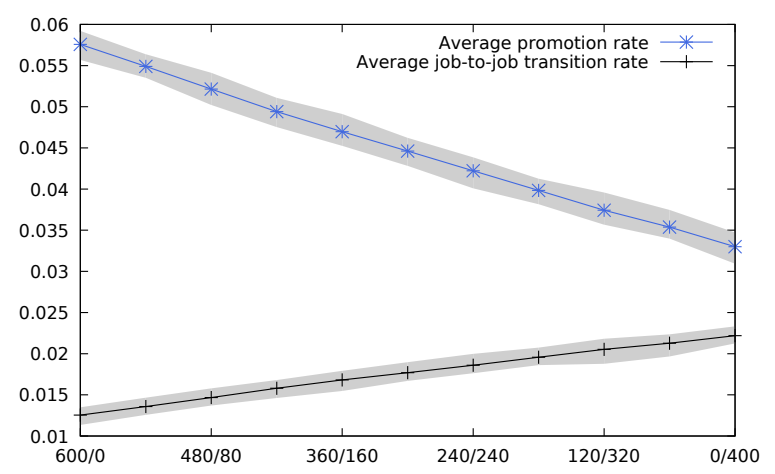

(d) Promotions

Figure 9: Market adjustments: simulation values are obtained by taking and average over the last 1000 iterations of each run, where one run consists of 1500 iteration. The values show an average over 100 simulation runs and the bands display the minimal and maximal average recorded.

workers are searching ${ }^{7}$.

\subsection{Effects on labour flows}

To demonstrate how the presence of pyramidal firm influences the labour flows and the allocation of workers to different types of jobs we incrementally increase the number of pyramidal firms on the market keeping the promotion cut-off at its benchmark equilibrium value $\bar{x}=45$. Figure 9 presents the results from the simulation and shows the adjustment of transition rates when the market moves from having only vertical firms to having only pyramidal firms. Averages of the variables as well as $95 \%$ confidence intervals are displayed. The transition of firm types is shown on the x-axis, where at the origin we have 600 firms with two positions and 0 firms with three positions $(600 / 0)$ or 1200 jobs in total. This is our benchmark model considered above. We gradually decrease the number of vertical firms and increase the number of pyramidal firms while keeping the total number of jobs constant. For example, (360/160) means 360 firms with two positions and 160 firms with three positions and so on. The last point (0/400) shows the case with no two-position firms and 400 pyramidal firms.

Changing the market structure by introducing pyramidal firms increases the senior vacancyfilling rate $q_{2}$ approximately five-fold (figure 9a). The presence of more three-position firms increases the number of junior workers in the market (figure 9c). Since there are more junior

\footnotetext{
${ }^{7}$ Additionally, the upper script "3" denotes a pyramidal firm.
} 
workers and because the promotion cut-off is kept constant, the pool of applicants to senior positions becomes larger and the probability that a firm finds a senior worker from the market increases. For instance, in the case when there are only pyramidal firms in the market $(0 / 400)$, the number of searching junior workers is on average $0.1332\left(=d_{11}^{S 3}+d_{21}^{N S}+2 d_{21}^{S S}\right)$ whereas in the benchmark case $(600 / 0)$ it is $0.0633\left(=d_{11}^{S}\right)$. On the other hand, there are on average $0.0775\left(=d_{00}^{3}+d_{10}^{3}+d_{20}\right)$ senior vacancies in the market with three-position firms only and $0.2543\left(=d_{00}+d_{10}\right)$ in the benchmark scenario. Hence, more $e_{1}$ workers compete for fewer senior vacancies and firms fill more often their $e_{2}$ positions from the market. Consequently, the number of internally promoted workers decreases while more $e_{1}$ workers reach senior position by changing firms (figure $9 \mathrm{~d}$ ). We further decompose the senior vacancy filling rate $q_{2}$ into senior vacancies filled by workers who were previously employed in two-position firms: $q_{2}^{2}$; and such filled by workers who were employed in three-position firms: $q_{2}^{3}$ (figure $\left.9 \mathrm{~b}\right)^{8}$. This distinction becomes relevant if the two types of firms set different promotion cut-offs. On the other hand, the job-finding rates $\lambda_{1}$ and $\lambda_{2}$ do not respond strongly to the changing market structure because they are primarily driven by workers' search intensity. ${ }^{9}$

\subsection{Optimal promotion}

Next, we study the optimal promotion cut-off in the market with heterogeneous firms. In that respect two questions arise. First, how does the optimal promotion policy of a pyramidal firm compare to that of a vertical one, and, second, how does the presence of pyramidal firms influence the optimal promotion threshold of the vertical firms. In order to study these issues, we adjust the approach to simulate the discounted sum of profits of a single firm, which is described and validated for our benchmark case in Appendix B, for the setting with heterogeneous firms.

We consider a market with 540 vertical firms and 40 pyramidal firms. As a starting point we keep the market promotion threshold at $\bar{x}=45$ and use the transition rates generated for this setting from the simulation: $\zeta^{0}=\left\{\lambda_{1}, \lambda_{2}, q_{1}, q_{2}\right\}=\{0.01449,0.01452,0.01614,0.00429\}$. We then compare the expected discounted profit of a single vertical respectively pyramidal firm across different values of its own promotion threshold $\bar{x}_{i}^{j}, j=2,3$. Figure 10 plots the results for a two- and three- position firm respectively. We observe that both types of firms should delay their promotion time in response to the firm heterogeneity. A vertical firm achieves highest expected profits if it sets the promotion time at $\bar{x}_{i}^{2}=75$, whereas a pyramidal firm maximizes expected profits at $\bar{x}_{i}^{3}=95$. This result is driven by the higher vacancy-filling rate of senior positions $\left(q_{2}\right)$ and the lower vacancy-filling rate of junior positions $\left(q_{1}\right)$, as already shown in figure 4. Firms would like to keep their junior worker longer, given that they have higher chance to hire a senior worker from the market and that finding a new junior worker becomes more difficult. Furthermore, for pyramidal firms it is optimal to promote later than their vertical competitors. Before discussing the intuition for this finding we verify whether our results qualitatively stay intact if we take into account the adjustment of the other firms on the market and of the transition rates in general equilibrium.

In order to obtain the general equilibrium promotion cut-offs in this market we again employ the procedure used already for the case of two skill groups and described in Appendix B. Since

\footnotetext{
${ }^{8}$ Note that: $q_{2}=q_{2}^{2}+q_{2}^{3}$

${ }^{9}$ See figure 14 in Appendix C.
} 

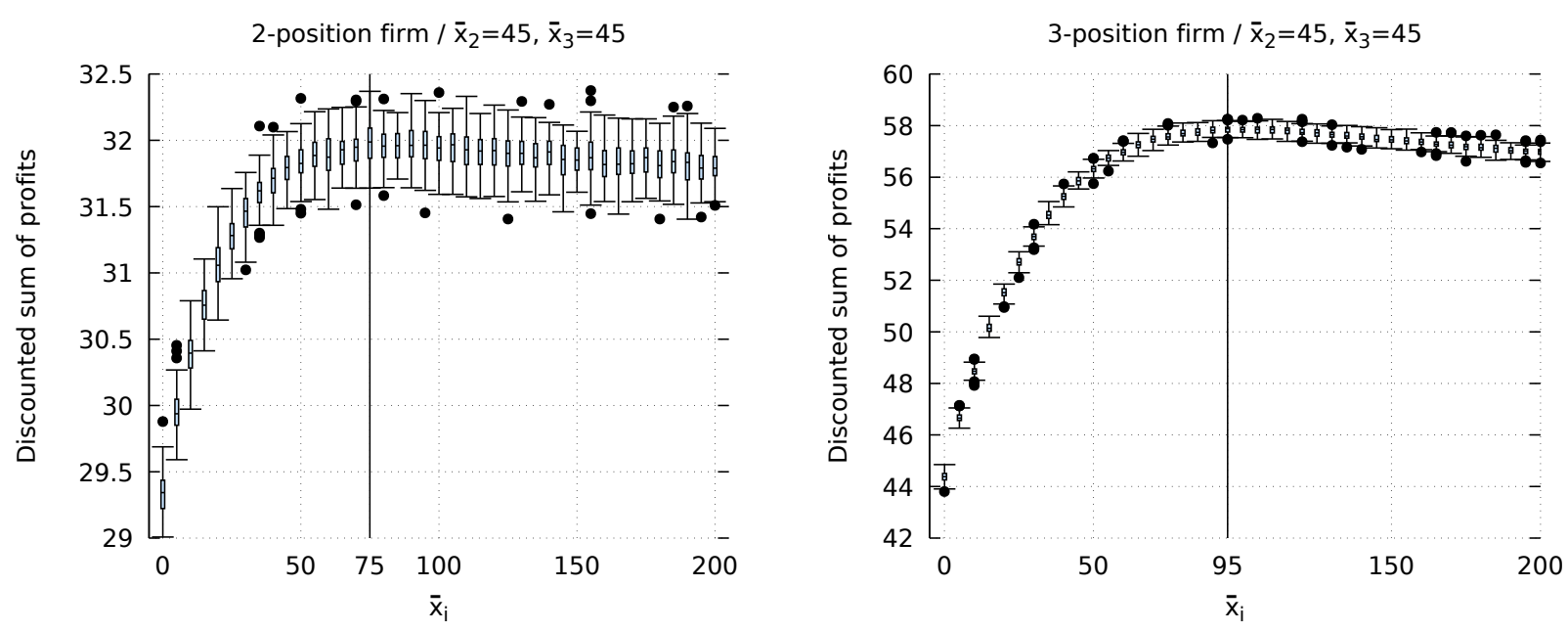

Figure 10: Optimal responses of deviating vertical (left panel) and pyramidal (right panel) firms with $\bar{x}^{2}=\bar{x}^{3}=45$.
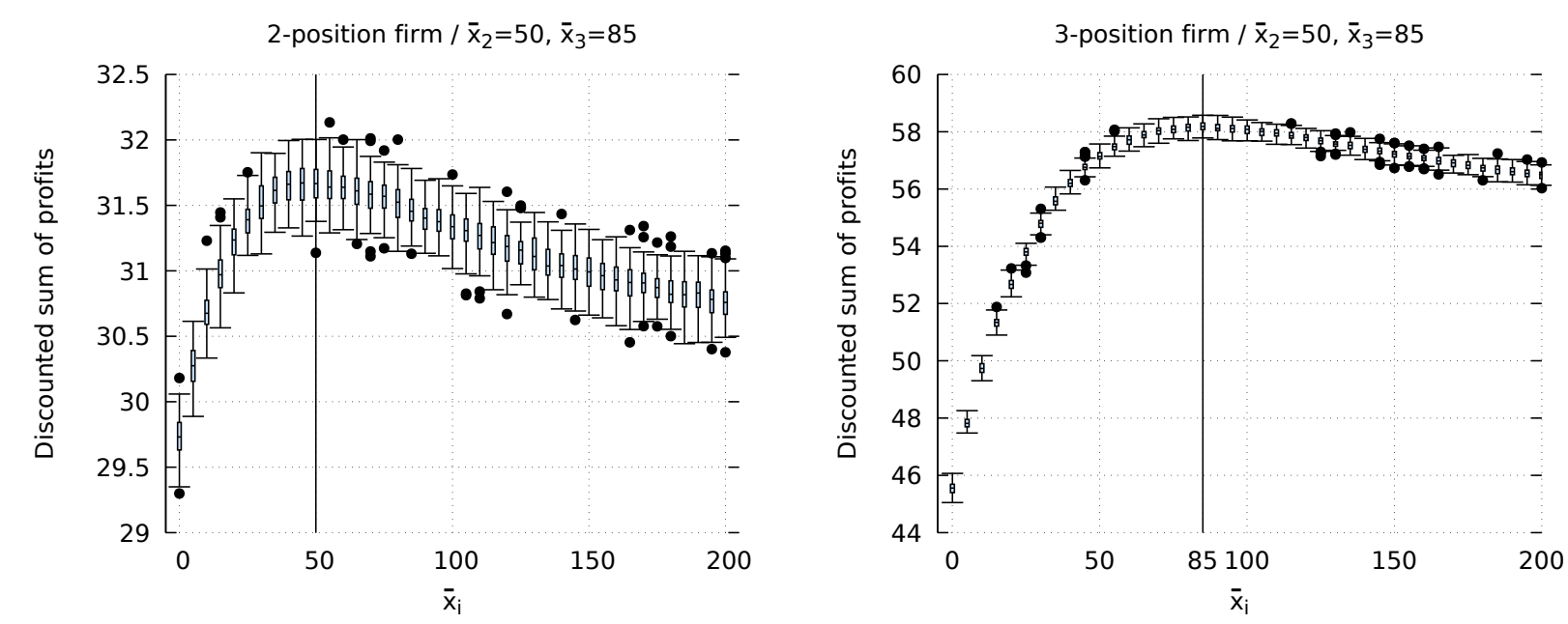

Figure 11: Profit function and best response of a two-position firm (left panel) and three-position firm (right panel) in a market with 540 vertical firms and 40 pyramidal firms.

we now have two types of firms, in each step of the algorithm we determine for given transition rates and cut-off values of both types of firms in the market the best response for each type of firm. However, since in this setting with heterogeneous firms we do not have an analytical characterization of the firm's best response function, we use the results from the best response simulations to guide us in which direction to alter the conjectured promotion cut-offs of both types of firms before simulating the new transition rates. The algorithm stops if the optimal response of both types of firms coincides with the conjectured promotion cut-offs.

Applying this procedure we find that $\left\{\bar{x}^{2 g e}, \bar{x}^{3 g e}\right\}=\{50,85\}$ is an equilibrium in the market with 540 vertical and 40 pyramidal firms. Figure 11 displays the expected discounted profits of the two types of firms as a function of their promotion threshold in this setting. The distribution of workers and firms as well as the equilibrium transition rates are summarized in table 6 . Hence, the insights that the presence of pyramidal firms induces delayed promotion of all firms, compared 


\begin{tabular}{c|c|c||c|c|c||c|c|c}
\hline \multicolumn{9}{c}{$a=1 ; \bar{x}^{2}=50 ; \bar{x}^{3}=85$} \\
\hline \hline & Sim & SD & & Sim & SD & Sim & SD \\
\hline$\lambda_{1}$ & 0.0145 & 0.0002 & $d_{00}$ & 0.1074 & 0.0021 & $d_{11}^{S 3}$ & 0.0028 & 0.0003 \\
$\lambda_{2}$ & 0.0146 & 0.0004 & $d_{00}^{3}$ & 0.0036 & 0.0004 & $d_{20}$ & 0.0056 & 0.0004 \\
$q_{1}$ & 0.0168 & 0.0002 & $d_{01}$ & 0.1528 & 0.0018 & $d_{21}^{N N}$ & 0.0045 & 0.0004 \\
$q_{2}^{2}$ & 0.0031 & 0.0001 & $d_{01}^{3}$ & 0.0052 & 0.0004 & $d_{21}^{N S}$ & 0.0038 & 0.0003 \\
$q_{2}^{3}$ & 0.0005 & 0.00004 & $d_{10}$ & 0.1254 & 0.0021 & $d_{21}^{S S}$ & 0.0008 & 0.0002 \\
$e_{0}$ & 0.3411 & 0.0040 & $d_{10}^{3}$ & 0.0056 & 0.0004 & Internally promoted & 0.0503 & 0.0006 \\
$e_{1}$ & 0.3266 & 0.0021 & $d_{11}^{N}$ & 0.1028 & 0.0014 & Promotion rate (vertical) & 0.0538 & 0.0007 \\
$e_{2}$ & 0.3334 & 0.0021 & $d_{11}^{N 3}$ & 0.0083 & 0.0004 & Promotion rate (pyramidal) & 0.0284 & 0.0010 \\
$n$ & 2.3677 & 0.0356 & $d_{11}^{S}$ & 0.0527 & 0.0017 & Job-to-job movers & 0.0110 & 0.0003 \\
\hline
\end{tabular}

Table 6: Distribution of firms and workers; and equilibrium transition rates. SD: standard deviation. Simulation values are obtained by taking and average over the last 1000 iterations of each run, where one run consists of 1500 iteration. Averages over 100 simulation runs are shown.

to the benchmark of a market of vertical firms, and that pyramidal firms should promote later than vertical ones, also apply in a full general equilibrium setting.

On average, $34.1 \%$ of agents are in simple jobs, $32.7 \%$ in junior positions and $33.4 \%$ in senior positions. Among those employed in professional jobs almost half are on level 1 and the other half occupies senior positions ${ }^{10}$. Further $6.1 \%$ of workers are searching on-the-job while on average $5 \%$ are internally promoted per year. Another $1.1 \%$ of junior workers move to a different firm to gain a promotion. In comparison with our benchmark case, having some firms with two level 1 jobs increases the equilibrium fraction of workers in junior positions. However, both the yearly promotion rate as well as the job transition rate decrease slightly compared to the benchmark model as result of the overall fewer senior jobs on the market and the larger promotion cut-offs firms choose in equilibrium. This is different from the partial equilibrium setting where the job-to-job transition rate increased as a result of firm heterogeneity (see figure 9d). We see that after endogenizing $\bar{x}^{2}$ and $\bar{x}^{3}$, the general equilibrium effect reverses the heterogeneous firm effect on the job-to-job transition rate and reduces the percentage of job-to-job movers from $1.4 \%$ in the partial equilibrium to $1.1 \%$ in the general equilibrium. Hence, in the equilibrium with heterogeneous firms, the job-to-job transition rate is slightly suppressed compared to the benchmark case where $1.2 \%$ of workers change firms to gain promotion. On the other hand, the negative impact of firm heterogeneity on the promotion rate (see figure 9d) is reinforced by the general equilibrium effect and the promotion rate is further reduced form $5.5 \%$ in the partial equilibrium to $5 \%$ in the general equilibrium. The rest of the transition rates are quantitatively very similar to the ones in the benchmark case with the exception of $q_{1}$ which is slightly lower. On average it takes longer for firms to fill their junior positions in the market with heterogeneous firms. There is a larger pool of competing vacancies for level 1 workers and, as shown above, in equilibrium firms choose longer promotion time to counteract this effect.

Furthermore, pyramidal firms set a higher promotion cut-off than vertical firms. Intuitively, this is due to the fact that for pyramidal firms the probability that the senior position is filled at a given point in time is larger than for a vertical firm and also there is the possibility that the

\footnotetext{
${ }^{10} p_{1}=0.3266 /(0.3266+0.3334)=0.4949$ or approximately $49.5 \%$
} 
other junior worker in the firm has already reached the promotion threshold and hence would be appointed to the senior position if the senior worker retires. Both these effects increase the firm's incentive to delay promotion in order not to risk loosing the junior worker. Hence, the pyramidal firm promotes later than the vertical one. Specifically, in equilibrium $63.2 \%$ of pyramidal firms have their senior position filled $\left(=\left(d_{01}^{3}+d_{11}^{N 3}+d_{11}^{3 S}+d_{21}^{N N}+d_{21}^{N S}+d_{21}^{S S}\right) /\left(d_{00}^{3}+d_{10}^{3}+d_{01}^{3}+d_{11}^{N 3}+\right.\right.$ $\left.\left.d_{11}^{3 S}+d_{20}+d_{21}^{N N}+d_{21}^{N S}+d_{21}^{S S}\right)\right)$ compared to $57 \%$ of vertical firms $\left(=\left(d_{01}+d_{11}^{N}+d_{11}^{S}\right) /\left(d_{00}+d_{10}+\right.\right.$ $\left.\left.d_{01}+d_{11}^{N}+d_{11}^{S}\right)\right)$. Further, $5.4 \%$ of the junior workers employed in vertical firms are promoted per year compared to $2.8 \%$ of workers in pyramidal firms. Due to their promotion cut-off pyramidal firms do not only have slower turnover in their junior positions compared to vertical firms, but also have junior workers and senior workers with higher average experience than their smaller competitors with vertical structure Average experience of junior workers in vertical firms is 29.3 vs. 49.6 for junior workers in pyramidal firms. Also, senior workers in vertical firms have on average experience of 50.8 compared to 80.7 for senior workers in pyramidal firms. This indicates a firm size wage gap of $6.3 \%$ in junior positions $\left(=\beta c_{1}\left(e^{\gamma 49.6}-e^{\gamma 29.3}\right) /\left(\beta c_{1} e^{\gamma 29.3}\right)\right)$ and $9.4 \%$ in senior positions $\left(=\beta c_{2}\left(e^{\gamma 80.7}-e^{\gamma 50.8}\right) /\left(\beta c_{2} e^{\gamma 50.8}\right)\right)$. Hence, our model shows that considering endogenous promotion choices can provide an explanation for the difference in workers' tenure and wages between small and large firms as reported in a survey by Oi and Idson (1999) and more recently by Lallemand et al. (2007) for five European countries. It can also capture a positive relationship between the firm size wage gap and the hierarchical levels as found by Fox (2009) for US and Swedish white-collar workers.

\section{Robustness check: complementarity between worker experi- ence}

In the benchmark model used so far we have assumed production function of the firm that is fully separable between the output of the different workers. In particular, under this assumption the marginal increase of a firm's output due to higher experience of a junior or senior worker does not depend on whether the other position(s) in the firm are filled or which experience workers filling these other positions have. Although this separability assumption strongly increases the analytical tractability of the model, it might be considered as somehow restrictive from an economic perspective. Relying on our simulation approach we can however check the robustness of our main findings if this assumption is dropped and a potential complementarity between the experience of junior and senior workers is taken into account. In particular, using again our benchmark setting with only vertical firms and homogeneous worker skills, we consider a CES production function of the form

$$
f\left(\mathbb{1}_{1}, x, \mathbb{1}_{2}, y\right)=\left[\mathbb{1}_{1}\left(d_{1}+c_{1} e^{\gamma x}\right)^{\frac{\sigma-1}{\sigma}}+\mathbb{1}_{2}\left(d_{2}+c_{2} e^{\gamma y}\right)^{\frac{\sigma-1}{\sigma}}\right]^{\frac{\sigma}{\sigma-1}},
$$

where $f\left(\mathbb{1}_{1}, x, \mathbb{1}_{2}, y\right)$ is the output of a firm which has a junior worker with experience $x$ and a senior worker with experience $y$. Here $\mathbb{1}_{1}$ and $\mathbb{1}_{2}$ are indicator functions which take a value of 1 if the respective position is filled and 0 otherwise. The parameter $\sigma$ is the elasticity of substitution between the junior and the senior worker and in the limiting case of $\sigma \rightarrow \infty$, we have the linear production function used in the benchmark model. The profit of the firm is given 


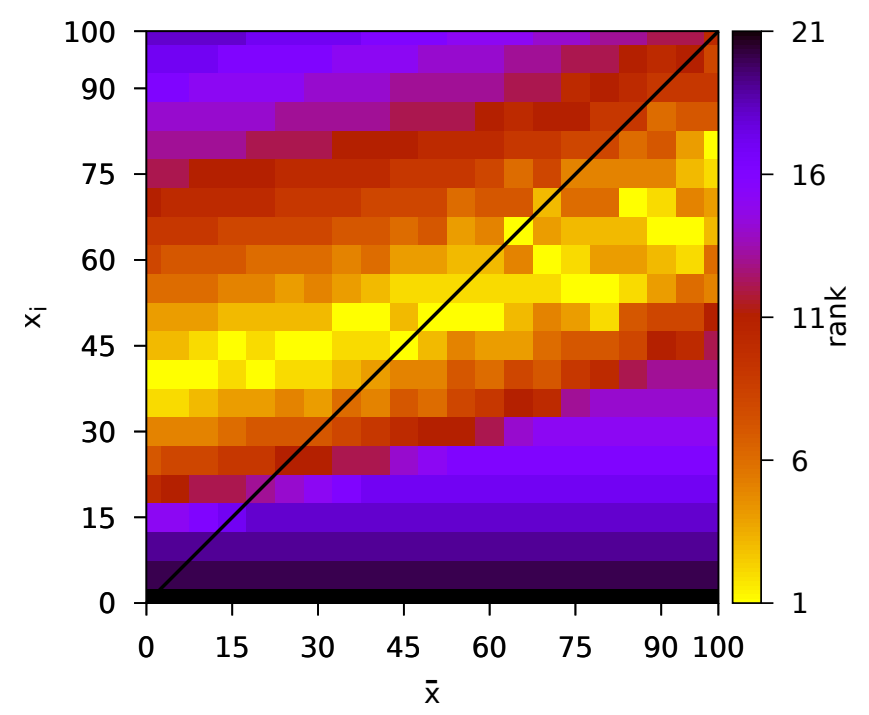

Figure 12: The optimal response of a single firm obtained by the simulation approach described in Appendix B. The average profit for each promotion cut-off of the deviating firm given $\bar{x}$ is recorded and the averages are ranked with 1 being the highest.

by $\pi\left(\left(\mathbb{1}_{1}, x, \mathbb{1}_{2}, y\right)=(1-\beta) f\left(\mathbb{1}_{1}, x, \mathbb{1}_{2}, y\right)\right.$.

Empirical estimates suggest that there is imperfect substitutability between young and old or experienced and inexperienced workers. For example, using data for the U.S., UK and Canada, Card and Lemieux (2001) estimate the elasticity of substitution between men with similar educational attainment but different ages to be in the interval 4-6. D'Amuri et al. (2010), on the other hand, find based on German data that the elasticity of substitution between workers with the same educational level but different experience is 3.3. We choose an intermediate value of the existing estimates of $\sigma=4$ and calculate for varying values of the market promotion cut-off the expected firm payoff under different values its own cutoff. Figure 12 clearly indicates that introducing a CES production technology preserves the result that the optimal promotion decision of a single firm increases in the market promotion cut-off. Actually, even the observation that choosing $\bar{x}_{i}=45$ is optimal for a firm if all competitors use $\bar{x}=45$ carries over to this case of a non-linear production function. Taking into account that transition rates are not directly influenced by the production function, but just by the choice of cut-offs this establishes that also in this setting $\bar{x}^{g e}=45$ is a general equilibrium. Overall, apart from the key feature of strategic complementarity between promotion times also our other qualitative findings seem to stay intact as we move to a general CES production technology.

\section{Conclusions}

In this paper we develop and analyze a model which embeds the choice of optimal promotion times by hierarchical firms in a search and matching labor market with on the job search, which captures the option of a firm to fill senior positions through outside recruiting rather than internal promotion. A new methodological approach combining analytical results with agent-based simulations allows us to characterize the promotion strategies in a general equilibrium of this model, both in the presence of workers with heterogeneous skills and of firms with heterogeneous 
hierarchical structures. Our findings about the effect of the level and heterogeneity of worker skills and of the firm's hierarchical structure on optimal promotion times are innovative insight into the determinants of firm behavior on the labor market and into the resulting implications for labor flows. They provide theory-based explanations for empirical observations about the difference in promotion times between high and low skill workers as well as about the relationship between firm size and human capital. Furthermore, our results also give rise to several innovative testable implication about the impact of different factors on promotion strategies, which can be used as the theoretical basis for future empirical work in this area. Our insight that the effects of parameter changes on promotion cut-offs are typically much smaller in a general equilibrium framework than under the assumption of fixed job-filling/job finding rates at the different hierarchical levels, highlights the importance of endogenizing the supply side of the labor market when analyzing the design of promotion strategies.

From a methodological perspective this paper illustrates the potential of a careful combination of analytical and simulation approaches for the analysis of labor markets with frictions and different types of heterogeneities. The flexibility that this approach allows with respect to the structure of the analyzed model opens the possibility for addressing a wide range of issues in labour economics and beyond.

The analysis presented in this paper can be extended in several promising directions. Apart from empirical work building on our results, endogenizing wages and considering a simultaneous setting of wages and promotion cut-offs by firms may provide further economic insights. Moreover, the impact of promotion strategies on wage inequality is a related promising area. Extending the framework developed in this paper allows to study the role of the promotion channel for transforming different types of skill heterogeneities into wage inequalities under different assumptions about the firms' hierarchical structure. In that respect also the role of professional networks for job transitions and emerging wage inequality might be considered. These networks might evolve endogenously through employment at the same company and influence the potential of workers for finding senior positions outside the own firm. Finally, the fact that individual firms do not internalize the general equilibrium effects in our model is likely to create a deadweight loss of welfare which opens space for the discusion of policy and regulation. 


\section{Appendix A: Additional Calculations for the Benchmark Case}

First, we solve equation (9), which is a first-order linear differential equation. This equation has the form $J_{10}^{\prime}(x)=r J_{10}(x)+g(x)$, where $g(x)$ is given by:

$$
-g(x)=\left(d_{1}+c_{1} e^{\gamma x}\right)(1-\beta)-s+q_{2} \frac{\left(\pi_{2}(\bar{x})+\Delta+s\right)}{r+\rho+q_{2}}+q_{2} K e^{\left(r+\rho+q_{2}\right) x}
$$

With $A$ denoting the integration constant the general solution of this equation is given by $J_{10}(x)=A e^{r x}+e^{r x} \int g(x) e^{-r x}$. The second part of this expression is given by:

$$
\begin{aligned}
e^{r x} \int g(x) e^{-r x} & =-e^{r x}\left[\int\left(d_{1}(1-\beta)-s+q_{2} \frac{\left(\pi_{2}(\bar{x})+\Delta+s\right)}{r+\rho+q_{2}}\right) e^{-r x} d x\right. \\
& \left.+\int c_{1}(1-\beta) e^{(\gamma-r) x} d x+\int q_{2} K e^{\left(\rho+q_{2}\right) x} d x\right] \\
& =\frac{d_{1}(1-\beta)-s}{r}+q_{2} \frac{\left(\pi_{2}(\bar{x})+\Delta+s\right)}{r\left(r+\rho+q_{2}\right)}-\frac{e^{r x} c_{1}(1-\beta) e^{(\gamma-r) x}}{\gamma-r}-\frac{e^{r x} q_{2} K e^{\left(\rho+q_{2}\right) x}}{\rho+q_{2}} \\
& =\frac{d_{1}(1-\beta)-s}{r}+q_{2} \frac{\left(\pi_{2}(\bar{x})+\Delta+s\right)}{r\left(r+\rho+q_{2}\right)}+\frac{c_{1}(1-\beta) e^{\gamma x}}{r-\gamma}-\frac{q_{2} K e^{\left(r+\rho+q_{2}\right) x}}{\rho+q_{2}}
\end{aligned}
$$

Further, we determine the function $J_{11}^{N}\left(0, x_{i}\right)$. To do so recall that $J_{11}^{N}(x, y)$ is given by:

$$
r J_{11}^{N}(x, y)=\pi_{1}(x)+\Delta+\pi_{2}(y)-\rho\left(J_{11}^{N}(x, y)-J_{10}(x)\right)+\frac{\partial J_{11}^{N}(x, y)}{\partial x}
$$

Inserting $J_{10}(x)$ into this equation we get:

$$
\begin{aligned}
(r+\rho) J_{11}^{N}(x, y) & =\pi_{1}(x)+\Delta+\pi_{2}(y)+\frac{\partial J_{11}^{N}(x, y)}{\partial x} \\
& +\rho\left[\frac{d_{1}(1-\beta)-s}{r}+q_{2} \frac{\pi_{2}(\bar{x})+\Delta+s}{r\left(r+\rho+q_{2}\right)}+A e^{r x}+\frac{c_{1}(1-\beta) e^{\gamma x}}{r-\gamma}-\frac{q_{2} K e^{\left(r+\rho+q_{2}\right) x}}{\rho+q_{2}}\right]
\end{aligned}
$$

The general solution of this linear first order differential equation is given by:

$$
\begin{aligned}
J_{11}^{N}(x, y) & =\frac{s\left(r+q_{2}\right)}{r\left(r+\rho+q_{2}\right)}+\frac{\rho K e^{\left(r+\rho+q_{2}\right) x}}{\rho+q_{2}}+\frac{d_{1}(1-\beta)-s}{r}+A e^{r x}+\frac{c_{1}(1-\beta) e^{\gamma x}}{r-\gamma} \\
& +\frac{\pi_{2}(y)+\Delta}{r+\rho}+\frac{\rho q_{2}\left(\pi_{2}(\bar{x})+\Delta\right)}{r\left(r+\rho+q_{2}\right)(r+\rho)}+D e^{(r+\rho) x}
\end{aligned}
$$

with $D$ being the integration constant. Evaluating this equation at $y=\bar{x}$, we should get $J_{11}^{N}(x, \bar{x})$, which implies that $D=0$, because:

$$
\frac{\left(\pi_{2}(\bar{x})+\Delta\right)}{r+\rho}+\frac{\rho q_{2}\left(\pi_{2}(\bar{x})+\Delta\right)}{r\left(r+\rho+q_{2}\right)(r+\rho)}=\frac{\left(\pi_{2}(\bar{x})+\Delta\right)\left(r+q_{2}\right)}{r\left(r+\rho+q_{2}\right)}
$$

Inserting $x=0$ and $y=x_{i}$, we get the function $J_{11}^{N}\left(0, x_{i}\right)$ :

$$
\begin{aligned}
J_{11}^{N}\left(0, x_{i}\right) & =\frac{s\left(r+q_{2}\right)}{r\left(r+\rho+q_{2}\right)}+\frac{\rho K}{\rho+q_{2}}+\frac{d_{1}(1-\beta)-s}{r}+A+\frac{c_{1}(1-\beta)}{r-\gamma} \\
& +\frac{\left(\pi_{2}\left(x_{i}\right)+\Delta\right)}{r+\rho}+\frac{\rho q_{2}\left(\pi_{2}(\bar{x})+\Delta\right)}{r\left(r+\rho+q_{2}\right)(r+\rho)}
\end{aligned}
$$


Proofs for the case with two skill levels. The differential equation for $J_{j f}^{N}(x, y)$ is given by:

$$
\begin{aligned}
(r+\rho) J_{j f}^{N}(x, y) & =\pi_{1}(x)+\pi_{2}^{f}(y)+\frac{\rho\left(d_{1}(1-\beta)-s\right)}{r}+\rho q_{2} \frac{\bar{\pi}_{2}\left(\bar{x}_{L}, \bar{x}_{H}\right)+s}{r\left(r+\rho+q_{2}\right)} \\
& +\rho A_{j} e^{r x}+\frac{\rho c_{1}(1-\beta) e^{\gamma x}}{r-\gamma}-\frac{\rho q_{2} K_{j} e^{\left(r+\rho+q_{2}\right) x}}{\rho+q_{2}}+\frac{\partial J_{j f}^{N}(x, y)}{\partial x}
\end{aligned}
$$

It can be rewritten as:

$$
\begin{aligned}
(r+\rho) J_{j f}^{N}(x, y) & =d_{1}(1-\beta)+\pi_{2}^{f}(y)+\frac{\rho\left(d_{1}(1-\beta)-s\right)}{r}+\rho q_{2} \frac{\bar{\pi}_{2}\left(\bar{x}_{L}, \bar{x}_{H}\right)+s}{r\left(r+\rho+q_{2}\right)} \\
& +\rho A_{j} e^{r x}+\frac{(\rho+r-\gamma) c_{1}(1-\beta) e^{\gamma x}}{r-\gamma}-\frac{\rho q_{2} K_{j} e^{\left(r+\rho+q_{2}\right) x}}{\rho+q_{2}}+\frac{\partial J_{j f}^{N}(x, y)}{\partial x}
\end{aligned}
$$

Let $D_{j f}$ denote the integration constant, so the general solution of the above equation becomes:

$$
\begin{aligned}
J_{j f}^{N}(x, y) & =\frac{d_{1}(1-\beta)+\pi_{2}^{f}(y)}{r+\rho}+\frac{\rho\left(d_{1}(1-\beta)-s\right)}{r(r+\rho)}+\rho q_{2} \frac{\bar{\pi}_{2}\left(\bar{x}_{L}, \bar{x}_{H}\right)+s}{r\left(r+\rho+q_{2}\right)(r+\rho)} \\
& +\frac{\rho A_{j} e^{r x}}{r+\rho-r}+\frac{(\rho+r-\gamma) c_{1}(1-\beta) e^{\gamma x}}{(r-\gamma)(r+\rho-\gamma)}-\frac{\rho q_{2} K_{j} e^{\left(r+\rho+q_{2}\right) x}}{\left(\rho+q_{2}\right)\left(r+\rho-\left(r+\rho+q_{2}\right)\right)}+D_{j f} e^{(r+\rho) x} \\
& =\frac{d_{1}(1-\beta)}{r}+\frac{\pi_{2}^{f}(y)}{r+\rho}+\frac{\rho q_{2} \bar{\pi}_{2}\left(\bar{x}_{L}, \bar{x}_{H}\right)}{r\left(r+\rho+q_{2}\right)(r+\rho)}+\left[\frac{-s}{r}+\frac{r s}{r(r+\rho)}+\frac{\rho q_{2} s}{r\left(r+\rho+q_{2}\right)(r+\rho)}\right] \\
& +A_{j} e^{r x}+\frac{c_{1}(1-\beta) e^{\gamma x}}{(r-\gamma)}+\frac{\rho K_{j} e^{\left(r+\rho+q_{2}\right) x}}{\left(\rho+q_{2}\right)}+D_{j f} e^{(r+\rho) x} \\
& =\frac{d_{1}(1-\beta)-s}{r}+\frac{\pi_{2}^{f}(y)}{r+\rho}+\frac{\rho q_{2} \bar{\pi}_{2}\left(\bar{x}_{L}, \bar{x}_{H}\right)}{r\left(r+\rho+q_{2}\right)(r+\rho)}+\frac{s\left(r+q_{2}\right)}{r\left(r+\rho+q_{2}\right)} \\
& +A_{j} e^{r x}+\frac{c_{1}(1-\beta) e^{\gamma x}}{(r-\gamma)}+\frac{\rho K_{j} e^{\left(r+\rho+q_{2}\right) x}}{\left(\rho+q_{2}\right)}+D_{j f} e^{(r+\rho) x}
\end{aligned}
$$

where $D_{j f}$ is the corresponding integration constant. Next we combine equations (15) and (17) to find solution for the auxilliary variable $\bar{J}_{j}(x)=J_{j 0}(x)+\Delta J_{j}(x)$ :

$$
\bar{J}_{j}(x)=\frac{d_{1}(1-\beta)-s}{r}+\left(r+q_{2}\right) \frac{\bar{\pi}_{2}\left(\bar{x}_{L}, \bar{x}_{H}\right)+s}{r\left(r+\rho+q_{2}\right)}+A_{j} e^{r x}+\frac{c_{1}(1-\beta) e^{\gamma x}}{r-\gamma}+\frac{\rho K_{j} e^{\left(r+\rho+q_{2}\right) x}}{\rho+q_{2}}
$$

Evaluating $J_{j L}^{N}(x, y)$ at $y=\bar{x}_{L}$ with the corresponding term $D_{j L}, J_{j H}^{N}(x, y)$ at $y=\bar{x}_{H}$ with the corresponding term $D_{j H}$ and taking a weighted average between the two we get $(1-$ $\left.\alpha_{2}\right) J_{j H}^{N}\left(x, \bar{x}_{H}\right)=\bar{J}_{j}(x)-\alpha_{2} J_{j L}^{N}\left(x, \bar{x}_{L}\right)$. The right-hand side of this equation is given by:

$$
\begin{aligned}
\bar{J}_{j}(x) & -\alpha_{2} J_{j L}^{N}\left(x, \bar{x}_{L}\right)=\left(r+q_{2}\right) \frac{\bar{\pi}_{2}\left(\bar{x}_{L}, \bar{x}_{H}\right)}{r\left(r+\rho+q_{2}\right)}-\alpha_{2} \frac{\pi_{2}^{L}\left(\bar{x}_{L}\right)}{r+\rho}-\alpha_{2} \frac{\rho q_{2} \bar{\pi}_{2}\left(\bar{x}_{L}, \bar{x}_{H}\right)}{r\left(r+\rho+q_{2}\right)(r+\rho)}-\alpha_{2} D_{j L} e^{(r+\rho) x} \\
& +\left(1-\alpha_{2}\right)\left[\frac{d_{1}(1-\beta)-s}{r}+\frac{\left(r+q_{2}\right) s}{r\left(r+\rho+q_{2}\right)}+A_{j} e^{r x}+\frac{c_{1}(1-\beta) e^{\gamma x}}{r-\gamma}+\frac{\rho K_{j} e^{\left(r+\rho+q_{2}\right) x}}{\rho+q_{2}}\right]
\end{aligned}
$$


Consider the first four terms of this equation:

$$
\begin{aligned}
& \frac{\bar{\pi}_{2}\left(\bar{x}_{L}, \bar{x}_{H}\right)}{r+\rho}+\frac{\rho q_{2} \bar{\pi}_{2}\left(\bar{x}_{L}, \bar{x}_{H}\right)}{r\left(r+\rho+q_{2}\right)(r+\rho)}-\alpha_{2} \frac{\pi_{2}^{L}\left(\bar{x}_{L}\right)}{r+\rho}-\alpha_{2} \frac{\rho q_{2} \bar{\pi}_{2}\left(\bar{x}_{L}, \bar{x}_{H}\right)}{r\left(r+\rho+q_{2}\right)(r+\rho)}-\alpha_{2} D_{j L} e^{(r+\rho) x} \\
= & \left(1-\alpha_{2}\right) \frac{\rho q_{2} \bar{\pi}_{2}\left(\bar{x}_{L}, \bar{x}_{H}\right)}{r\left(r+\rho+q_{2}\right)(r+\rho)}+\left(1-\alpha_{2}\right) \frac{\pi_{2}^{H}\left(\bar{x}_{H}\right)}{r+\rho}-\alpha_{2} D_{j L} e^{(r+\rho) x}
\end{aligned}
$$

because $\bar{\pi}_{2}\left(\bar{x}_{L}, \bar{x}_{H}\right)-\alpha_{2} \pi_{2}^{L}\left(\bar{x}_{L}\right)=\left(1-\alpha_{2}\right) \pi_{2}^{H}\left(\bar{x}_{H}\right)$. Comparing $\bar{J}_{j}(x)-\alpha_{2} J_{j L}^{N}\left(x, \bar{x}_{L}\right)$ with $(1-$ $\left.\alpha_{2}\right) J_{j H}^{N}\left(x, \bar{x}_{H}\right)$ we can see that $\left(1-\alpha_{2}\right) D_{j H} e^{(r+\rho) x}=-\alpha_{2} D_{j L} e^{(r+\rho) x}$, so that $\left(1-\alpha_{2}\right) D_{j H}+$ $\alpha_{2} D_{j L}=0$.

\section{Appendix B: Details of the Simulation Framework}

\section{General Simulation Setup}

In the simulation of the model we consider a firm population $N_{F}$ and a worker population $N_{W}$ with $\left|N_{F}\right|=n_{F},\left|N_{W}\right|=n_{W}$. The sizes of both populations stay constant over time since a new worker is added to the population only when a member of the population retires and a new firm is added only if an existing firm has become empty and leaves the market. Each worker $j \in N_{W}$ is characterized by her skill level (low/high) and each firm $i \in N_{F}$ by its promotion cut-off(s) $\left(\bar{x}_{i}^{L}, \bar{x}_{i}^{H}\right)$. Any worker or firm entering the population inherits this characteristic from the agent it replaces. The scenarios with a single skill group are treated as a special case of the general setup in which all workers have low skills. The simulation evolves in discrete time steps. Initially, at $t=0$ all firms have no employees (type $d_{00}$ ) and all workers are in simple jobs. Afterwards, in every period $t=1, . . T$ the following steps are executed

1. Every firm $i \in N_{F}$ with a vacant senior position and a junior worker with skill $s \in\{L, H\}$ and experience $x \geq \bar{x}_{i}^{s}$ promotes this worker to the senior position.

2. All firms $i \in N_{F}$ with open junior or senior positions post these vacancies.

3. Every worker in a simple job sends with probability $z$ an application to a random junior vacancy.

4. Every searching junior worker (i.e. every junior worker whose experience is above its employer's promotion threshold) sends with probability $z$ an application to a random senior vacancy.

5. Every firm $i \in N_{F}$ for each of its vacancies randomly (with equal probabilities) selects one of its applicants and hires this worker. If the firm has not received any applications then the vacancy is not filled in period $t$.

6. The experience of all junior workers is updated.

7. Every senior worker retires with probability $\rho$.

8. All statistics (employed, unemployed, filled/unfilled vacancies, job finding rates, job filling rates) for period $t$ are recorded. 

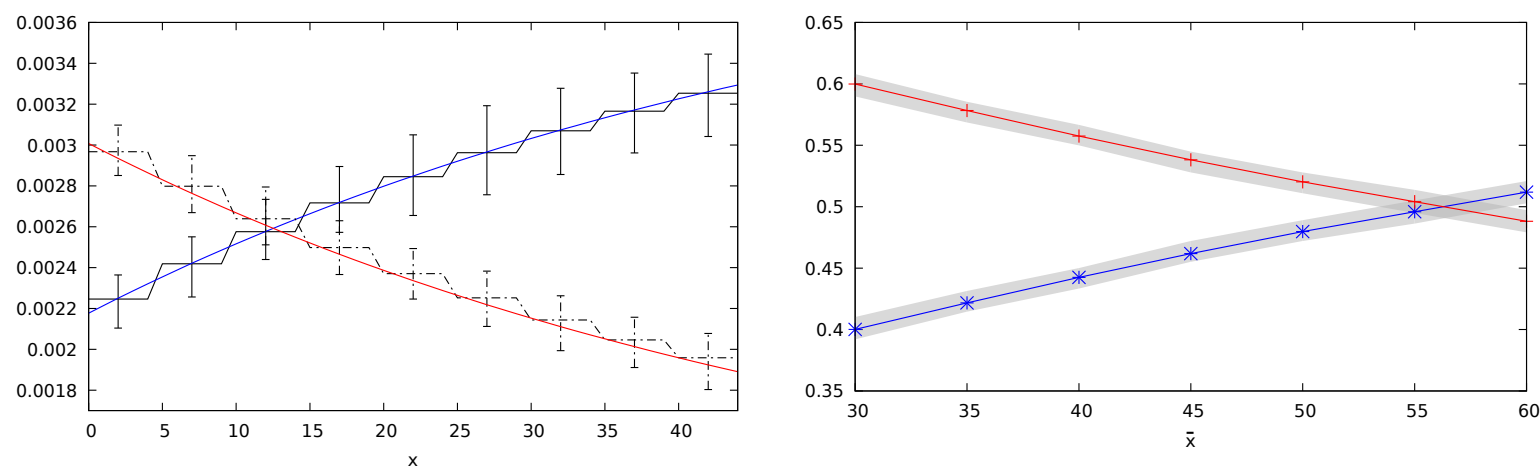

Figure 13: Left panel: Number of $d_{10}$ firms as a function of the junior worker's experience (solid line). Number of $d_{11}^{N}$ firms as a function of the junior worker's experience (dashed line). The vertical bars represent the minimum and maximum value recorded during the 100 simulation runs where each value is an average over the last 500 iterations of each run and one run consists of 1000 iterations. Right panel: Fraction of workers in junior positions (blue line) and senior positions (red line) for different market promotion cut-offs. The confidence bands display the minimal and maximal average recorded.

The job-finding rate at the first level $\left(\lambda_{1}\right)$ is defined as the number of agents in simple jobs who found a junior position in the current period as a fraction of the total number of agents in simple jobs in the beginning of the period. Similarly, the job-finding rate at the second level $\left(\lambda_{2}\right)$ is the fraction of junior workers who found a senior position in another firm in the current period relative to the total number of searching junior workers in the beginning of the period. On the other hand, the job-filling rate of junior positions $\left(q_{1}\right)$ is the number of filled junior vacancies during the current period as a fraction of total number of junior vacancies in the beginning of the period. Analogously, the job-filling rate of senior positions $\left(q_{2}\right)$ is the fraction of filled senior vacancies in the current period (excluding promotions) relative to the total number of senior vacancies in the beginning of the period. Further, the promotion rate is calculated as the fraction of promoted workers in the current period relative to the total number of employed junior workers in the beginning of the period. On the other hand, the job-to-job transition rate is defined as the newly hired managers (excluding promotions) as a fraction of the total number of junior workers. And finally, $\alpha_{1}$ and $\alpha_{2}$ are the fractions of low skill applicants in the junior and senior market, respectively.

In our simulation we consider populations of size $n_{F}=600, n_{W}=1000$ and for a given profile of promotion thresholds $\left\{\left(\bar{x}_{i}^{L}, \bar{x}_{i}^{H}\right)\right\}_{i \in N_{F}}, 100$ simulation runs are done where each run consists of 1500 iterations. We collect the average values of the job-finding rates $\left(\lambda_{1}, \lambda_{2}\right)$, the vacancy-filling rates $\left(q_{1}, q_{2}\right)$, the distribution of firms and workers $\left(d_{00}, d_{10}, d_{01}, d_{11}^{N}, d_{11}^{S}, e_{0}, e_{1}, e_{2}\right)$, the fractions of low skill applicants in the two markets $\left(\alpha_{1}, \alpha_{2}\right)$ and the number of exiting firms per period $(n)$ over the last 1000 periods of each run. The first 500 periods are disregarded in order to allow the system to reach its stationary distribution.

In order to demonstrate the precision of the results obtained through the simulation we apply our method to the benchmark case of only low-skilled workers, for which analytical results are available. The good match of the different transition rates obtained in the simulation with the exact values is demonstrated in Table in the main text. Here we present additional figures that should be compared with the numerical results discussed in section 2.3. The left panel of figure 

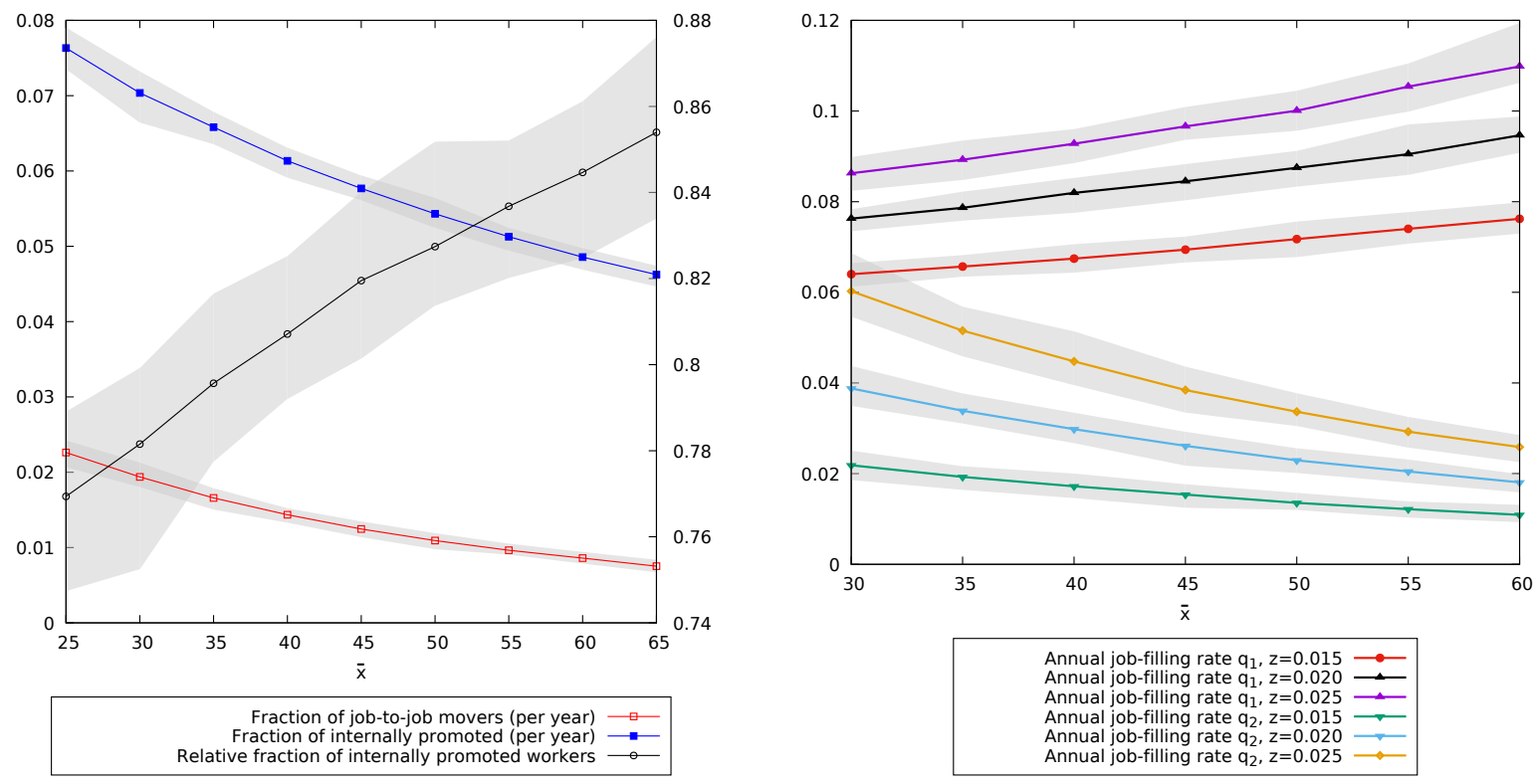

Figure 14: Left panel: fraction of externally (job-to-job movers) and internally promoted workers for different values of $\bar{x}$. Right panel: job filling rates for junior and senior positions for different search intensities of workers. The values show an average over 100 simulation runs and the confidence bands display the minimal and maximal average recorded.

13 shows the number of firms of type $d_{10}$ and $d_{11}^{N}$ as a function of the junior worker's experience. This figure replicates closely figure 2, which can be seen by comparing the simulation results with the blue and red curve which are taken from figure 2 . The right panel of figure 13, to be compared with the right panel of figure 2, shows the dependence of the fraction of workers in junior and senior positions from the promotion cut-off $\bar{x}$ used by all firms. Again lines match very well those shown in figure 2 .

Figure 14 is a replication of figure 3 and shows the fraction of externally (job-to-job movers) and internally promoted workers for different values of $\bar{x}$ as well as well as the firms job filling rates for junior and senior positions for different search intensities of workers. Also in this respect the results obtained by simulation qualitatively and quantitatively are in close accordance with the analytical results.

To illustrate that ability to simulate the market with heterogeneous firm profiles can allow for helpful additional insights even in scenarios for which a numerical determination of the equilibrium based on analytical results is possible, we show in figure 15 how the fraction of internally promoted workers at a firm depends on the firm's own promotion threshold if all other firms promote at the equilibrium value of $\bar{x}=45$. The figure shows that the fraction of internally promoted workers decreases if $\bar{x}_{i}$ becomes larger, which is qualitatively different from an increase of the promotion level $\bar{x}$ of all firms, which induces an increase of the fraction of internally promoted.

\section{Finding a General Equilibrium}

In Table 7 the numerical procedure for finding general equilibrium promotion cut-offs with the use of simulations is illustrated for the case with a fraction of $a=0.7$ low skill work- 


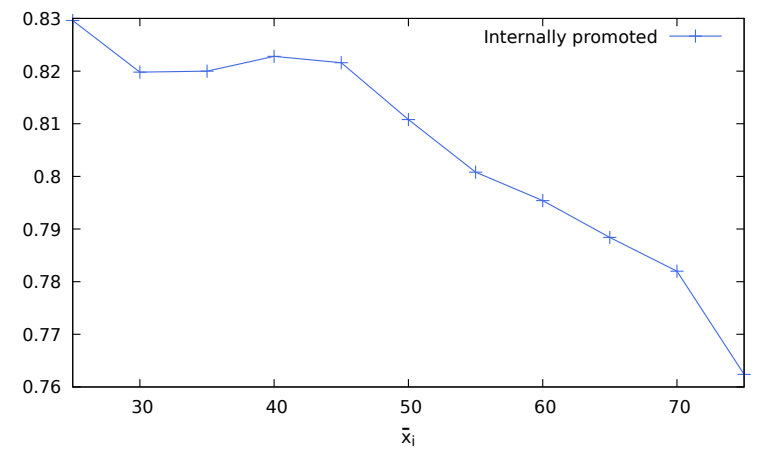

Figure 15: Fraction of internally promoted workers of a single firm $i$ for $\bar{x}_{i}=$ [25..75], while $\bar{x}=45$ is kept fixed. $\bar{x}_{i}$ is increased in steps of 5 . For each $\bar{x}_{i}$ we let the firm $i$ fill its senior position 5000 times and plot the fraction of internal promotions out of those 5000 hires.

ers. In step (1) we use as an input for the simulation the partial equilibrium values found in section 4.2: $\bar{x}_{L}=60$ and $\bar{x}_{H}=28$ which are optimal under the fixed transition rates: $\zeta^{0}=\left\{\lambda_{1}, \lambda_{2}, q_{1}, q_{2}, \alpha_{1}, \alpha_{2}\right\}=\{0.0145,0.0146,0.0171,0.0036,0.7,0.7\}$. These are labeled as "Conjectured Cut-Offs". The transition rates reported below the conjectured cut-offs are the averages of the last 1000 iterations of 100 runs, where one run consists of 1500 iterations (standard deviation is given in parenthesis). The row "Opt. Cut-Offs" then displays the optimal promotions given these transition rates. The algorithm stops once the optimal cut-off values coincide with the conjectured cut-off values.

\begin{tabular}{|c|c|c|c|}
\hline \multicolumn{4}{|c|}{$a=0.7$} \\
\hline$k$ & (1) & $(2)$ & $(3)$ \\
\hline $\begin{array}{c}\text { Conjectured } \\
\text { Cut-Offs }\end{array}$ & $\left\{\bar{x}^{L}, \bar{x}^{H}\right\}=\{60,28\}$ & $\left\{\bar{x}^{L}, \bar{x}^{H}\right\}=\{58,27\}$ & $\left\{\bar{x}^{L}, \bar{x}^{H}\right\}=\{56,28\}$ \\
\hline $\begin{array}{c}\text { Rates } \zeta^{k} \\
\text { (through } \\
\text { Simulation) }\end{array}$ & $\begin{array}{c}\alpha_{1}=0.6680 ; \alpha_{2}=0.6045 \\
(0.0050) ;(0.0169) \\
\lambda_{1}=0.0145 ; \lambda_{2}=0.0147 \\
(0.0002) ;(0.0005) \\
q_{1}=0.01751 ; q_{2}=0.00337 \\
(0.0002) ;(0.0001)\end{array}$ & $\begin{array}{c}\alpha_{1}=0.6689 ; \alpha_{2}=0.6059 \\
(0.0043) ;(0.0143) \\
\lambda_{1}=0.0145 ; \lambda_{2}=0.0147 \\
(0.0002) ;(0.0005) \\
q_{1}=0.01731 ; q_{2}=0.00350 \\
(0.0002) ;(0.0002)\end{array}$ & $\begin{array}{l}\alpha_{1}=0.6752 ; \alpha_{2}=0.6149 \\
\quad(0.0046) ;(0.0133) \\
\lambda_{1}=0.0145 ; \lambda_{2}=0.0145 \\
\quad(0.0002) ;(0.0004) \\
q_{1}=0.01726 ; q_{2}=0.00354 \\
\quad(0.0001) ;(0.0001)\end{array}$ \\
\hline Opt. Cut-Offs & $\left\{\bar{x}^{L}, \bar{x}^{H}\right\}=\{45,27\}$ & $\left\{\bar{x}^{L}, \bar{x}^{H}\right\}=\{51,28\}$ & $\left\{\bar{x}^{L}, \bar{x}^{H}\right\}=\{53,28\}$ \\
\hline$k$ & $(4)$ & $(5)$ & $(6)$ \\
\hline $\begin{array}{l}\text { Conjectured } \\
\text { Cut-Offs }\end{array}$ & $\left\{\bar{x}^{L}, \bar{x}^{H}\right\}=\{54,28\}$ & $\left\{\bar{x}^{L}, \bar{x}^{H}\right\}=\{55,29\}$ & $\left\{\bar{x}^{L}, \bar{x}^{H}\right\}=\{55,28\}$ \\
\hline $\begin{array}{c}\text { Rates } \zeta^{k} \\
\text { (through } \\
\text { Simulation) }\end{array}$ & $\begin{array}{c}\alpha_{1}=0.6739 ; \alpha_{2}=0.6202 \\
(0.0049) ;(0.0116) \\
\lambda_{1}=0.0145 ; \lambda_{2}=0.0146 \\
(0.0002) ;(0.0004) \\
q_{1}=0.01707 ; q_{2}=0.00365 \\
(0.0002) ;(0.0001)\end{array}$ & $\begin{array}{c}\alpha_{1}=0.6747 ; \alpha_{2}=0.6189 \\
(0.0042) ;(0.0134) \\
\lambda_{1}=0.0145 ; \lambda_{2}=0.0145 \\
(0.0002) ;(0.0004) \\
q_{1}=0.01720 ; q_{2}=0.00356 \\
(0.0002) ;(0.0001)\end{array}$ & $\begin{array}{c}\alpha_{1}=0.6733 ; \alpha_{2}=0.6169 \\
\quad(0.0048) ;(0.0130) \\
\lambda_{1}=0.0145 ; \lambda_{2}=0.0145 \\
\quad(0.0002) ;(0.0005) \\
q_{1}=0.01716 ; q_{2}=0.00357 \\
\quad(0.0002) ;(0.0001)\end{array}$ \\
\hline Opt. Cut-Offs & $\left\{\bar{x}^{L}, \bar{x}^{H}\right\}=\{61,29\}$ & $\left\{\bar{x}^{L}, \bar{x}^{H}\right\}=\{54,28\}$ & $\left\{\bar{x}^{L}, \bar{x}^{H}\right\}=\{55,28\}$ \\
\hline
\end{tabular}

Table 7: Steps to finding the general equilibrium promotion cut-offs $\bar{x}_{L}^{g e}$ and $\bar{x}_{H}^{g e}$ for $a=0.7$. The values show an average over 100 simulation runs with the standard deviation in parenthesis. 


\section{Determining Firms' Optimal Promotion Cut-offs}

If the simulations are used only to determine the transition rates for a given uniform strategy profile, we set $\left(x_{i}^{L}, x_{i}^{H}\right)=\left(\bar{x}^{L}, \bar{x}^{H}\right)$ for all $i \in N_{F}$ and collect only the data discussed in the previous subsection. However, in scenarios, in which no analytical characterization of the optimal promotion cut-off of a firm for a given strategy profile of the other firms is available, the simulations can also be used to determine the firm's optimal response.

In order to find such a best response to given threshold values $\left(\bar{x}^{L}, \bar{x}^{H}\right)$ of the competitors we first employ the simulation to determine the (long-run) transition rates if all firms employ these thresholds and then, using these rates, calculate the expected discounted sum of profits of a single firm $i$ for all values of $\left(x_{i}^{L}, x_{i}^{H}\right)$ from a finite grid covering the relevant range of $x^{L}$ and $x^{H}$. Using this approach we implicitly assume that the change of the single firm's threshold does not affect the transition rates on the market, which is consistent with the assumption of a continuum of firms underlying the theoretical model. For clarity of exposition we assume in the following description that all workers have the same skill such that the firm strategy is described by a single threshold $x_{i}^{L}$. The extension to the case of two skill levels as well as to other model extensions, like pyramidal firms, is straight forward and not described in detail. ${ }^{11}$

For the calculation of the expected discounted payoff we assume that $\tau_{1}, \tau_{2}, \tau_{3}, \tau_{4}$ are random variables such that $\tau_{1} \sim \operatorname{Exp}\left(q_{1}\right), \tau_{2} \sim \operatorname{Exp}\left(q_{2}\right), \tau_{3} \sim \operatorname{Exp}\left(\lambda_{2}\right)$ and $\tau_{4} \sim \operatorname{Exp}(\rho)$, where $q_{1}, q_{2}$ and $\lambda_{2}$ are the transition rates generated by the simulation and $\rho$ is the retirement rate. Hence, $\tau_{1}$ represents the waiting time until finding a junior worker, $\tau_{2}$ is the time until finding a senior worker from the market, $\tau_{3}$ is the time until the junior worker who is searching for a senior position moves to another firm and $\tau_{4}$ is the time until the senior worker retires.

We simulate a hypothetical firm from its entry to its exit from the market. Initially, the new $d_{00}$ firm makes the random draws, $\tau_{1}$ and $\tau_{2}$. If $\min \left\{\tau_{1}, \tau_{2}\right\}=\tau_{1}$, the firm finds a junior worker first and becomes of $d_{10}$ type. Conversely, if $\min \left\{\tau_{1}, \tau_{2}\right\}=\tau_{2}$ the firm finds the senior worker first and becomes of $d_{01}$ type. Next, if the firm is in the $d_{10}$ state, it makes a random draw for $\tau_{2}$ which is compared to the time left until the worker achieves $x_{i}^{L}$, the promotion cut-off of the considered firm. Whichever comes first determines into which state the firm will transition next: $d_{11}^{N}$ or $d_{01}$, respectively.

On the other hand, if the firm after its first hire is of $d_{01}$ type, it either finds a junior worker or the senior worker retires in which case the firm exits. To determine which of these two possibilities are realized, random draws for $\tau_{1}$ and $\tau_{4}$, are made. If $\min \left\{\tau_{1}, \tau_{4}\right\}=\tau_{1}$, the firm finds a junior worker and becomes of $d_{11}^{N}$ type and if $\min \left\{\tau_{1}, \tau_{4}\right\}=\tau_{4}$, the firm exits the labour market. Furthermore, if the firm is in $d_{11}^{N}$ state, a random draw $\tau_{4}$ is made which is then compared with the time left until the junior worker achieves $x_{i}^{L}$. If the worker gains the $\bar{x}_{i}^{L}$ level of experience first, the firm transitions into $d_{11}^{S}$ state. Otherwise, the senior worker retires and the firm becomes of $d_{10}$ type. Finally, for a firm in the state $d_{11}^{S}$, the random draws $\tau_{3}$ and $\tau_{4}$ are compared. If $\min \left\{\tau_{3}, \tau_{4}\right\}=\tau_{3}$, the searching junior worker moves to a different firm, whereas if $\min \left\{\tau_{3}, \tau_{4}\right\}=\tau_{4}$, the senior worker retires and is immediately replaced by the junior one. In both cases the firm becomes of $d_{01}$ type.

Once the sequence of the considered firm's states from its entry until its exit from the market

\footnotetext{
${ }^{11}$ Details of the extension of our approach to the different model extensions is available from the authors upon request.
} 
and the time spent in each state have been determined, the discounted sum of the firm's profits is calculated based on this data. In order to obtain an estimation of the expected firm's profit, the average discounted profit over 40000 instances of this firm is calculated. For each considered value of the threshold $x_{i}^{L}$ we calculate 100 estimations of the expected profit in this way. The best response of the firm to $\left(\bar{x}^{L}, \bar{x}^{H}\right)$ is then determined as the value $x_{i}^{L}$ among all thresholds in the considered grid for which the mean of the 100 estimated expected discounted profit values is highest. In figure 8 we illustrate the approach by applying it to our benchmark scenario with uniform skills of workers. The left panel of the figures shows how well the expected discounted profit of the firm is approximated using our simulation approach and the right panel reproduces the best response function shown in figure 5. In particular, the right panel of the figure illustrates that the also a purely simulation-based procedure, which also relies on the simulation-based best response function would arrive at the correct general equilibrium value of $\bar{x}=45$, since this is where the first diagonal coincides with the highest ranked value of $\bar{x}_{i}$.

\section{Appendix C: Pyramidal Firms}

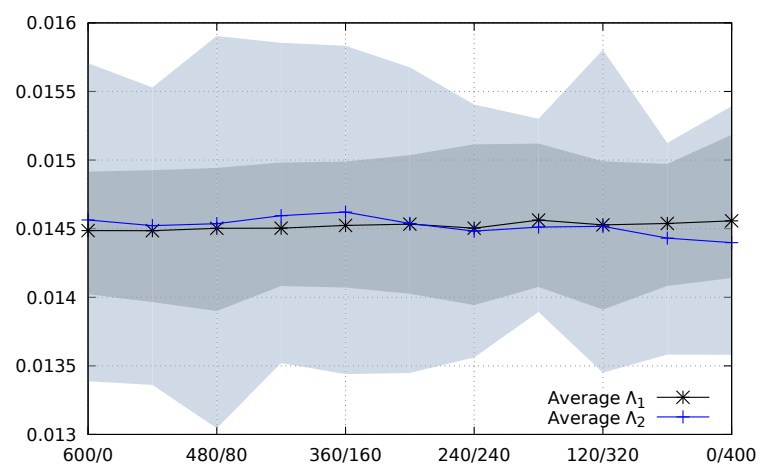

Figure 16: Job-fining rates for a varying fraction of pyramidal firms. The values show an average over 100 simulation runs and the confidence bands display the minimal and maximal average recorded.

\section{References}

Albrecht, J. W., P. A. Gautier, and S. B. Vroman (2003). Matching with multiple applications. Economics Letters 78, 67-70.

Albrecht, J. W. and S. B. Vroman (2002). A matching model with endogenous skill requirements. International Economic Review 43, 283-305.

Axtell, R. (2018). Endogenous firm dynamics and labor flows via heterogeneous agents. In C. Hommes and B. LeBaron (Eds.), Handbook of Computational Economics, Volume 4, Chapter 3, pp. 157-213. Elsevier.

Bagger, J., F. Fontaine, F. Postel-Vinay, and J.-M. Robin (2014). Tenure, experience, human capital, and wages: A tractable equilibrium search model of wage dynamics. The American Economic Review 104, 1551-1596. 
Baker, G., M. Gibbs, and M. Holmström (1994). The internal economics of the firm: Evidence from personnel data. The Quarterly Journal of Economics 109, 881-919.

Bidwell, M. and E. Mollick (2015). Shifts and ladders: Comparing the role of internal and external mobility in managerial careers. Organization Science 26(6), 1629-1645.

Bingley, P. and N. Westergaard-Nielsen (2003). Returns to tenure, firm-specific human capital and worker heterogeneity. International Journal of Manpower 24(7), 774-788.

Brown, C. and J. Medoff (1989). The employer size-wage effect. Journal of political Economy 97(5), 1027-1059.

Burdett, K., C. Carillo-Tudela, and M. Coles (2011). Human capital accumulation and labor market equilibrium. International Economic Review 52(3), 657-677.

Burdett, K. and M. Coles (2003). Equilibrium wage-tenure contracts. Econometrica 71(5), 1377-1404.

Burdett, K. and D. T. Mortensen (1998). Wage differentials, employer size and unemployment. International Economic Review 39(2), 257-273.

Caliendo, L., F. Monte, and E. Rossi-Hansberg (2015). The anatomy of French production hierarchies. Journal of Political Economy 123(4), 809-852.

Card, D. and T. Lemieux (2001). Can falling supply explain the rising return to college for younger men? a cohort-based analysis. The Quarterly Journal of Economics 116(2), 705746.

Cassidy, H., J. DeVaro, and A. Kauhanen (2016). Promotion signaling, gender, and turnover: New theory and evidence. Journal of Economic Behavior $\&$ Organization 126, 140-166.

D'Amuri, F., G. I. Ottaviano, and G. Peri (2010). The labor market impact of immigration in western germany in the 1990s. European Economic Review 54(4), 550-570.

Dawid, H. and D. Delli Gatti (2018). Agent-based macroeconomics. In C. Hommes and B. LeBaron (Eds.), Handbook of Computational Economics, Volume 4, Chapter 2, pp. 63156. Elsevier.

Dawid, H., S. Gemkow, P. Harting, S. van der Hoog, and M. Neugart (2018). Agent-based macroeconomic modeling and policy analysis: The eurace@unibi model. In S.-H. Chen, M. Kaboudan, and Y.-R. Du (Eds.), Handbook on Computational Economics and Finance, Chapter 17, pp. 490-519. Oxford University Press.

DeVaro, J. (2006). Strategic promotion tournaments and worker performance. Strategic Management Journal 27, 721-740.

DeVaro, J. and M. Waldman (2012). The signalling role of promotions: Further theory and empirical evidence. Journal of Labor Economics 30(1), 91-147.

Diamond, P. A. (1982). Wage determination and efficiency in search equilibrium. The Review of Economic Studies 49(2), 217-227. 
Dosi, G., M. Pereira, A. Roventini, and M. Virgillito (2017). When more flexibility yields more fragility: The microfoundations of keynesian aggregate unemployment. Journal of Economic Dynamics and Control 81, $162-186$.

Farber, H. (1999). Mobility and stability: the dynamics of job change in labor markets. In O. Ashenfelter and D. Card (Eds.), Handbook of Labor Economics. North Holland, Amsterdam.

Fox, J. T. (2009). Firm-size wage gaps, job responsibility, and hierarchical matching. Journal of Labor Economics 27(1), 83-126.

Freeman, R. (2007). Labor Market Institutions Around the World, pp. Chapter 34. London: Sage. Alternate chapter title: National Economic Performance NBER WP \# 13,242.

Freeman, R. B. (1998). War of the models: Which labour market institutions for the 21st century? Labour Economics 5(1), 1-24.

Garicano, L. (2000). Hierarchies and organization of knowledge in production. Journal of Political Economy 108(5), 874-904.

Garicano, L. and E. Rossi-Hansberg (2015). Knowledge-based hierarchies: Using organizations to understand the economy. Annual Review of Economics 7, 1-30.

Gibbons, R. and M. Waldman (1999). A theory of wage and promotion dynamics inside firms. The Quarterly Journal of Economics 114(4), 1321-1358.

Iftikhar, Z. and A. Zaharieva (2018). General equilibrium effects of immigration in germany: Search and matching approach. forthcoming in the Review of Economic Dynamics.

Lallemand, T., R. Plasman, and F. Rycx (2007). The establishment-size wage premium: evidence from european countries. Empirica 34(5), 427-451.

Lazear, E. P. and S. Rosen (1981). Rank-order tournaments and optimum labor contracts. Journal of Political Economy 89(5), 841-864.

Lluis, S. (2005). The role of comparative advantage and learning in wage dynamics and intrafirm mobility: Evidence from Germany. Journal of Labor Economics 23(4), 725-767.

McCue, K. (1996). Promotions and wage growth. Journal of Labor Economics, 175-209.

Mortensen, D. T. (1982). The matching process as a noncooperative bargaining game. In J. McCall (Ed.), The Economics of Information and Uncertainty, pp. 233-258. University of Chicago Press.

Neugart, M. and M. Richiardi (2018). Agent-based models of the labor market. In S.-H. Chen, M. Kaboudan, and Y.-R. Du (Eds.), Handbook on Computational Economics and Finance, Chapter 22, pp. 667-687. Oxford University Press.

Oi, W. Y. and T. L. Idson (1999). Firm size and wages. Handbook of labor economics 3, $2165-2214$. 
Pissarides, C. A. (1985). Short-run equilibrium dynamics of unemployment, vacancies, and real wages. The American Economic Review 75(4), 676-690.

Pissarides, C. A. (1994). Search unemployment with on-the-job search. Review of Economic Studies 61, 457-475.

Pissarides, C. A. (2009). The unemployment volatility puzzle: Is wage stickiness the answer? Econometrica 7r7(5), 1339-1369.

Pissarides, C. A. and B. Petrongolo (2001). Looking into the black box: A survey of the matching function. Journal of Economic Literature 39(2), 390-431.

Rogerson, R., R. Shimer, and R. Wright (2005). Search-theoretic models of the labour market: A survey. Journal of Economic Literature 43(4), 959-988.

Stupnytska, Y. and A. Zaharieva (2017). Optimal policy and the role of social contacts in a search model with heterogeneous workers. Journal of Public Economic Theory 19(5), 957-985.

Waldman, M. (2009). Theory and evidence in internal labour markets. Cornell University CRI 2009-013.

Zabojnik, J. and D. Bernhardt (2001). Corporate tournaments, human capital acquisition, and the firm size-wage relation. Review of Economic Studies 68, 693-716. 